University of Redlands

\title{
The Spatially Interactive Literature Analysis System Study Tool: A GIS Tool for Interpreting History
}

A Major Individual Project submitted in partial satisfaction of the requirements

for the degree of Master of Science in Geographic Information Systems

\author{
by \\ Alyssa King \\ Diana Sinton, Ph.D., Committee Chair \\ Lillian Larsen, Ph.D.
}

August 2009 
The Spatially Interactive Literature Analysis System Study Tool:

A GIS Tool for Interpreting History

Copyright (C) 2009

by

Alyssa King 
The report of Alyssa King is approved.

Lillian Larsen, Ph.D.

Diana Sinton, Ph.D., Committee Chair

August 2009 



\section{Acknowledgements}

This project could not have been completed without the support, encouragement and guidance of faculty, staff, peers and friends. I would like to acknowledge Dr. Diana Sinton, my advisor and committee chair, for her knowledge and expertise that helped me think outside of the (GIS) box. I would also like to acknowledge Dr. Lillian Larsen, my client and reader, for her enthusiasm for teaching which often led to extended meetings (which were appreciated). The combined knowledge and enthusiasm made the project engaging and intellectually challenging for the entire duration of the project.

Many thanks to the technical support team who oversaw the development of SILAS.ST. Huge thanks to the significant time and energy of Nathan Strout, who provided the necessary programming and guidance. And many thanks to Brandon Davis for being there to address laptop malfunctions, and to Ruben Ortiz for his smooth transition into the MS GIS program following Brandon's unfortunate layoff. Additional thanks to John Laska, who oversaw the MS GIS Program's ITS. And from ESRI, I must thank Steve Rozic for his wonderful instruction of ArcObjects and contribution to my project.

The originator of SILAS, Steve Benzek, set a high standard for achievement and I thank him for his visionary presence and encouragement. I had the wonderful opportunity to speak with Anne Knowles and Charlie Frye regarding similar projects, and their individual insights and feedback were invaluable to this project's design. SILAS.ST would not have been justified without the evaluative feedback from David Smith and Catherine Walker, for which I thank them for their time and critique.

A good friend and editor, I must thank Sarah Anderson for her thorough last minute editing of my thesis-- I could not have edited this whole document without you. And last, but not least, all of my peers in Cohort 14, the MS GIS faculty, my family and friends, who have provided endless amounts of motivation and amusement. 



\begin{abstract}
The Spatially Interactive Literature Analysis System Study Tool:

A GIS Tool for Interpreting History

by

Alyssa King

The Spatially Interactive Literature Analysis System Study Tool (SILAS.ST) follows in the tradition of the original SILAS, developed by Stephen Benzek (MS GIS Cohort 12). This second phase of SILAS focuses on the educational functionality of the application. With SILAS.ST, students can overlay and juxtapose information from multiple sources and explore and document the historical information for each source brought into ESRI's ArcGIS, a geographic information system (GIS). Current geographic metadata standards are not suitable for documenting historical sources in GIS, and often they are too cumbersome for students who are new to GIS and metadata. SILAS.ST has been fitted with its own metadata standard for the purpose of documenting historical geographic data. When students fill out and share information in the metadata forms, they will better understand the historical relevance and uncertainty inherent in the maps they create and the map layers they encounter when studying historical topics. Students will also learn how to document historical sources using the custom metadata, easing the transition from critiquing textual sources to evaluating visual map layers. Additional customization of the ArcMap user interface, such as custom toolbars, buttons and direct access to the new metadata forms, will aid in the introduction of digital mapping technologies to humanities students. SILAS.ST has earned the Association of American Geographer's (AAG) Amy Mather New Scholar Award for 2009, which honors students for their outstanding
\end{abstract} contribution to the field of Biblical Geography. 



\section{Table of Contents}

Chapter 1 - Introduction....................................................................................................1

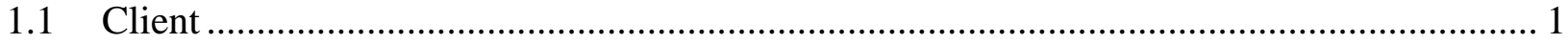

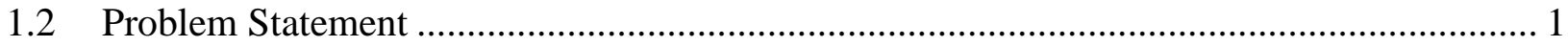

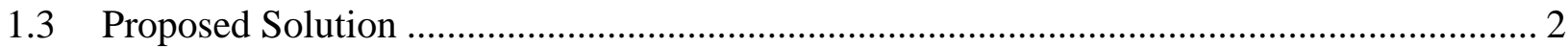

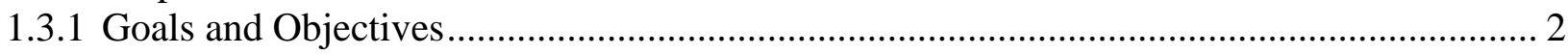

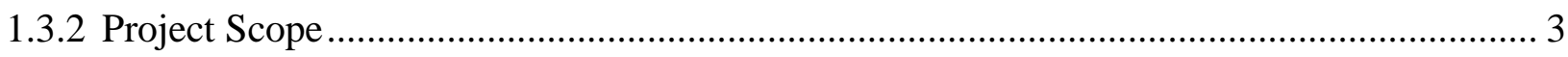

1.3.3 Methods (Major Task Summary) …………………..................................................... 4

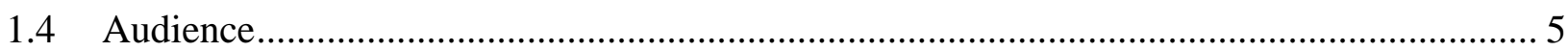

1.5 Overview of the Rest of this Report.............................................................................. 5

Chapter 2 - Background and Literature Review....................................................................7

$2.1 \quad$ Nature of Geography and Education ...........................................................................

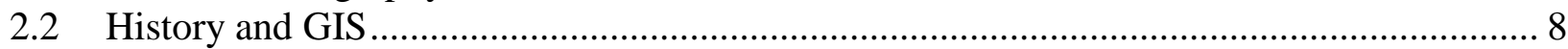

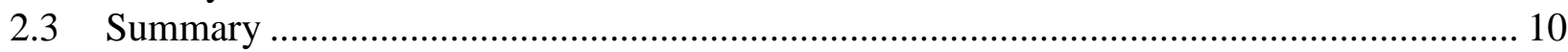

Chapter 3 - SILAS.ST Project Plan............................................................................13

3.1 Problem Statement ………………………………………………………….... 13

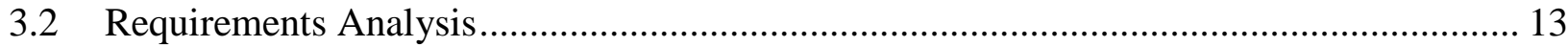

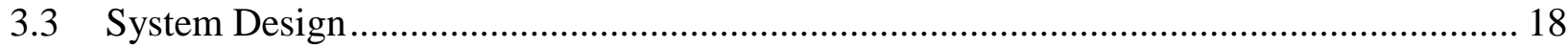

3.3.1 ArcMap 9.3

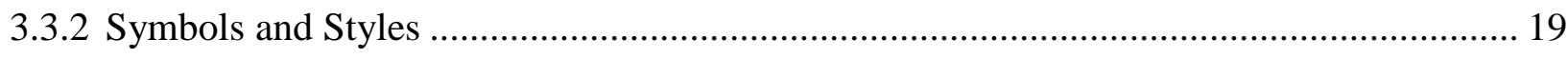

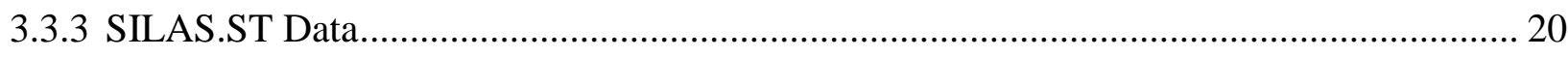

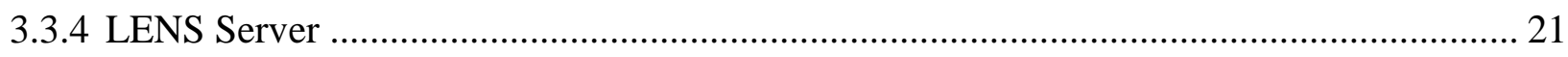

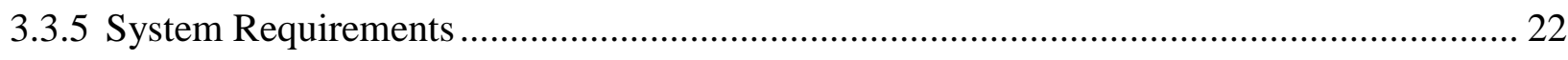

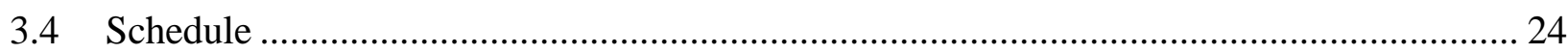

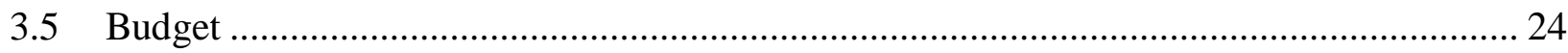

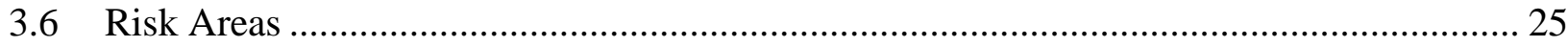

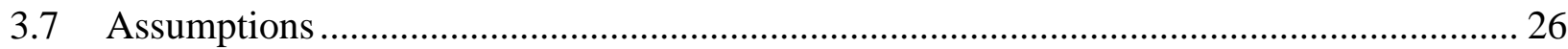

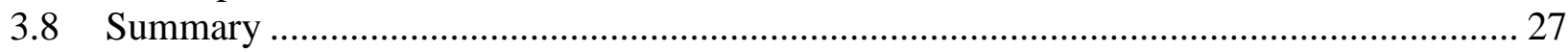

Chapter 4 - SILAS.ST Metadata Design ......................................................................................29

4.1 Interface Design ..................................................................................................... 29

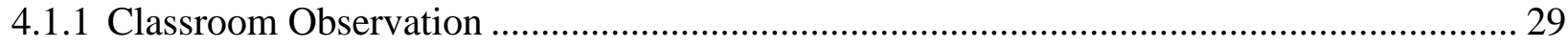

4.1.2 Proposed Toolbars and Interface ................................................................................. 31

4.2 Initial Construction of Metadata .................................................................................... 32

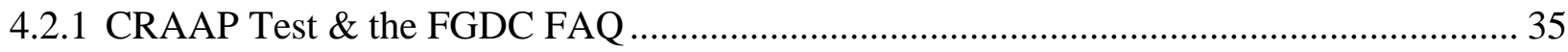

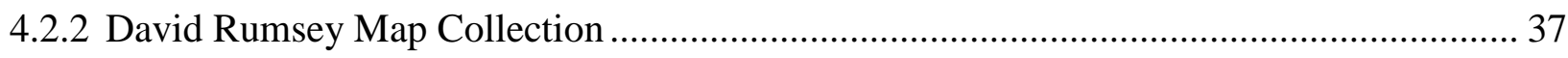

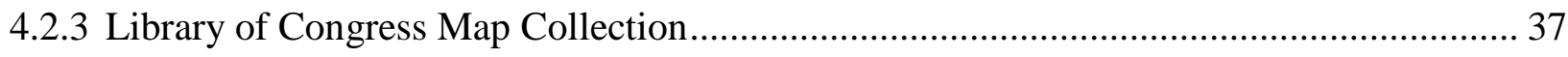

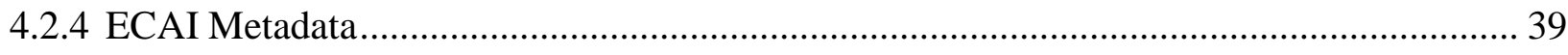

4.3 Related Projects in Historical GIS: Anne Knowles \& Charlie Frye ……............................. 39

4.3.1 Historical Holocaust Database ............................................................................................... 39 
4.3.2 The ArcGIS Citation Data Model and Method .................................................................. 41

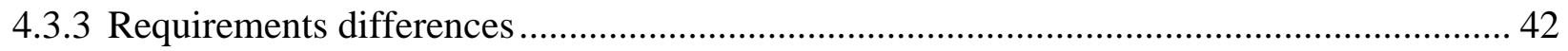

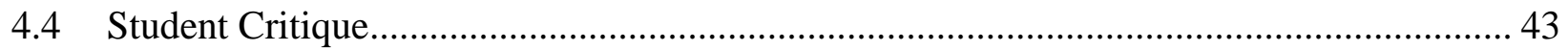

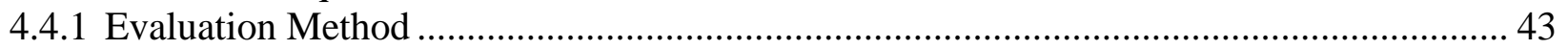

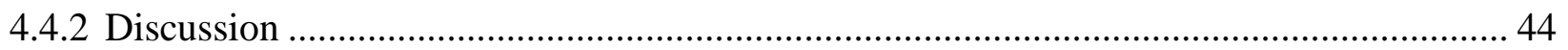

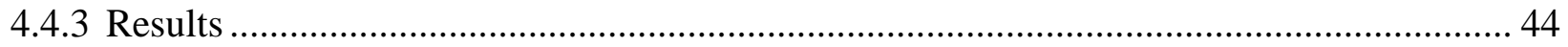

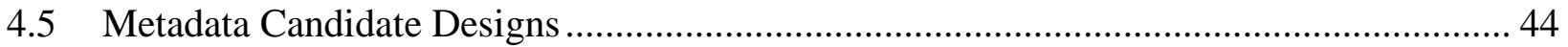

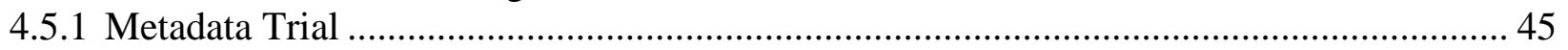

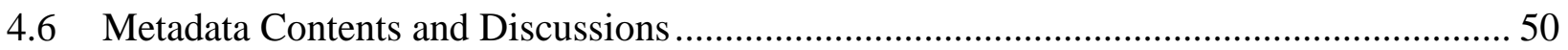

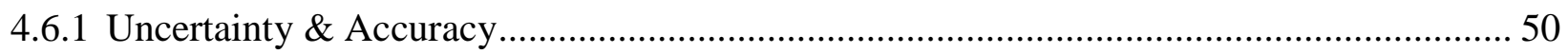

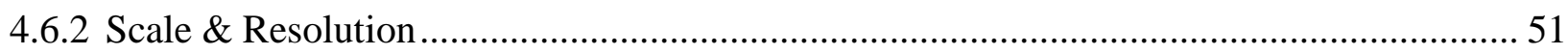

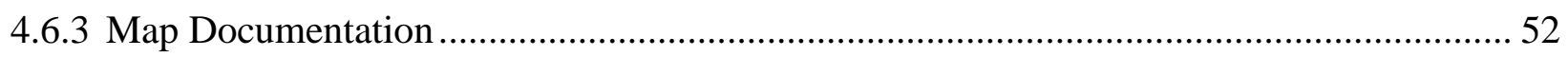

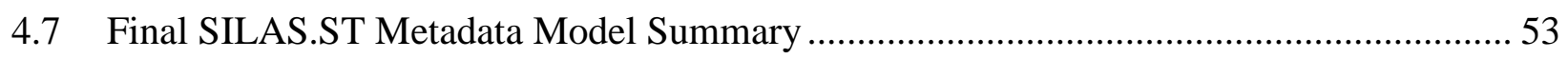

4.7.1 Student Made Maps.......................................................................................................... 54

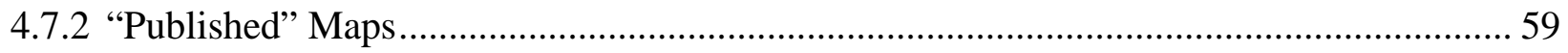

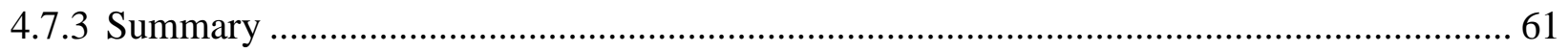

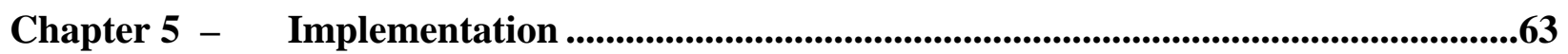

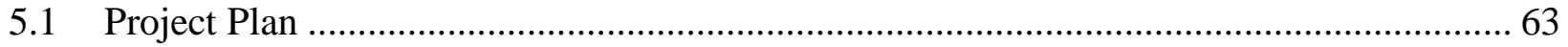

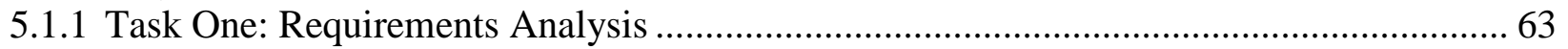

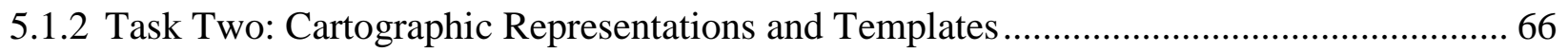

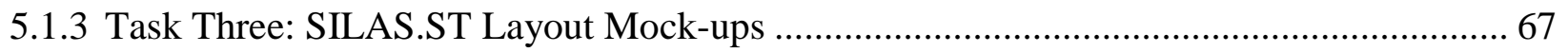

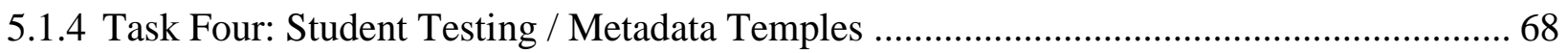

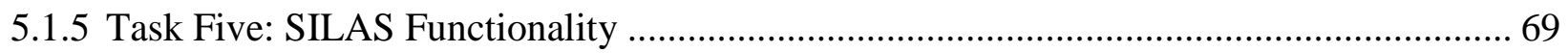

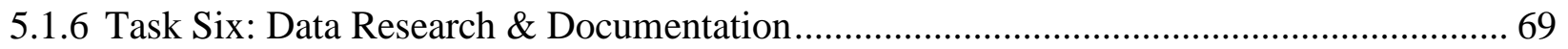

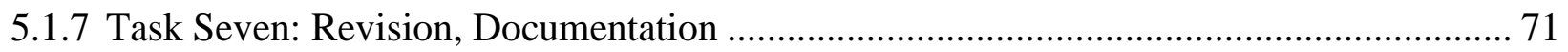

5.1.8 Task Eight: Revision, Fine Tuning, Documentation ........................................................ 72

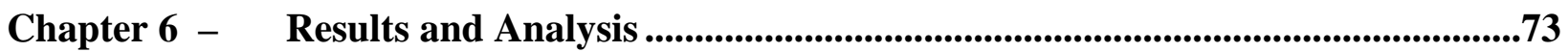

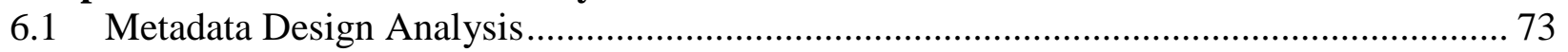

6.1.1 Evaluation by the Manager of Instructional Technology and a Consultant in GIS

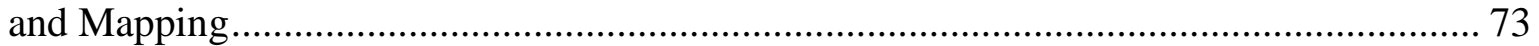

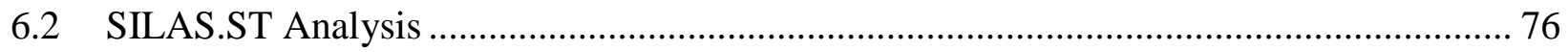

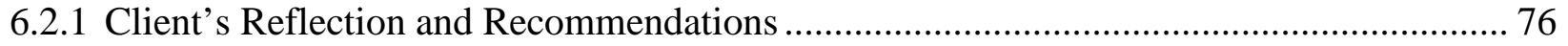

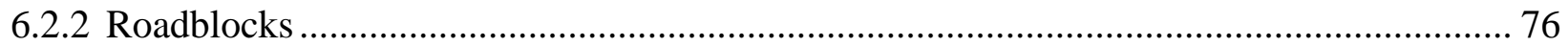

Chapter 7 - Conclusions and Future Work...............................................................................77

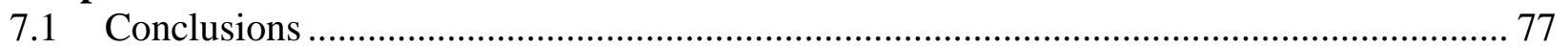

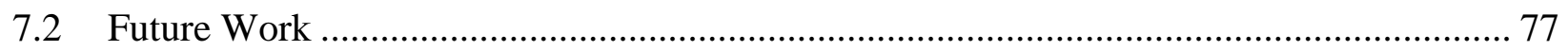

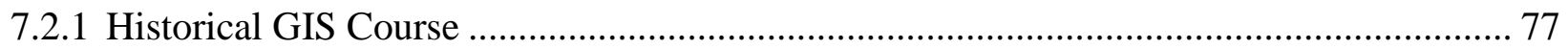

7.2.2 Representing Uncertainly with Cartography and Fuzzy Logic ............................................. 78 
7.2.3 ArcSDE Database Management \& System Architecture for a Multiuser Work Environment

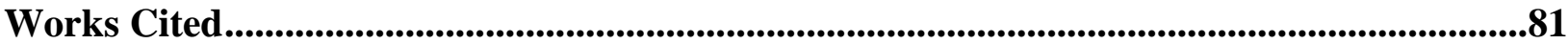

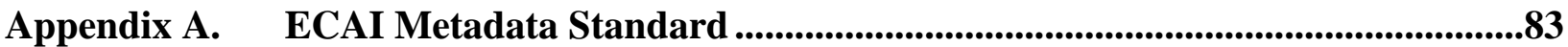

Appendix B. SILAS.ST Metadata Evaluation .................................................................85

Appendix C. Example Permissions Request ...........................................................................8.86

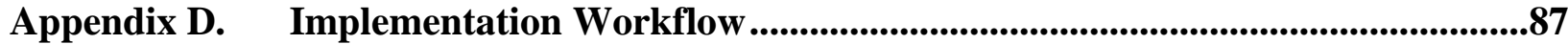

Appendix E. $\quad$ SILAS.ST Lesson Plans ..................................................................................89 



\section{Table of Figures}

Figure 1 SILAS.ST project workflow diagram....................................................... 4

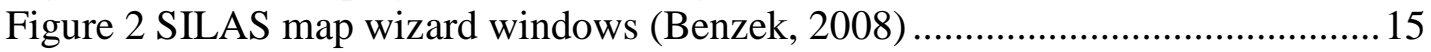

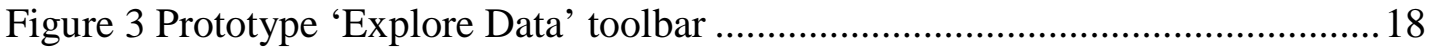

Figure 4 Prototype metadata editor dialog form ................................................... 19

Figure 5 Sample fonts and styles from ESRI's Historical Symbols and Styles .........20

Figure 6 Proposed SILAS.ST system architecture ...............................................22

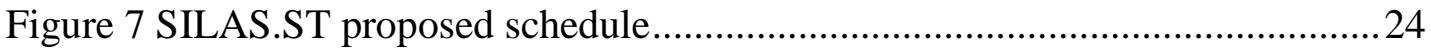

Figure 8 Screenshot from in-class exercise using ESRI's ArcMap .......................... 30

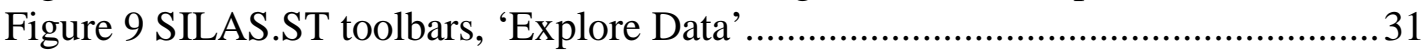

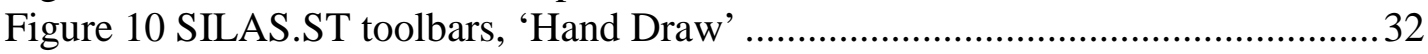

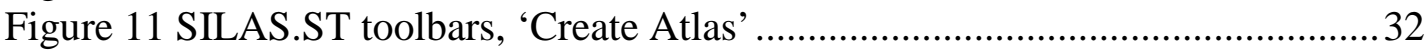

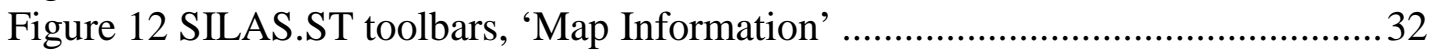

Figure 13 Documenting accuracy, first and second attempt ...................................40

Figure 14 Documenting accuracy and data lineage, first attempt............................40

Figure 15 Example source table, from the ArcGIS CDM .......................................4 41

Figure 16 Example object in a feature class, which sources listed, from the CDM

(Frye, The ArcGIS Citation Data Model and Method, 2008) ..................................42

Figure 17 SILAS.ST prototype tabs to be critiqued by students ............................. 44

Figure 18 Metadata trial, 'Quick Facts' tab with dropdown boxes ..........................46

Figure 19 Metadata trial, 'Origin \& Authority' ........................................................4 47

Figure 20 Citation requirement for a student-made map ..................................... 47

Figure 21 Metadata trial, 'Relevance \& Purpose' .................................................48

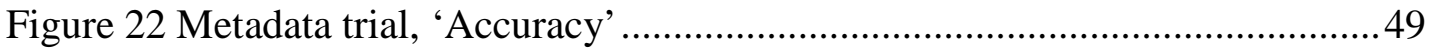

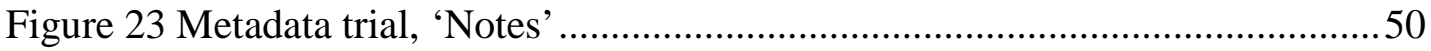

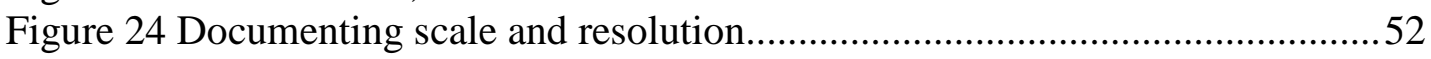

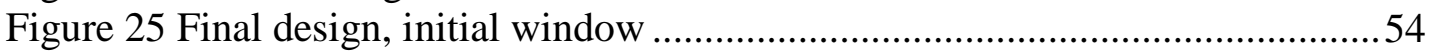

Figure 26 Final SILAS.ST Map Information design, 'Quick Facts’, student version

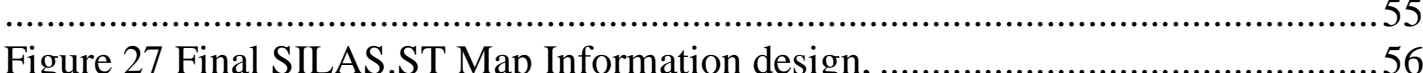

Figure 28 Final SILAS.ST Map Information design, ............................................ 57

Figure 29 Final SILAS.ST Map Information design, ...........................................58

Figure 30 Final SILAS.ST Map Information design, 'Notes', student version ..........59

Figure 31 Final SILAS.ST Map Information design, 'Quick Facts’, general version

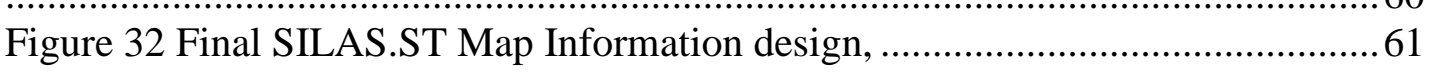

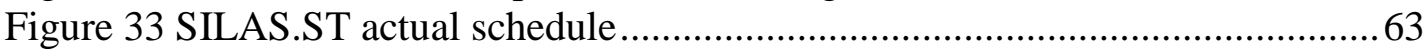

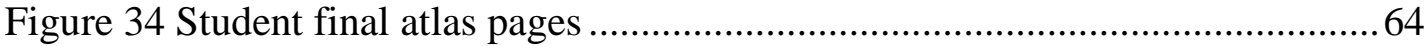

Figure 35 Student's unique symbolization, draft and final map..............................65

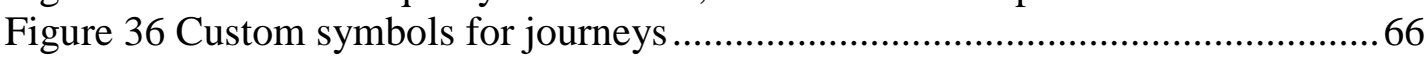

Figure 37 Custom 'floating' point marker for places............................................66

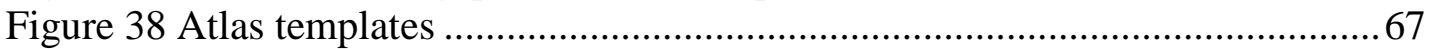

Figure 39 Final SILAS.ST 'Explore Data’ toolbar .............................................67

Figure 40 Final SILAS.ST 'Hand Draw’ toolbar..................................................67 


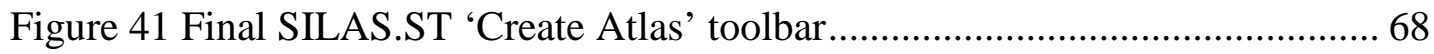

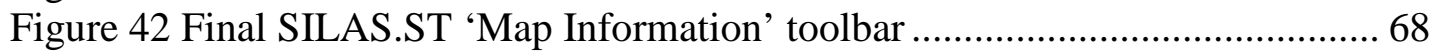

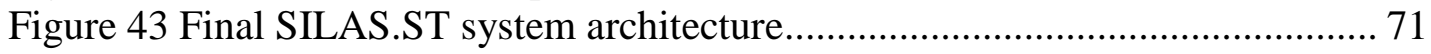

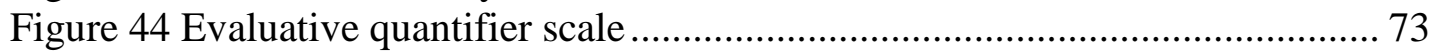

Figure 45 Implementing SILAS.ST on the university computers flowchart ............ 87

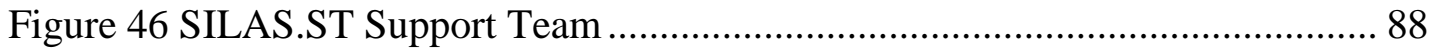

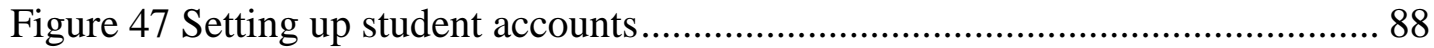

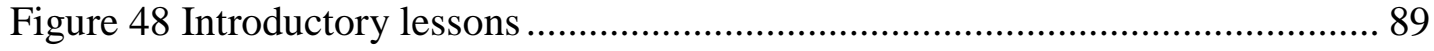

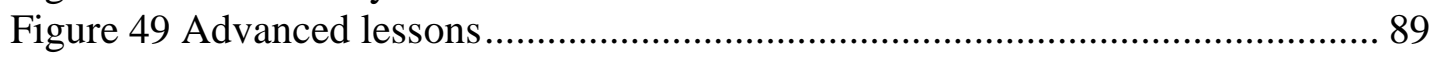




\section{List of Tables}

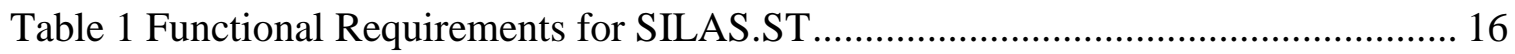

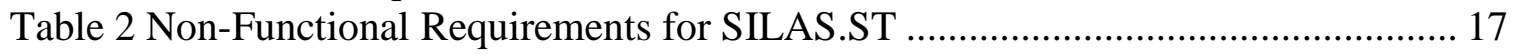

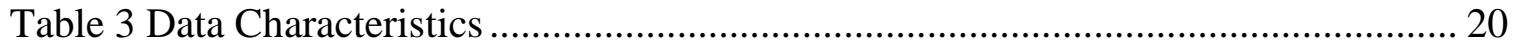

Table 4 Hardware Requirements from the ESRI Support Center .................................... 22

Table 5 Supported Operating Systems from the ESRI Support Center ........................... 23

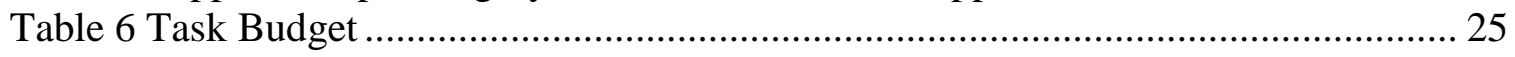

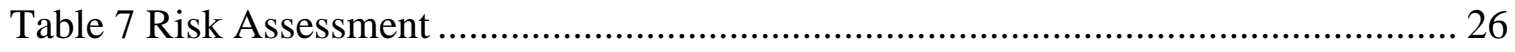

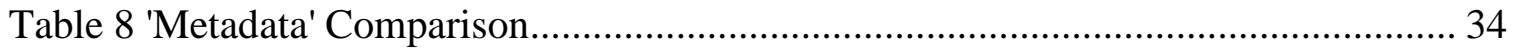

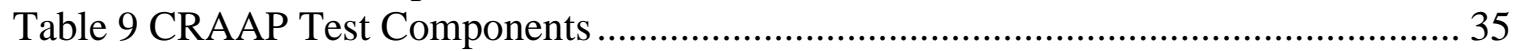

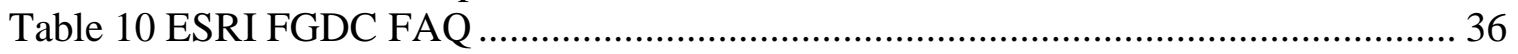

Table 11 Library of Congress Map Collection Documentation..................................... 38

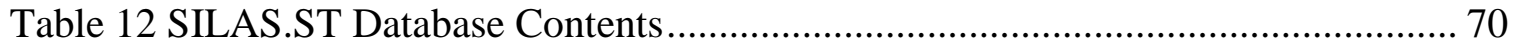

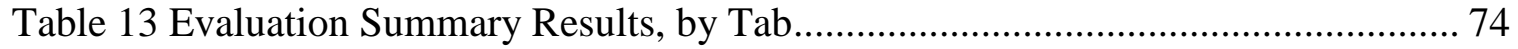

Table 14 Evaluation Summary Results, by Question .................................................. 75 



\section{List of Acronyms and Definitions}

$\begin{array}{ll}\text { AAG } & \text { Association of American Geographers } \\ \text { COM } & \text { Component Object Model } \\ \text { CRAAP } & \text { Currency, Relevance, Authority, Accuracy, and Purpose Test } \\ \text { ECAI } & \text { Electronic Cultural Atlas Initiative } \\ \text { ESRI } & \text { Environmental Systems Research Institute } \\ \text { FAQ } & \text { Frequently Asked Questions } \\ \text { FGDC } & \text { Federal Geographic Data Committee } \\ \text { GIS } & \text { Geographic Information Systems } \\ \text { ITS } & \text { Information Technology Services } \\ \text { LOC } & \text { Library of Congress } \\ \text { METS } & \text { Metadata Encoding \& Transmission Standard } \\ \text { MIP } & \text { Major Individual Project } \\ \text { MS GIS } & \text { Master of Science in Geographic Information Systems } \\ \text { SILAS } & \text { The Spatially Interactive Literature Analysis System } \\ \text { SILAS.ST } & \text { The Spatially Interactive Literature Analysis System Study Tool } \\ \text { SRTM } & \text { Shuttle Radar Topography Mission } \\ \text { VB } & \text { Visual Basic, specific to this project, Visual Basic .NET, or VB.NET } \\ \text { VBA } & \text { Visual Basic for Applications } \\ \text { VM } & \text { Virtual Machine }\end{array}$





\section{Chapter 1 - Introduction}

The Spatially Interactive Literature Analysis System Study Tool (SILAS.ST) follows in the tradition of the original SILAS, developed by Stephen Benzek (MS GIS Cohort 12). The client for this project, Professor Lillian Larsen, had requests for the second phase of SILAS that focused on greater educational functionality of the application. In the first phase of SILAS Benzek created a web application that used simplified GIS tools and functions. His web application made GIS accessible to non-GIS users. This second phase addresses the intellectual needs of using historical sources in GIS. In order to meet the requirements of my client, several design considerations have been explored to address the barrier of using GIS for historical humanities education. A proposed design solution and methods are touched upon in this chapter. This document in total outlines the development, design, and implementation of this project, to be submitted in fulfillment of the MS GIS program requirements.

\subsection{Client}

Professor Lillian Larsen of the Religious Studies Department at the University of Redlands oversaw the first phase of the Spatially Interactive Literature Analysis System (SILAS) while she was the client of Stephen Benzek (MS GIS Cohort 12). Professor Larsen had limited exposure to GIS and its capabilities prior to working with Benzek. However, she wanted to include a geographical component to her courses because she believes that maps can help to critically engage students' inquiries regarding the bible and its historical context. The first phase of SILAS focused on GIS system architecture for integrating GIS into the classroom, and Professor Larsen gained a better understanding of the benefits and drawbacks of GIS software.

For the second phase, Professor Larsen proposed the idea of a "spatial laboratory." Building upon Benzek's work, she envisioned an interactive environment in which students could overlay various geographic sources and include their own notes and observations. The design and implementation of the second phase was achieved by understanding her field of research and addressing her needs as a professor. The final product, the Spatially Interactive Literature Analysis System Study Tool (SILAS.ST), will eventually contribute to her future biblical studies classes.

\subsection{Problem Statement}

This project considers several major challenges for individuals (my client among them), who typically do not use advanced digital technologies, such as GIS, in their courses. One of the most significant challenges for humanities faculty to recognize is that out-ofbox GIS software is not ideally suited for exploratory or educational use because of its learning curve. Another significant challenge is that GIS is not ideally suited for historical research due to the nature of historic sources.

Therefore, the goal of this second phase of SILAS is to make GIS applicable to the exploration of biblical research and accessible to undergraduate students. Biblical 
geography has been studied for a long time, but traditionally with a "positivistic" edge that excludes speculation and critical evaluation of the information. Professor Larsen wants her students to read historical texts with a critical eye and focus on how geography influences texts. A "spatial laboratory" would enable her to integrate and evaluate geographical sources into her courses, and allow students to understand the nature of historical and biblical geographical sources.

\subsection{Proposed Solution}

To meet the needs of an undergraduate professor teaching religious history, the second phase of SILAS includes a study tool that aids in the student evaluation of historical sources. The new name reflects this addition: the Spatially Interactive Literature Analysis System Study Tool (SILAS.ST).

One component of this study tool is a customized metadata standard. Within ArcGIS, the software supporting SILAS and SILAS.ST, all documentation that accompanies map layers is contained within the "metadata"-- data about the data. Current geographic metadata standards are not ideally suited for undergraduate students documenting historical sources in GIS because metadata standards are often too complex for students who are new to both GIS and metadata. By reformatting and reorganizing metadata information fields supplied by ESRI to emulate the historical method approach used by historians, SILAS.ST has its own metadata standard. Students can easily fill out and view this metadata within SILAS.ST, which encourages students to read and edit the documentation. Having this available helps them understand the limitations of the data with which they work. This added intellectual component increases the value of GIS as a study tool.

Beyond metadata, several customizations to ESRI's ArcMap interface help make the software user interface more intuitive for humanities students. Using SILAS.ST, students can overlay base maps and choose an extent of their study area. Customized toolbars help students "hand draw" map information related to their inquiries on top of the base maps. A “Create Atlas” toolbar helps students lay out an atlas page, which includes scale bars, legend, graphics and labels. SILAS.ST allows students to create a professional looking atlas page of their maps and research. The final SILAS.ST application will be available for my client's students to access from a server that will be available to undergraduate students during the academic year.

\subsubsection{Goals and Objectives}

The completion of SILAS.ST represents a pedagogical achievement in incorporating and teaching historical sources in GIS. SILAS.ST also represents a successful bridging of my background in art history and visual culture, and my interest in GIS.

From this project, I have gained a firsthand understanding of project implementation and design. I have also learned how to creatively integrate GIS into a discipline that is not commonly approached by spatial and information analysis. This project was achieved by meeting the following goals:

- Support and advance multidisciplinary collaboration with my advisor and my client. 
- Learn how to program and customize an ArcMap interface to make it useful within a non-GIS classroom.

- Translate GIS concepts into language that can be understood by an audience of students unfamiliar with GIS.

- Evaluate my project work by students, my advisor and client for its ability to visually communicate GIS concepts to a wider audience.

I hope to keep close ties to academia following this program. This unique opportunity to explore the collaboration between GIS and religion has been a very valuable experience, both in terms of project implementation and GIS integration.

\subsubsection{Project Scope}

The original SILAS project was implemented using ArcGIS Server and the previous version of ArcGIS 9.2 software. It featured a biblical text search, annotation tools and a few biblical era data layers. Instead of reviving the system architecture used in the first SILAS phase, I chose to develop a standalone ArcMap document using ArcGIS 9.3. I chose this basic system architecture because the original server-based SILAS, using ArcGIS 9.2, had many glitches. Once the campus-wide software image was updated, it was no longer functional. By switching to a standalone ArcMap document, the project will also be compatible with ArcGIS software upgrades for the foreseeable future. Compared to ArcMap, ArcGIS Server was limited in terms of functionality. For example, adding analysis tools to the server interface is not easily achieved by someone unfamiliar with ArcGIS Server. In ArcMap, access to analysis tools from the main interface is significantly easier even for users new to ArcGIS. The ArcMap interface is likewise easily customized for all levels of GIS users.

Also included within my project scope is a set of cartographic symbols and styles for historical representations in ArcMap. This set includes symbols that convey spatial uncertainty, including generalized point markers that hover over rather than point specifically at a location. In addition to including ESRI's 2006 issue of historical fonts and historical cartographic representation files, I spent time creating my own symbology styles within ArcMap.

One of the main components of the project's scope was a functional metadata editor that could be accessed within the SILAS.ST ArcMap document. This metadata editor was designed with non-GIS users in mind, and it avoids GIS specific terms. The content and concepts covered are directly relevant to history and historical inquiry. A style sheet, used for viewing this customized metadata, was put together using XML in Stylus Studio 2009 XML Enterprise Suite Release 2.

The final delivered study tool allows students to easily navigate the interface and explore data relevant to their area of study. This project makes it easier for students to understand the historical relevance and certainty of any map they create or encounter. A set of example introductory and advanced lesson plans, written with my client in mind, accompany the final implemented project (See Appendix D and Appendix E). 


\subsubsection{Methods (Major Task Summary)}

In order to complete this project, several individual tasks were met. Before the project was underway, the following workflow diagram was proposed to help guide design, development and implementation.

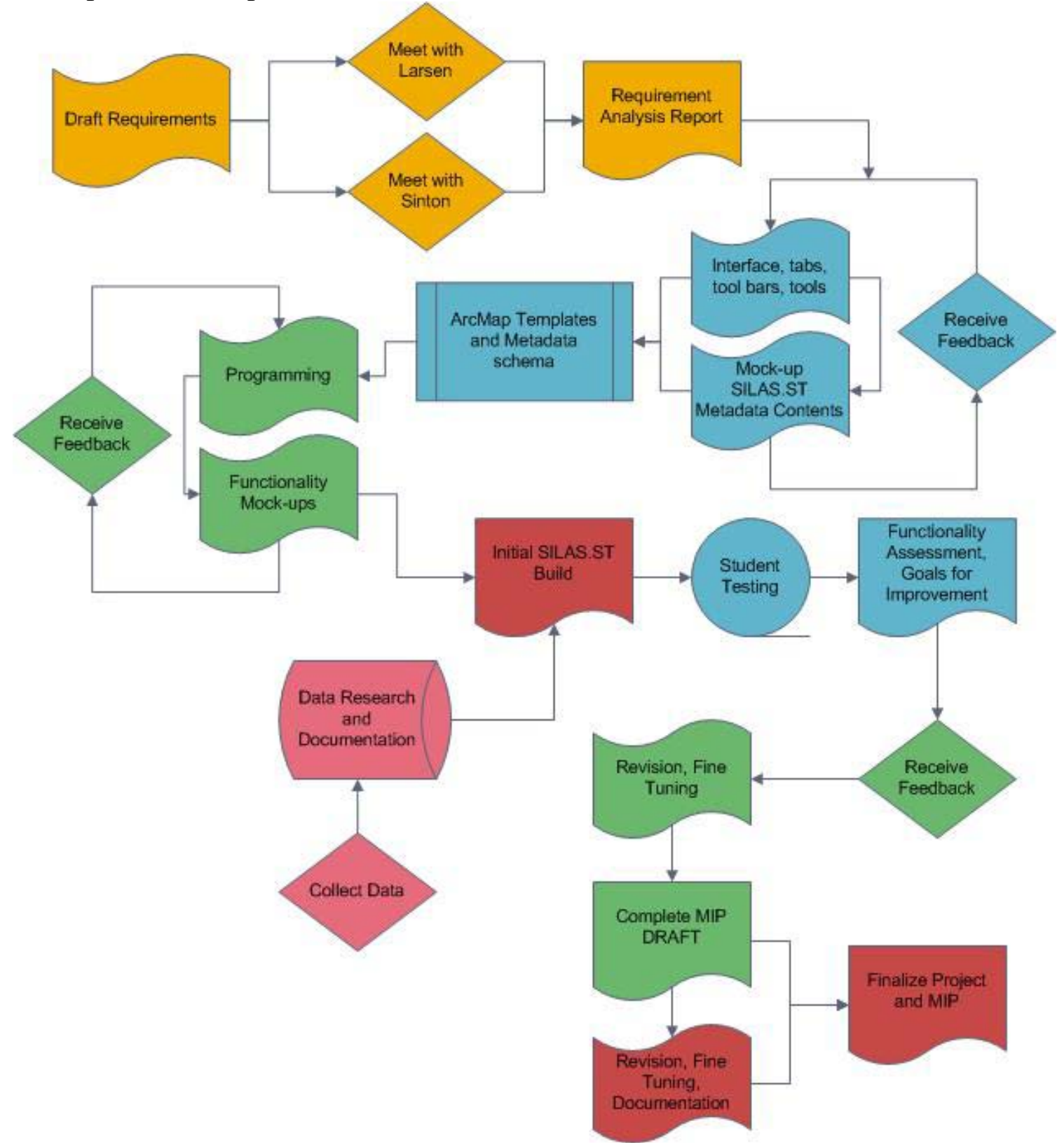

Figure 1 SILAS.ST project workflow diagram

During the first few months, a list of desired functionalities was drafted and reviewed with my advisor. This list included the technical requirements for each component. Through discussion with both my advisor and my client, I assembled a prioritized, tentative list of functions. Later in the process, I attended my client and advisor's co-taught three-hundred level undergraduate religion course, Historical Search 
for Jesus. Based on course observations and the functions discussed with both client and advisor, I began to create various mock-ups of toolbars and layouts. Collaborating closely with my advisor and client regarding content and organization, this process underwent much revision and critique.

Data research and acquisition took place as data became available from my client. In this process, I created a few customized cartographic representations and templates for the new SILAS. Continuous revision yielded satisfactory cartographic representations that best visualize historical data. I also took an ESRI instructor-led course on cartography that demonstrated new techniques.

After completing the three-day ESRI Instructor-led course, "Introduction to Programming ArcObjects Using VBA," I began customizing and developing buttons and forms within ArcMap. At this point, I began to consider the feasibility of functions and their priority for the project. Classroom observations helped tremendously in determining where students struggled in using the software.

For testing, I had to complete a prototype of my metadata before students left for summer break. Students in REL 305 provided qualitative evaluations of my first prototype of the SILAS.ST metadata. I also received feedback from my advisor and my client, and other individuals with expertise in 1) teaching, 2) geographic information science, and 3) history on later prototypes of my metadata standard.

I integrated all of these components into the new SILAS.ST after satisfactorily meeting my client and advisor's requirements. I also addressed issues that surfaced from the student and mentor evaluations. I encountered some programming glitches towards the end of the project, as I had expected. At this point, I had to determine the feasibility and priority of fixing the problems as programming assistance was limited.

After more revisions, I had a completed SILAS.ST application. I finalized my Major Individual Project (MIP) and turned it in to my advisor in preparation for my defense on July 21, 2009. Once defended, I considered the MS GIS faculty's edit suggestions and put the final touches on the project and submitted it in fulfillment of MS GIS Program requirements.

\subsection{Audience}

This project draws on the collaborative input of various disciplines: geography, education, history and GIS. It will be of particular interest to those with an appreciation for historical methodologies and questions of pedagogy. In outlining the project's development, I assume some familiarity with GIS software.

\subsection{Overview of the Rest of this Report}

This first chapter of my report introduces SILAS.ST and sets the stage for the rest of the project documentation. Chapter 2 addresses the history of geography in education and the development of GIS for teaching history, citing authors and major trends. The concepts covered in Chapter 2 are also discussed in Chapter 4, which covers the design of SILAS.ST. Chapter 3 outlines the proposed project plan, as envisioned early on in the preliminary of the project, and Chapter 5 follows up with greater detail regarding the actual implementation of SILAS.ST. The results and analysis discussed in Chapter 6 help 
to gauge the success of the project, and Chapter 7 draws conclusions about the project and recommends future work. 


\section{Chapter 2 - Background and Literature Review}

As noted previously, the primary areas of research relevant to the second phase of SILAS (SILAS.ST) include the pedagogy of geography, historical methodologies, and GIS. An added emphasis on the teaching of geography and history specifically addresses an undergraduate humanities audience. Of particular interest are methods that integrate historical sources with GIS and documentation that adds pedagogical value to maps and spatial analysis when teaching history with GIS.

\subsection{Nature of Geography and Education}

One of the main challenges SILAS has confronted is introducing the usefulness of spatial data in an academic discipline that does not traditionally use geography for critical analysis. For some background on geography's historiography, Malcolm Douglas, author of The History, Psychology, and Pedagogy of Geographic Literacy, addresses past issues concerning the integration of geography into the classroom (Douglas, 1998). Douglas worries about the future of thinking geographically, stating "[T]he persistence of an approach to [general curriculum] instruction that emphasizes a quantitative definition of knowledge over a qualitative one” could de-emphasize the goal of learning qualitatively (Douglas, 1998). He describes a history curriculum that emphasizes learning names and dates, versus the broader historical context that contained the past events. He is afraid geography could similarly become a static discipline, with quantitative aspects (memorization of names and places) as its sole focus. While Douglas' writing is dated relative to the development of GIScience, it is interesting to consider Douglas' apprehension with respect to the technical learning curve required to utilize a GIS. He fears the technology will obviate future interest in geographic inquiry and the geography profession (Douglas, 1998). Geographer Daniel Sui shares the same apprehension, worried that GIS will be used solely as a static source of data rather than a tool that aides in the analysis and interpretation of geographic phenomena (as cited in Douglas, 1998).

Douglas would be comforted to know that ten years after his writing a "cartographic revolution” has developed a generation of superior mapping tools and digital data resources that have significantly facilitated spatial analysis, and more importantly, qualitative learning (Wiegand, 2006). This is not solely due to advances in mapping technology. It is rather the combination of intellectual and technical skills that have helped researchers and students ask better research questions when analyzing spatial patterns, allowing them to more deeply probe spatial relationships and to identify causes (Gregory \& Ell, 2007). Anne Knowles, a well-known historical geographer, found that mapping assignments helped her undergraduate students organize information and make historical comparisons. Interaction with maps also helped them find geographical information in textual sources and test hypotheses by overlaying this information (Knowles, 2000).

Evidence of this spatial-thinking revolution is seen in a number of resources describing the integration of GIS in the classroom across a variety of disciplines (Sinton \& Lund, 2007). Patrick Wiegand, a geographer and educator, suggests that using GIS in the classroom requires "a more collaborative, open pedagogy with greater emphasis on 
individual or small group learning.” This ultimately reshapes the archetypal roles of teacher and student, as both become learners in a new environment (Wiegand, 2006). In turn, Marsha Alibrandi, a teacher and longtime advocator of geographic education, discusses the overall trend of "co-construction" and "co-instruction" that has appeared with the introduction of GIS to the social studies classroom (2003). Alibrandi notes the leveling of students and teacher that occurs when integrating this technology with traditional subject matter —often students are more adept in learning new software and applying their knowledge to the task at hand. Students having the upper hand technologywise "...[is] a good thing, because the teacher is still leading through modeling learning with students” (Alibrandi, 2003).

GIS has not necessarily revived the discipline of geography, however. Geographical tools have been blamed as the enabling cause for the demise of geography in school curriculum (Downs, 2004). Before the advent of GIS, K-12 teachers had relied on globes and atlases to facilitate the teaching of geography, and the retaining of bland factual knowledge was a method of teaching geography. It was easy to teach and easy to learn (Downs, 2004). GIS has renewed interest in geography, but it is still only one tool in the discipline, such as the globe and atlas. Downs warns that careless use and adoption of GIS may once again simplify the discipline of geography. Care must go into the instruction and content of the tool, and GIS is not a means to an end in the discipline of geography (Downs, 2004). In order for SILAS.ST, or any other GIS applications, to be pedagogically effective, it must be thoughtfully integrated with course content.

\subsection{History and GIS}

When dealing with historical sources, effort is required to make GIS suitable for conducting historical research. This includes acquiring data, providing adequate training for teachers and students, and learning how to properly inquire into and interpret problems spatially (Wiegand, 2006; Sinton \& Lund, 2007; Gregory \& Ell, 2007).

Steve Benzek's SILAS addressed the access and usability of GIS for teachers and students. SILAS was purposefully developed with simplified GIS components using the University of Redlands' existing ArcGIS software. The final product was a web based application, using ArcGIS Server, which made the application widely available and did not require students to own or maintain the software. This architectural choice follows the current trend of web-based media for sharing and conveying spatial history sources (Knowles, 2008). By placing sources in an interactive environment, authors allow users to interact with and draw their own conclusions about history, rather than push for a particular interpretation.

While SILAS overcame many of the hurdles of integrating GIS software in the classroom, a number of additional difficulties unique to historical mapping were not addressed in this first phase of the project.

Similar to most web mapping applications, SILAS was good for identifying what and where, or as Ian Gregory calls it, "crude spatial-pattern spotting.” However, in order to make GIS a scholarly tool, it is important that GIS be coupled with instruction of how to get to the cause of the patterns (Gregory \& Ell, 2007). Professors must know how to 'read' a map as much as students need to know how to see information on a map. Knowles describes how the concept of "layers" in mapping had the greatest bearing upon her students' understanding of history and place. She taught this concept by having her 
undergraduate students manually overlay mylar sheets with different printed themes and map elements, reinforcing the point "that places are complex, and that mapping spatial phenomena can reveal important, sometimes surprising juxtapositions” (Knowles, 2000). Some students' understanding of geography comes strictly from virtual globe mapping applications, like Google Earth. While such tools have revived general interest in geographical technologies, students need to rethink the pinpointing techniques they learned from using Google Earth and similar virtual globe applications. Both historians and students using GIS should not focus on pin pointing exact locations, instead, they should use GIS to the benefit of handling data's spatial, temporal and attribute qualities.

GIS provides a wealth of analytical tools, especially to data rich fields such as earth science and sociology. For humanities disciplines, GIS techniques are difficult to apply because these disciplines are not as quantitatively data rich (Jessop, 2008). Historical data is inherently imprecise and incomplete; measures of uncertainty and generalization in existing historical data must be taken into account when interpreting spatial trends and patterns (Knowles, 2002; Gregory \& Ell, 2007). While SILAS’s pinpointing and annotation capabilities were useful, the data management capabilities of GIS were never utilized for handling historical data during the first phase of SILAS.

SILAS used a number of sources for data, specifically biblical sources for mapping. Candidate sources, such as HaperCollins Atlas of Bible History, contain a variety of biblical-era maps that combine text with geographic locations and approximates place names using historical sources to construct the geography of the past (Pritchard, 2008). Other sources, such as The HarperCollins Visual Guide to the New Testament, methodically deduce biblical geographic locations using archeological remnants (Reed, 2007). All of these types of sources are susceptible to historical inaccuracy, and the precision of place locations will never be known. This fact is often overlooked because of the assumed authority of printed maps.

Another common shortfall of these types of atlases, particularly thematic maps, is the parsing of maps and information by theme (Gregory \& Ell, 2007). Often this does little to advance our understanding of the whole topic. The absence of an overarching explanation makes individual maps simply patterns on paper as the reader is inundated with individual backgrounds and descriptions organized by themes (Gregory \& Ell, 2007). The benefit of GIS is the ability to consume these individual, imprecise data sources and convert them to thematic layers of information that can be overlaid on top of each other, allowing the user to view and compare the patterns through the layers. With additional background reading, an explanation of the patterns is more likely to emerge. This interactivity of information is a valuable pedagogical tool.

Historical sources brought into GIS were probably never meant to be explored and manipulated in the ways they are typically used with GIS software (Gregory \& Ell, 2007). Thus data quality and the many terms used to evaluate it (error, blunders, accuracy, precision, uncertainty) are difficult to evaluate. They often thwart attempts to confidently analyze and integrate data within GIS (Gregory \& Ell, 2007). In historybased disciplines, "[there is] little cause to value images over words and based on the bulk of the evidence scholars have every reason to treat visualization as an inferior form of thought and communication” (Jessop, 2008).

Metadata and documentation are both critical in digital humanities projects because they provide necessary assessment and evaluation of data sources. They likewise 
have their own benefits and limitations due to their different structures. Documentation is a general and open-ended way of cataloging information about data. Similar to historians' footnotes, it can be very in-depth and thorough. Metadata however is highly structured, using a standardized database-type format such as the Federal Geographic Data Committee (FGDC) standard or Dublin Core, to document the content, quality and condition of the data (Gregory \& Ell, 2007). Metadata standards are created and maintained by information services and library science, and are used in a variety of fields. Formatting metadata to rigorous standards allows data to be uniformly managed, easily located and routinely updated. The formats are limited by the lowest common denominator between data types so as to be as widely applicable as possible. Good metadata also enables resource discovery, allowing data to be found and easily shared (Jessop, 2008). Classical documentation's open-ended format allows for scholarly critique of data and informs the user of the data's purpose and use. However, documentation is not standardized, and using non-standardized documentation limits its use. Historians looking to document their data should consider the intended use of their data and how that compares to their common practices of documentation in their own specific discipline (Gregory \& Ell, 2007). For an effective metadata standard, Jessop recommends collaboration among all interested disciplines (2008).

As an example of historical metadata, the Electronic Cultural Atlas Initiative's (ECAI) Metadata Clearinghouse has its own metadata standard for the purpose of cataloging historical spatial data. ECAI is a global group of scholars who are formulating a virtual cultural library, with emphasis on the geographical and temporal attributes of the data. The ECAI metadata standard is based on the Dublin Core, a widely used metadata standard, with additional ECAI fields that account for the contextual footprint of the data (Johnson, 1998). The Dublin Core standard is not well suited to documenting spatial and geographical information because it was designed to be applicable to many fields of research. It documents both the spatial and temporal extents in one field, known as the Coverage field. For use in a spatial database comprised of historical sources, a single field documenting both time and place is not satisfactory. ECAI has better defined the Coverage field to include the bounding latitude and longitude points, the relevant historical or archaeological periods, resolution of a map or digital position recording, and the geography by which the data was aggregated. "In order to simplify searching, ECAI limits the coverage metadata to a single bounding box by making these elements nonrepeatable” (Johnson, 1998). By adding their own contextualizing fields and redefining Dublin Core's ambiguous Coverage to better document spatial and temporal attributes, ECAI has made their database searchable by location and time, within the frame of Dublin Core formatting (Gregory \& Ell, 2007). The more interoperable the cataloguing method, the more easily it facilitates queries and relevant results.

\subsection{Summary}

GIS provides an environment for users to interact with data from multiple sources and see patterns through the layers. The potential interactivity between endless combinations of data overlays allow viewers to draw their own conclusions about spatial patterns. However, the patterns are not necessarily self-explanatory. Additional background reading and instruction is necessary to explain the patterns that emerge. Likewise, 
training with GIS is crucial for properly interpreting patterns and their causes. GIS is a valuable and powerful pedagogical tool, but only when used properly.

Historians interested in using GIS need to learn how to handle the spatial, temporal and attribute qualities of data. The data management and documentation capabilities of GIS have not been well utilized for teaching how to interpret historical data. Part of the problem is that the historical sources brought into GIS were not intended to be analyzed and manipulated as data sources typically are within GIS software.

As this project demonstrates, documentation is the key to interpreting historical sources in GIS in order to preserve the original purpose of the source and to inform the user of its proper use and interpretation. However, current geographic metadata standards supported by ArcGIS are not suitable for student documentation of historical geographic data. Traditional documentation used by historians is open-ended, and thus better able to inform the user of a given body of data's purpose and use. The SILAS.ST metadata format incorporates some of the benefits of the open-ended documentation format used by historians. As stated above, the more interoperable the documentation strategy, the more easily it will facilitate queries and provide relevant results. By using its own standardized metadata for documenting historical geographic data, rather than relying on an established format, the SILAS.ST metadata challenges users to critically assess their data using historical methods. 



\section{Chapter 3 - SILAS.ST Project Plan}

The SILAS.ST design revolves around my client's undergraduate humanities students who are not GIS experts. Having her students learn to use GIS software for advanced analysis is not a high priority for my client. With SILAS.ST, students will instead use GIS to apply geography to history as they evaluate historical sources using geography. The goal of this project is to create a GIS user interface designed to help the students pursue their historical inquiries. With relatively little instruction, students should be able to easily navigate through the SILAS.ST program, from layering data, through filling out metadata, to final map production. The SILAS.ST application and data will be available to students on University of Redlands' lab computers during the semester when they are taking my client's course. This chapter outlines the project analysis and planning. The project analysis and planning will guide the design and implementation of SILAS.ST in Chapters 4 and 5.

\subsection{Problem Statement}

For my client, who does not typically use advanced digital technologies such as GIS in her courses, this project addresses several major challenges. As previously noted, these are: out-of-box GIS software is not ideally suited for exploratory or educational use because of its learning curve and GIS is not ideally suited for historical research because of the nature of historic sources.

Professor Larsen wants her students to read historical texts with a critical eye by focusing on the interplay between geography and texts. Although biblical geography has been around for a long time, it has traditionally retained a "positivistic" edge, that excluded speculation and critical evaluation of information. Adopting a less static approach, my client envisioned the creation of a "spatial laboratory" that would allow students to integrate and evaluate geographical and textual sources, allowing students to understand the nature of historical and biblical geographical sources. Therefore, the goal of this second phase of SILAS is to make GIS applicable to the exploration of biblical research and accessible to her undergraduate students.

As noted above, there are fundamental problems that challenge the field of historical GIS. These challenges underlie the design and implementation of this project. GIS is not ideally suited for historical research, because GIS was not designed to visualize historical sources with "fuzzy" information. On the other end, historical sources were not originally intended to be explored and manipulated as map layers typically are within GIS. These barriers need to be considered in order to successfully integrate GIS with history.

\subsection{Requirements Analysis}

The second phase of SILAS builds from the system developed by Stephen Benzek (MS GIS Cohort 12) by adding a study tool that promotes a geographical approach to reading ancient texts, using a GIS. This tool helps undergraduate students represent historical qualitative information and evaluate historical sources. Designed to be used by an 
audience largely unfamiliar with GIS and spatial concepts, the final standalone application is straightforward and customized to fit the needs of an undergraduate, humanities audience. The historical components of biblical research are incorporated into a metadata standard meant for documenting historical information. In essence, this new tool will encourage the student user to approach the bible as a historical document.

As noted above, the first phase of SILAS focused heavily on the challenge of using ArcGIS software for education, and Benzek chose ArcGIS Server as the system architecture because of its usability for students new to the software. However, the server architecture did not use the ArcGIS software to its full potential. Thus, for the second phase, SILAS.ST uses existing ArcGIS software and hardware provided by the university. Created as a standalone ArcMap document using ArcGIS 9.3, SILAS.ST will be accessible on the university lab computers by a shared server folder. By switching to a standalone system architecture, a range of customizations are available through the existing ArcMap interface options, and by programming the system using ArcObjects. This change in system architecture and customization of the interface helps break the barrier that new users often face when using ArcMap. At the same time it does not limit access to the full GIS software.

In testing formats for the original SILAS, Benzek considered a "wizard" interface to assist students in setting up a map document (Figure 2). A "wizard" typically includes multiple successive windows that provide options and require user input to complete a complex task for the user. In the initial project proposal, I suggested a wizard for helping students determine the initial setup, data, extent and time period of their map. Because ArcMap is a relatively complex interface for new users, I also explored other options aside from creating a wizard. I found these better identify layers and maps relevant for student inquires. 


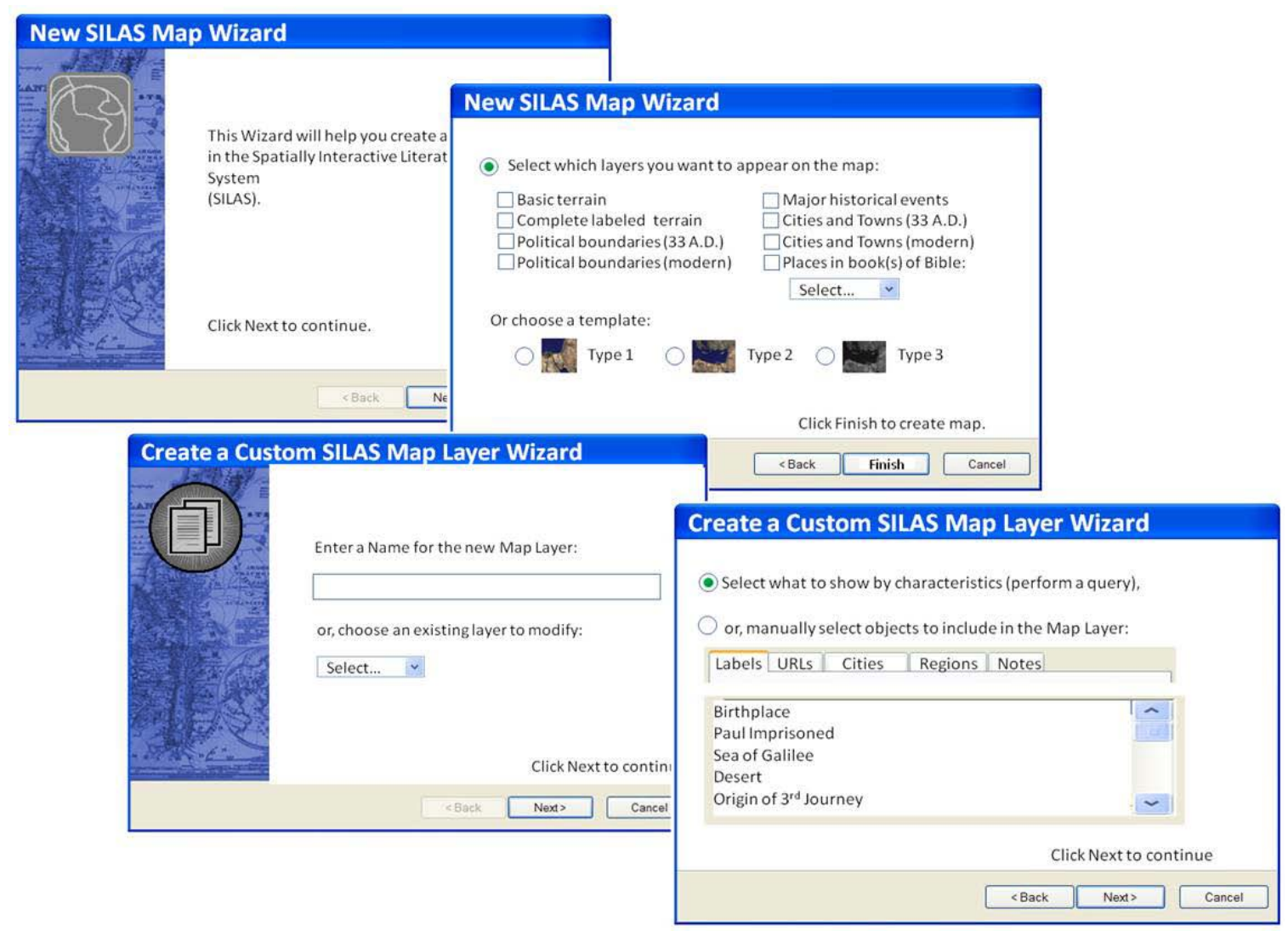

Figure 2 SILAS map wizard windows (Benzek, 2008)

To address the often uncertain and "fuzzy" data related to historical research, I experimented with cartographic representations, attempting to represent spatial uncertainty. My main goal was for students to understand that historical data is varied in degrees of certainty. Because historical sources are by nature incomplete and ambiguous, incorporating data into a GIS creates many challenges. In addition to the fragmented and ambiguous nature of sources, history is commonly preserved in narrative and textual documents. Visual representation is rare. As Anne Knowles suggests in her paper, A Case for Teaching Geographic Visualization without GIS, of all the humanistic disciplines, history is the least amendable to lending itself to visualization (Knowles, 2000). The textual narrative will change from text to any visualization of that text (Claiden-Yardley, 2008). The information and quality of the original text is often lost in visualization. My client understands this barrier, and she utilizes this discrepancy between qualitative text and quantitative representation to her pedagogical benefit. In this context, visualization serves as a tool to inspire critical questions.

To guide the transition between textual narrative and visual narrative, SILAS.ST includes a customized metadata editor, using natural and less technical language so it can be easily understood and populated by students. Students will be able to read information about the feature class layer and determine its relevance to their own research. The tailored metadata viewer and metadata editor are accessed within the SILAS.ST ArcMap document, instead of the more inconvenient ArcCatalog location. 
The final system will help students easily navigate the metadata interface and identify data relevant to their inquiry. It will also help them understand the historical relevance and certainty of the map they create. As noted earlier, a set of introductory lesson plans will accompany the final project. The following tables outline the specific non-functional and functional requirements for SILAS.ST as discussed in this section.

\section{Table 1 Functional Requirements for SILAS.ST}

\begin{tabular}{|c|c|c|}
\hline \multicolumn{2}{|r|}{ Functional Requirements } & Priority \\
\hline 1 & The metadata should be accessible in ArcMap & Required \\
\hline 2 & The metadata will have a customized stylesheet & Required \\
\hline 3 & The metadata should be editable & Required \\
\hline 4 & $\begin{array}{l}\text { The metadata will have the basic identification fields used by the } \\
\text { FGDC }\end{array}$ & Required \\
\hline 5 & The metadata should keep track of who made edits & Optional \\
\hline 6 & The metadata should be viewable outside of ArcCatalog & Required \\
\hline 7 & The metadata will be able to be saved with the data layer & Required \\
\hline 8 & $\begin{array}{l}\text { Students will be able to access the map layout interface via a } \\
\text { toolbar }\end{array}$ & Required \\
\hline 9 & Students will be able to add a North Arrow to their map layout & Required \\
\hline 10 & Students will be able to add new text to their map layout & Required \\
\hline 11 & $\begin{array}{l}\text { Students will be able to add images and pictures to their map } \\
\text { layout }\end{array}$ & Required \\
\hline 12 & Students will be able to flip and rotate images on their map layout & Required \\
\hline 13 & $\begin{array}{l}\text { Students will be able to print preview and print the content of their } \\
\text { map layout }\end{array}$ & Required \\
\hline 14 & $\begin{array}{l}\text { Students should be able to print (or export) map layouts that they } \\
\text { create }\end{array}$ & Required \\
\hline 15 & $\begin{array}{l}\text { ArcMap will have customized button icons and labels for } \\
\text { commands and toolbars }\end{array}$ & Required \\
\hline 16 & ArcMap will have tooltips for every command & Desired \\
\hline 17 & $\begin{array}{l}\text { Students will be able to Identify, Find and Measure features within } \\
\text { ArcMap }\end{array}$ & Required \\
\hline 18 & Students will be able to bookmark extents & Required \\
\hline 19 & Students will be able to zoom in and out, and to Full Extent & Required \\
\hline 20 & $\begin{array}{l}\text { Students will be able to change transparency and swipe layers } \\
\text { from a toolbar }\end{array}$ & Required \\
\hline 21 & Students will be able to add feature classes from the database & Required \\
\hline 22 & $\begin{array}{l}\text { Students will be able to search words and names in the NRSV } \\
\text { Bible, launched from ArcMap }\end{array}$ & Desired \\
\hline 23 & $\begin{array}{l}\text { Students will be able to draw rectangles, polygons, circles, } \\
\text { ellipses, lines, curvy lines, freehand lines, and markers }\end{array}$ & Required \\
\hline 24 & Students will be able to change existing shapes of object they draw & Required \\
\hline 25 & $\begin{array}{l}\text { Students will be able to label features with text, splined text, and } \\
\text { callouts }\end{array}$ & Required \\
\hline
\end{tabular}


Table 1 Functional Requirements for SILAS.ST (Continued)

\begin{tabular}{c|l|c} 
& \multicolumn{1}{|c}{ Functional Requirements } & Priority \\
\hline 26 & Students will be able to save their drawings and labels as layers & Required \\
\hline 27 & The Wizard should offer base maps of physical geography & Optional \\
\hline 28 & The Wizard should offer temporal extents & Optional \\
\hline 29 & $\begin{array}{l}\text { The Wizard should narrow down to a User specified geographical } \\
\text { extent }\end{array}$ & Optional \\
\hline 30 & The Wizard should have BACK and NEXT Buttons & Optional \\
\hline 31 & Original ArcGIS toolbars and commands will still be available & Required \\
\hline 32 & Students will have access to the original SILAS data layers & Desired \\
\hline 33 & $\begin{array}{l}\text { Students should have access to ESRI's 2006 issue of historical } \\
\text { fonts and historical cartographic representation files }\end{array}$ & Desired \\
\hline 34 & SILAS.ST will be available on workstation lab computers & Required \\
\hline 35 & $\begin{array}{l}\text { SILAS.ST data and metadata will be available to workstation lab } \\
\text { computers }\end{array}$ & Required \\
\hline 36 & Students will be able to save their map documents & Required
\end{tabular}

Table 2 Non-Functional Requirements for SILAS.ST

\begin{tabular}{c|l|c}
\multicolumn{1}{|c}{ Non-Functional Requirements } & Priority \\
\hline 1 & The metadata should be intuitively accessed by Students & Required \\
\hline 2 & The metadata should be intuitively edited by Students & Required \\
\hline 3 & The metadata should be intuitively read by Students & Required \\
\hline 4 & $\begin{array}{l}\text { The metadata fields and organization should be understood by } \\
\text { students }\end{array}$ & Required \\
\hline 5 & The Metadata will appropriately document student made datasets & Required \\
\hline 6 & $\begin{array}{l}\text { The Metadata will appropriately document georeferenced David } \\
7\end{array}$ & $\begin{array}{l}\text { The Metadata will appropriately document georeferenced and } \\
\text { digitized atlas maps from various sources }\end{array}$ \\
\hline 8 & $\begin{array}{l}\text { Students will be able to intuitively customize a map layout for } \\
\text { course assignments }\end{array}$ & Required \\
\hline 9 & $\begin{array}{l}\text { Students will be able to naturally explore and navigate the } \\
\text { ArcMap user interface and data layers }\end{array}$ & Required \\
\hline 10 & $\begin{array}{l}\text { Students will be able to easily manipulate layer's transparency for } \\
\text { comparative analysis }\end{array}$ & Required \\
\hline 11 & $\begin{array}{l}\text { Students will be able to 'hand draw' shapes and text onto data } \\
\text { layers, in place of editing data layers }\end{array}$ & Required \\
\hline 13 & The Wizard should be optional & Desired \\
\hline 15 & Data will be stored and accessed at a central location & Optional \\
\hline
\end{tabular}




\subsection{System Design}

Based on the functional and non-functional requirements, this section presents the initial proposal for the SILAS.ST design. Below are the individual proposed components that make-up the proposed SILAS.ST system. More details regarding the final design and implementation of the components are covered in Chapter 5.

\subsubsection{ArcMap 9.3}

As noted above, SILAS.ST uses the existing ArcMap 9.3 software available on the University of Redlands workstation computers. The tool creates an ArcMap Document which can be used by students and saved in individual student folders at an external shared location. Using ArcObjects and the customizable options provided in ArcMap, I am redesigning the graphical user interface. This includes several toolbars with custom commands, similar to the early prototype for an exploratory toolbar for the SILAS.ST application (Figure 3).

\section{Explore Data

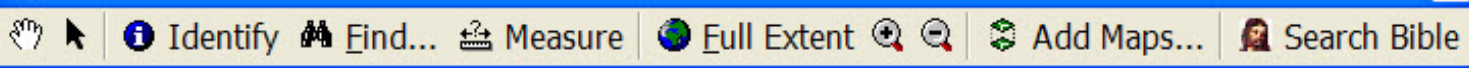

Figure 3 Prototype 'Explore Data’ toolbar

Using a simple editor and some general instruction from ESRI's Developer Network, VB6 will be used to create a custom metadata editor. This involves creating an ActiveX DLL that references the ESRI Object Library. This also includes a class that implements esriCatalogUI.IMetadataEditor and a dialog form for user input, as seen in Figure 4 (How to create a custom metadata editor, 2004). 


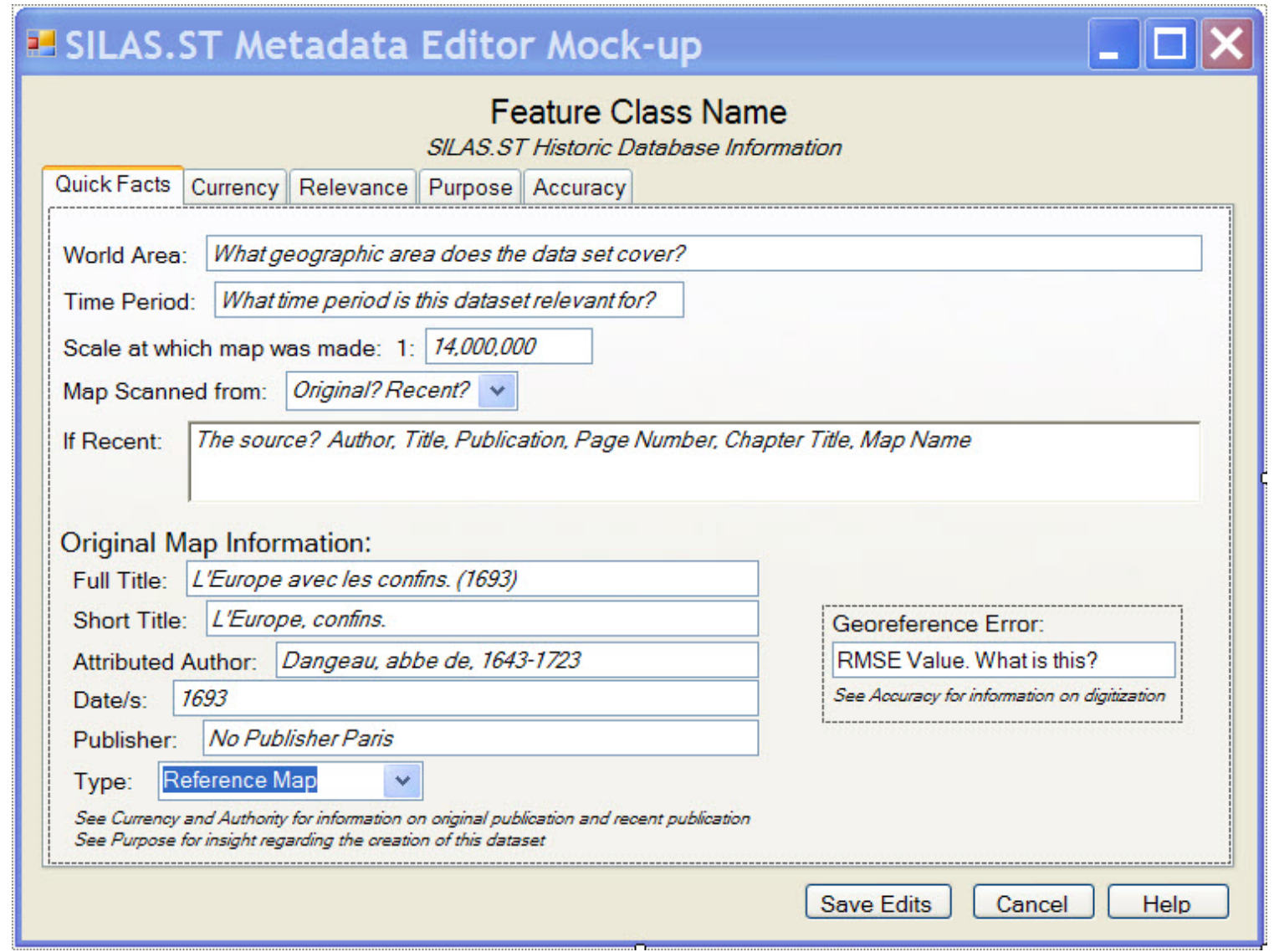

Figure 4 Prototype metadata editor dialog form

To view the metadata, a custom stylesheet will display the information collected in the metadata editor. This requires creating an HTML page that embeds the XML elements containing the metadata information, and becoming familiar with the data structure in which the FGDC metadata stores the information I want to display (How to create a custom stylesheet, 2009).

\subsubsection{Symbols and Styles}

Symbols and styles related to historical research are created using the advanced cartographic representation tools available in ArcMap 9.3. Additional symbols from ESRI's Mapping Center ArcGIS Resources are included. The Mapping Center contains a set of symbols and fonts specifically for creating a historical looking map, as seen in Figure 5. This is a fun and relatively simple "add-in" for SILAS.ST, giving students a variety of ways of displaying and representing the data with which they are working. 


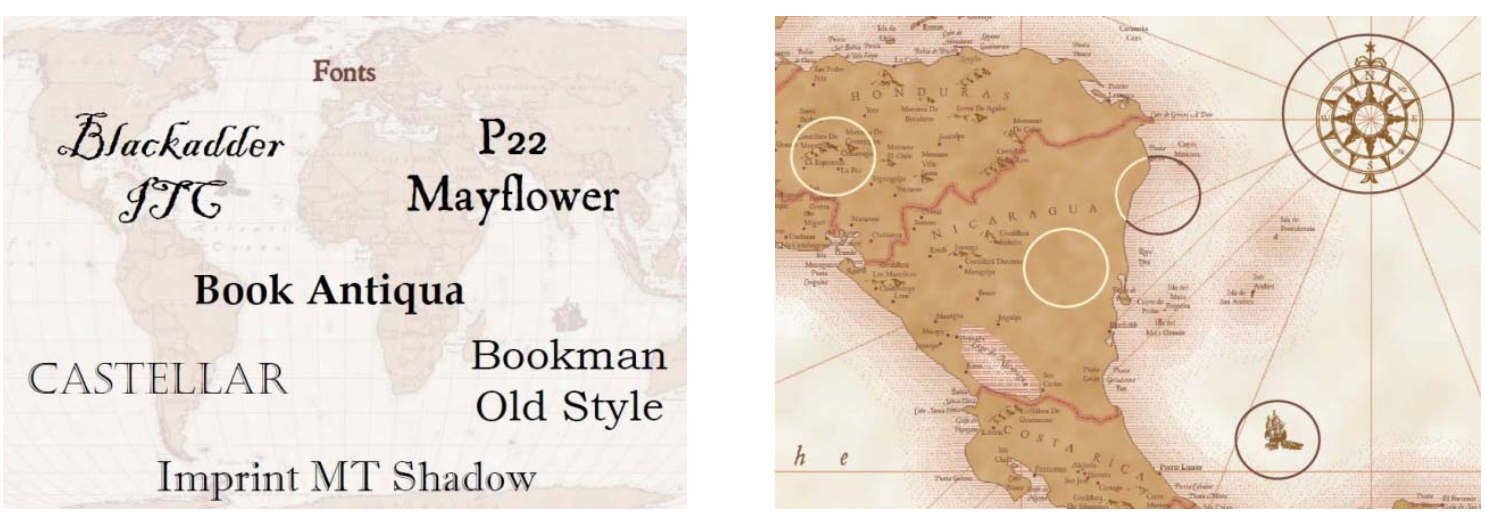

Figure 5 Sample fonts and styles from ESRI's Historical Symbols and Styles

\subsubsection{SILAS.ST Data}

Developing an extensive geodatabase was not a top priority for SILAS.ST, instead, acquiring and integrating a variety of representative sources is the main goal. By doing this, SILAS.ST utilizes the documentation capabilities of customized metadata. Instructions for how to scan, georeference, digitize and share sources via the SILAS.ST database were included for anyone familiar with GIS. They afford my client the wherewithal to include more data. In the event that my client wants her students to learn how to import data into GIS, I have included an outline for a course on historical GIS that she could co-teach with an MS GIS faculty member (Chapter 7.2).

Below are the data characteristics as they appeared in the input data list (Table 3). This table details the processing required to bring a historical source into GIS and the relevant information for storage and use. This information would be important to include when documenting data lineage in the metadata.

\section{Table 3 Data Characteristics}

\begin{tabular}{|c|c|c|c|}
\hline Component & \multicolumn{2}{|r|}{ Details } & Notes \\
\hline \multirow{6}{*}{$\begin{array}{c}\text { Data } \\
\text { Identification }\end{array}$} & Dataset Name: & HCBA_Jewish_Diaspora & \\
\hline & Location: & C:IMyDocs\MIPISILASSTScratch.gdb & $\begin{array}{l}\text { Downloaded to personal } \\
\text { computer, will be moved }\end{array}$ \\
\hline & Source: & HarperCollins Atlas of Bible History & \\
\hline & Page(s) & 160,161 & \\
\hline & Metadata Available: & Yes & \\
\hline & Metadata Recorded: & In progress & \\
\hline Permissions & $\begin{array}{l}\text { Authorization from } \\
\text { HarperCollins: }\end{array}$ & In progress, request mailed 3/18/09 & \\
\hline \multirow{3}{*}{$\begin{array}{l}\text { Data Volume } \\
\text { Considerations }\end{array}$} & Source of Data: & Blackboard & Downloaded \\
\hline & $\begin{array}{l}\text { Total Dataset } \\
\text { Volume: }\end{array}$ & $107.01 \mathrm{~KB}$ & \\
\hline & $\begin{array}{c}\text { Total Scanned Data } \\
\text { Volume: }\end{array}$ & $9.989 \mathrm{Mb}, 10.902 \mathrm{Mb}$ & \\
\hline
\end{tabular}


Table 3 Data Characteristics (Continued)

\begin{tabular}{|c|c|c|c|}
\hline Component & \multicolumn{2}{|r|}{ Details } & Notes \\
\hline \multirow{6}{*}{$\begin{array}{l}\text { Scanning } \\
\text { Considerations }\end{array}$} & $\begin{array}{l}\text { Original Dataset } \\
\text { Name: }\end{array}$ & $\begin{array}{l}\text { HCBA_9_Diaspora_160, } \\
\text { HCBA_9_Diaspora_161 }\end{array}$ & $\begin{array}{c}\text { Represents one image } \\
\text { spread across two pages }\end{array}$ \\
\hline & $\begin{array}{l}\text { Source Agency } \\
\text { Name: }\end{array}$ & $\begin{array}{c}\text { University of Redlands Religion } \\
\text { Department }\end{array}$ & Scanned by student \\
\hline & $\begin{array}{l}\text { Internet Location } \\
\text { (Redlands } \\
\text { Blackboard): }\end{array}$ & $\begin{array}{l}\text { HISTORICAL SEARCH FOR JESUS- } \\
\text { LARSEN (2009SP) (REL-305-01- } \\
\text { 2009SP) > COURSE DOCUMENTS > } \\
\text { HARPERCOLLINS BIBLE ATLAS }\end{array}$ & $\begin{array}{l}\text { Unsure where data will } \\
\text { exist when the } \\
\text { blackboard site is taken } \\
\text { down. Client has digital } \\
\text { copies. }\end{array}$ \\
\hline & Digital Data Format: & .tif & \\
\hline & Original Sheet Size: & 9.5" x 7" & One page (separate) \\
\hline & $\begin{array}{l}\text { Minimum scan } \\
\text { resolution: }\end{array}$ & 300 dpi & \\
\hline \multirow{3}{*}{ Data Conversion } & Crop: & Crop to image extent & Conserve image \\
\hline & Dimensions: & $2048 \times 1700,2228 \times 1706$ & Two pages \\
\hline & $\begin{array}{l}\text { Convert to Digital } \\
\text { Format: }\end{array}$ & .jpg & .tif would not display \\
\hline \multirow{4}{*}{$\begin{array}{c}\text { Georeferencing } \\
\text { Effort }\end{array}$} & Projection: & Europe Albers Equal Area Conic & $\begin{array}{l}\text { Other projections in } \\
\text { consideration }\end{array}$ \\
\hline & Reference Layer: & world_countries.shp & ESRI shapefile \\
\hline & RMSE: & $13081.09714,11752.49225$ & \\
\hline & $\begin{array}{l}\text { Georeferencing } \\
\text { Stored As: }\end{array}$ & Update Georeferencing & \\
\hline \multirow{2}{*}{ Digitizing Effort } & Stored: & C:IMyDocs\MIP\SILASSTScratch.gdb & \\
\hline & Shape: & $\begin{array}{l}\text { Polygons } \\
\end{array}$ & \\
\hline \multirow{2}{*}{ Metadata Entry } & Format: & Custom SILAS.ST Metadata Editor & \\
\hline & Date Entered: & $\begin{array}{l}\text { In progress } \\
\end{array}$ & \\
\hline \multirow{3}{*}{$\begin{array}{l}\text { Data } \\
\text { Availability and } \\
\text { Cost }\end{array}$} & $\begin{array}{c}\text { Copy Right } \\
\text { Restrictions: } \\
\end{array}$ & In progress, granted by HarperCollins & \\
\hline & $\begin{array}{l}\text { Number of Student } \\
\text { Users per Semester: }\end{array}$ & In progress, granted by HarperCollins & \\
\hline & Permissions Expire: & In progress, granted by HarperCollins & \\
\hline
\end{tabular}

(For the complete list and description of the final SILAS.ST database contents, see Table 12.)

\subsubsection{LENS Server}

Available to University of Redlands faculty, the server purchased for the LENS Initiative will host the SILAS.ST components, allowing student access to the SILAS.ST data and documents via the Lewis Hall lab computers (Figure 6). A multiuser geodatabase will allow students to simultaneously access and save data edits. 


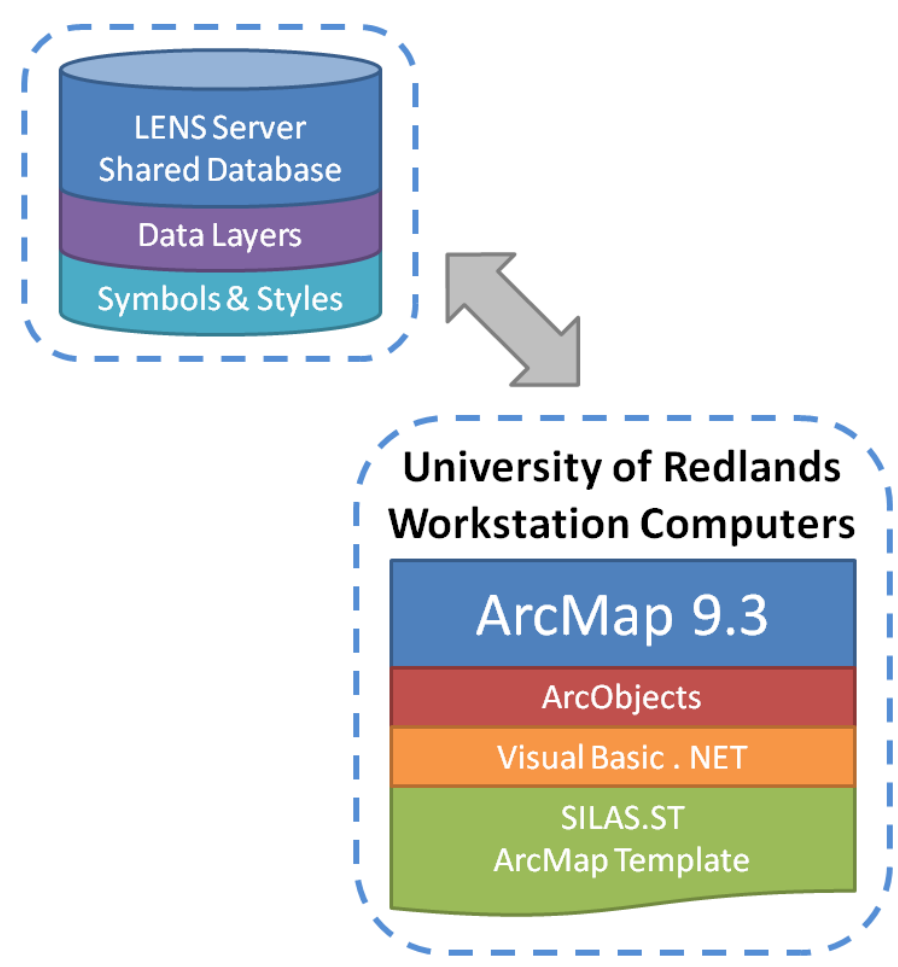

Figure 6 Proposed SILAS.ST system architecture

\subsubsection{System Requirements}

Regarding the hardware and software requirements, SILAS.ST will be operating on the University of Redlands workstation computers. The hardware and operating system requirements for running SILAS.ST are outlined in Table 4 and Table 5, respectively.

Table 4 Hardware Requirements from the ESRI Support Center

\begin{tabular}{c|c} 
CPU Speed & ArcView Hardware Requirements \\
\hline Processor & $1.6 \mathrm{GHz}$ recommended or higher \\
\hline Memory/RAM & Intel Core Duo, Pentium 4 or Xeon Processors \\
\hline $\begin{array}{c}\text { Display } \\
\text { Properties }\end{array}$ & $1 \mathrm{~GB}$ minimum, 2 GB recommended or higher \\
\hline $\begin{array}{c}\text { Screen } \\
\text { Resolution }\end{array}$ & 24 bit color depth \\
\hline Swap Space & 1024 x 768 recommended or higher at Normal size (96dpi) \\
\hline
\end{tabular}


Table 4 Hardware Requirements from the ESRI Support Center (Continued)

\begin{tabular}{|c|c|}
\hline & ArcView Hardware Requirements \\
\hline Disk Space & $\begin{array}{l}2.4 \mathrm{~GB} \\
\text { In addition, up to } 50 \mathrm{MB} \text { of disk space maybe needed in the } \\
\text { Windows System directory (typically C: } 1 \text { Windows } \backslash \text { System32). You } \\
\text { can view the disk space requirement for each of the } 9.3 \text { components } \\
\text { in the Setup program. }\end{array}$ \\
\hline $\begin{array}{l}\text { Video/Graphics } \\
\text { Adapter }\end{array}$ & $\begin{array}{l}\text { 24-bit capable graphics accelerator } \\
\text { An OpenGL } 1.3 \text { or higher compliant video card is required, with at } \\
\text { least } 32 \mathrm{MB} \text { of video memory, however } 64 \mathrm{MB} \text { of video memory or } \\
\text { higher is recommended. }\end{array}$ \\
\hline $\begin{array}{l}\text { Networking } \\
\text { Hardware }\end{array}$ & $\begin{array}{c}\text { Simple TCP/IP, Network Card or Microsoft Loopback Adapter is } \\
\text { required for the License Manager. }\end{array}$ \\
\hline Media Player & DVD-ROM drive is required to install the application. \\
\hline
\end{tabular}

(ESRI Support Center, http://wikis.esri.com/wiki/display/ag93bsr/ArcGIS+Desktop)

Table 5 Supported Operating Systems from the ESRI Support Center

\begin{tabular}{|c|c|c|c|}
\hline $\begin{array}{l}\text { Supported Operating } \\
\text { System }\end{array}$ & $\begin{array}{l}\text { Minimum } \\
\text { Version }\end{array}$ & $\begin{array}{l}\text { Maximum } \\
\text { Version }\end{array}$ & Limitations \\
\hline Windows 2000 Professional & SP3 & SP4 & \\
\hline $\begin{array}{l}\text { Windows } 2003 \text { (32-bit) } \\
\text { Server Standard, } \\
\text { Enterprise \& Datacenter }\end{array}$ & SP1 & SP2 & \\
\hline $\begin{array}{l}\text { Windows } 2003 \text { (64-bit } \\
\text { (EM64T)) Server Standard, } \\
\text { Enterprise \& Datacenter }\end{array}$ & SP1 & SP2 & $\begin{array}{l}\text { 64-bit } \\
\text { processors } \\
\text { support }\end{array}$ \\
\hline $\begin{array}{l}\text { Windows } 2008 \text { (32-bit) } \\
\text { Server Standard, } \\
\text { Enterprise \& Datacenter }\end{array}$ & & & \\
\hline $\begin{array}{l}\text { Windows } 2008 \text { (64-bit } \\
\text { (EM64T)) Server Standard, } \\
\text { Enterprise \& Datacenter }\end{array}$ & & & $\begin{array}{l}\text { 64-bit } \\
\text { processors } \\
\text { support }\end{array}$ \\
\hline $\begin{array}{c}\text { Windows XP (32-bit) } \\
\text { Professional Edition, Home } \\
\text { Edition }\end{array}$ & SP1 & SP3 & $\begin{array}{l}\text { Windows XP } \\
\text { SP2 \& } \\
\text { SP3 Limitations }\end{array}$ \\
\hline
\end{tabular}

(ESRI Support Center, http://wikis.esri.com/wiki/display/ag93bsr/ArcGIS+Desktop) 


\subsection{Schedule}

My following proposed project schedule is composed of a series of tasks, with sub tasks and predecessors. The tasks structure the development of the project over the course of the year. Individual tasks are discussed in depth in section 5.1. Milestones were included to signal the completion of a task. Often the completion of these milestones is required for the subsequent tasks to be started. An updated schedule is included in section 5.1.

\begin{tabular}{l} 
Task Name \\
\hline TASK ONE : Requirements Analysis \\
\hline Draft Requirements \\
Meet with Diana Sinton \\
Meet with Lillian Larson \\
Requirement Analysis Report \\
\hline TASK TWO : SILAS Layout Mock-ups \\
\hline Wizard Screens, Flow Chart \\
\hline SILAS Interface, tabs, tool bars, tools \\
\hline ArclMap Templates and Wizard Schema \\
\hline Learning VB for Applications for New ArcGIS Developers \\
\hline TASK THREE : Data Research \& Documentation \\
\hline TASK FOUR : Cartographic Representations \\
\hline Feedback \& Updates with Advisor, Client \\
\hline Introduction to Programming ArcObjects Using VBA \\
\hline Developing Apps with ArcServer Using .NET Framework \\
\hline TASK FIVE : SILAS Functionality \\
\hline Programming \\
\hline Functionality Mock-ups \\
\hline Extending the ArcGIS Desktop Applications \\
\hline Initial SILAS Assessment \\
\hline TASK SIX : Student Testing \\
\hline Functionality Assessment, Goals for Improvement \\
\hline Intro to Programming ArcObjects Using the Java Platform \\
\hline TASK SEVEN : Revision, Fine Tuning, Documentation \\
\hline Complete MIP DRAFT \\
\hline TASK EIGHT : Revision, Fine Tuning, Documentation \\
\hline FINALIZE MIP \\
\hline SILAS Application \\
\hline SILAS Tutorials \\
\hline
\end{tabular}

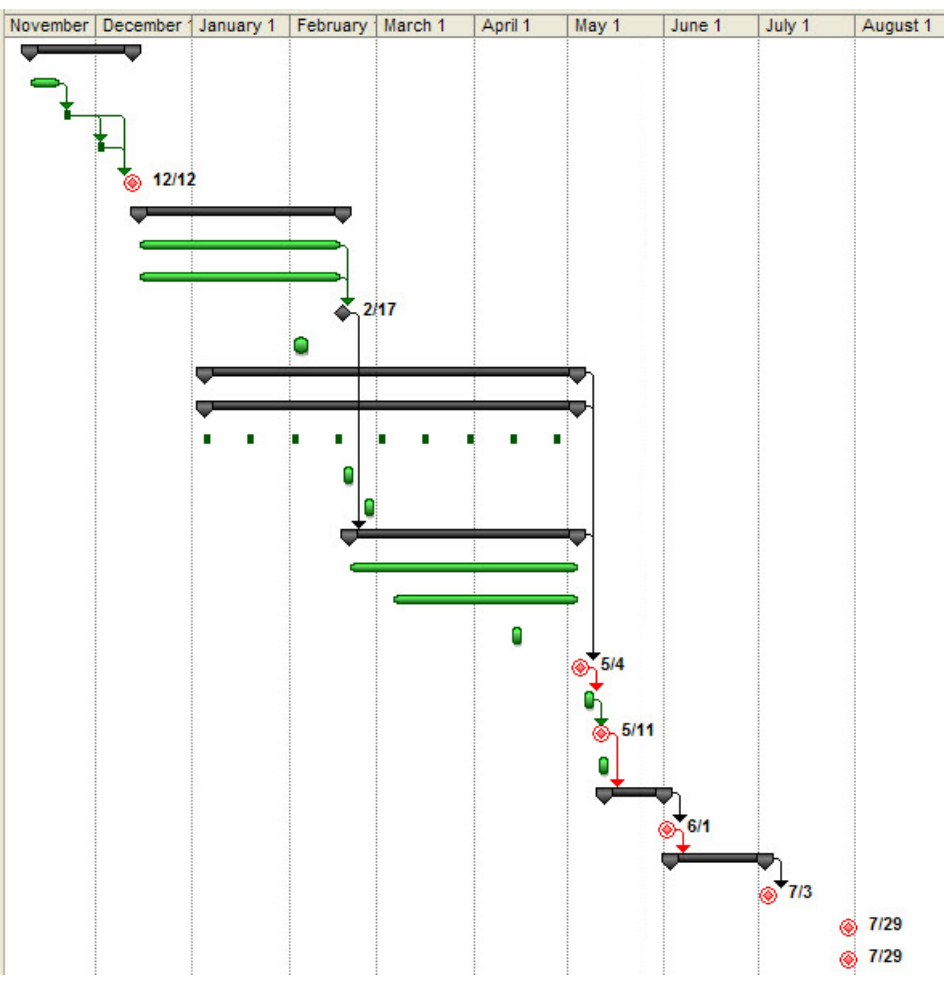

Figure 7 SILAS.ST proposed schedule

As is evident here, this schedule includes three ESRI instructor-led classes, along with meetings with both advisor and client on a regular basis.

\subsection{Budget}

A proposed time budget to complete each task outlined the time allotted (Table 6). An estimated 600 to 700 hours is the length of time projects within the MS GIS program usually take to complete. This time budget helps the project development stay on task. These tasks were completed in tandem with other MS GIS required courses that are not documented in this project schedule and budget. 
Table 6 Task Budget

\begin{tabular}{l|c|c}
\multicolumn{1}{c|}{ TASK } & $\begin{array}{c}\text { Approximate } \\
\text { Time Period }\end{array}$ & $\begin{array}{c}\text { Budgeted } \\
\text { Hours }\end{array}$ \\
$\begin{array}{l}\text { TASK ONE: Requirements Analysis } \\
\text { Requirement Analysis Report }\end{array}$ & 25 days & 15 \\
\hline $\begin{array}{l}\text { TASK TWO: SILAS Layout Mock-ups } \\
\text { ArcMap Templates and Wizard Schema }\end{array}$ & 46 days & 25 \\
\hline TASK THREE: Data Research \& Documentation & 18 weeks & 40 \\
\hline TASK FOUR: Cartographic Representations & 18 weeks & 40 \\
\hline $\begin{array}{l}\text { TASK FIVE: SILAS Functionality } \\
\text { Initial SILAS Assessment }\end{array}$ & 56 days & 250 \\
\hline $\begin{array}{l}\text { TASK SIX: Student Testing } \\
\text { Functionality Assessment, Goals for Improvement }\end{array}$ & 3 days & 20 \\
\hline $\begin{array}{l}\text { TASK SEVEN: Revision, Documentation } \\
\text { Complete MIP DRAFT }\end{array}$ & 13 days & 100 \\
\hline $\begin{array}{l}\text { TASK EIGHT: Revision, Fine Tuning, } \\
\text { Documentation } \\
\text { FINALIZE MIP } \\
\text { SILAS Application } \\
\text { SILAS Tutorials }\end{array}$ & 22 days & 150 \\
& Total: & 640 Hours \\
\cline { 2 - 4 } & &
\end{tabular}

\subsection{Risk Areas}

Before starting the project, a project risk assessment was compiled to demonstrate my confidence and knowledge of the project and anticipate where I might have difficulties (Table 7). Having a mitigation plan prepared ahead of time is helpful should any of the risks prevent the completion of the project. A value of one to five was assigned to each risk, with five being the most severe project setback and/or the most likely to happen. These two factors were then multiplied together to show the amount of risk exposure this project might face. 
Table 7 Risk Assessment

\begin{tabular}{|c|c|c|c|c|}
\hline Risk & Severity & Probability & Mitigation & Exposure \\
\hline $\begin{array}{l}\text { Inexperience } \\
\text { with } \\
\text { Programming }\end{array}$ & 4 & 5 & $\begin{array}{l}\text { - Consider other customizable options } \\
\text { that provide a similar functionality, but } \\
\text { may be more complex } \\
\text { - Chose not to make SILAS a web } \\
\text { application } \\
\text { - Take ESRI Programming Classes } \\
\text { - Utilize MS GIS Professors/Staff for } \\
\text { assistance }\end{array}$ & 20 \\
\hline $\begin{array}{l}\text { Managing } \\
\text { the } \\
\text { Complexity } \\
\text { of SILAS }\end{array}$ & 3 & 4 & $\begin{array}{l}\text { - Create many prototypes, ask for } \\
\text { functionality feedback } \\
\text { - Research the known limits and } \\
\text { capacities of various system } \\
\text { architectures, try not to exceed them } \\
\text { - Seek constant feedback from advisor, } \\
\text { client and students }\end{array}$ & 12 \\
\hline Lack of Data & 2 & 4 & $\begin{array}{l}\text { - Make use of existing Data } \\
\text { - Seek creative alternatives, or } \\
\text { collaborations with other scholars }\end{array}$ & 8 \\
\hline $\begin{array}{c}\text { Poor } \\
\text { Outcome of } \\
\text { Student } \\
\text { Testing }\end{array}$ & 2 & 3 & $\begin{array}{l}\text { - Organize sessions well in advance } \\
\text { with the school, my advisor and client } \\
\text { - Make efficient use of the time with } \\
\text { students by preparing several } \\
\text { scenarios/prototypes and having a set } \\
\text { of questions in mind that need answers }\end{array}$ & 6 \\
\hline $\begin{array}{c}\text { Copying } \\
\text { Other Bible } \\
\text { Mapping } \\
\text { Applications }\end{array}$ & 1 & 4 & $\begin{array}{l}\text { - Research other applications that are } \\
\text { currently available } \\
\text { - Determine ahead of time the extent of } \\
\text { collaborations with other groups } \\
\text { - Scrutinize other applications and } \\
\text { improve upon them for use as historical } \\
\text { tools within a classroom }\end{array}$ & 4 \\
\hline
\end{tabular}

\subsection{Assumptions}

The risk assessment was based on my assumptions regarding the project. Because the proposed SILAS.ST project required application development with which I had little experience, I built assumptions into my planning for the project. Below my assumptions are outlined in a list, made before I began to work on SILAS.ST. The goal was to identify ahead of time what I assumed about the development and implementation of this project, so that I could later reflect on the actuality of the project and make recommendations for future projects.

These assumptions are as follows:

- The programming I learn will be enough to meet the requirements outlined in the requirements analysis.

- ArcMap will perform the desired functionality outlined in the requirements and will be a suitable system architecture for my client. 
- I will be far enough along to provide a prototype of my project for student evaluation, so to get useful feedback before the students are on summer break.

- There will be a successful integration of Stephen Benzek's work into the new system architecture and no need to reproduce his previous work.

- The client will provide data to be converted to digital data.

\subsection{Summary}

This preliminary project plan for SILAS.ST guided the creation of an ArcMap 9.3 Document with a database with data layers and additional support documents on an external server (Figure 6). Since the target users are not be GIS experts, nor are they necessarily interested in learning the functions of GIS, the data processing and functionality were be kept to a minimum. The proposed interface customizations met the protocol outlined in the functional and non-functional requirements by essentially catering to a humanities audience. As noted above, the SILAS.ST program will run on University of Redlands' lab computers, which met the hardware and software requirements for running ArcGIS. ArcObjects and VB programming were used for customizations outside of what ArcMap allows under the customization menu.

By following the proposed schedule and completing each task in a timely manner, the final delivered system was submitted in partial fulfillment of the University of Redlands Masters in GIS program requirements by August 2009. 



\section{Chapter 4 - SILAS.ST Metadata Design}

This chapter outlines the design considerations of the interface and metadata that were included in the final project. Considerable effort went into contents and organization of the metadata, with several drafts and prototypes. I sought qualitative evaluations from both students and educators. The final designs, presented at the conclusion of this chapter, represent months worth of planning and evaluating.

\subsection{Interface Design}

One of the goals of SILAS.ST is to develope an interface that makes the out-of-box ArcMap software more accessible for humanities students. I designed toolbars using a combination of ArcMap customizable options and ArcObjects, based on observations of students using ArcMap for class assignments.

\subsubsection{Classroom Observation}

As noted above, for the duration of the spring semester at the University of Redlands, I was given the opportunity to observe my client and advisor's co-taught three-hundred level religion course - Historical Search for Jesus. This course used a variety of media to construct a conceptual image of the historical Jesus, as recorded and stereotyped through time. Because the original SILAS was in the process of being updated, the students were instead introduced to ArcMap using SILAS data layers. After a few hours of instruction, students were able to draw points and mark place names found in the bible passages they were assigned to read. They later connected the points to show the journey of a selected biblical figure, as seen in Figure 8. 


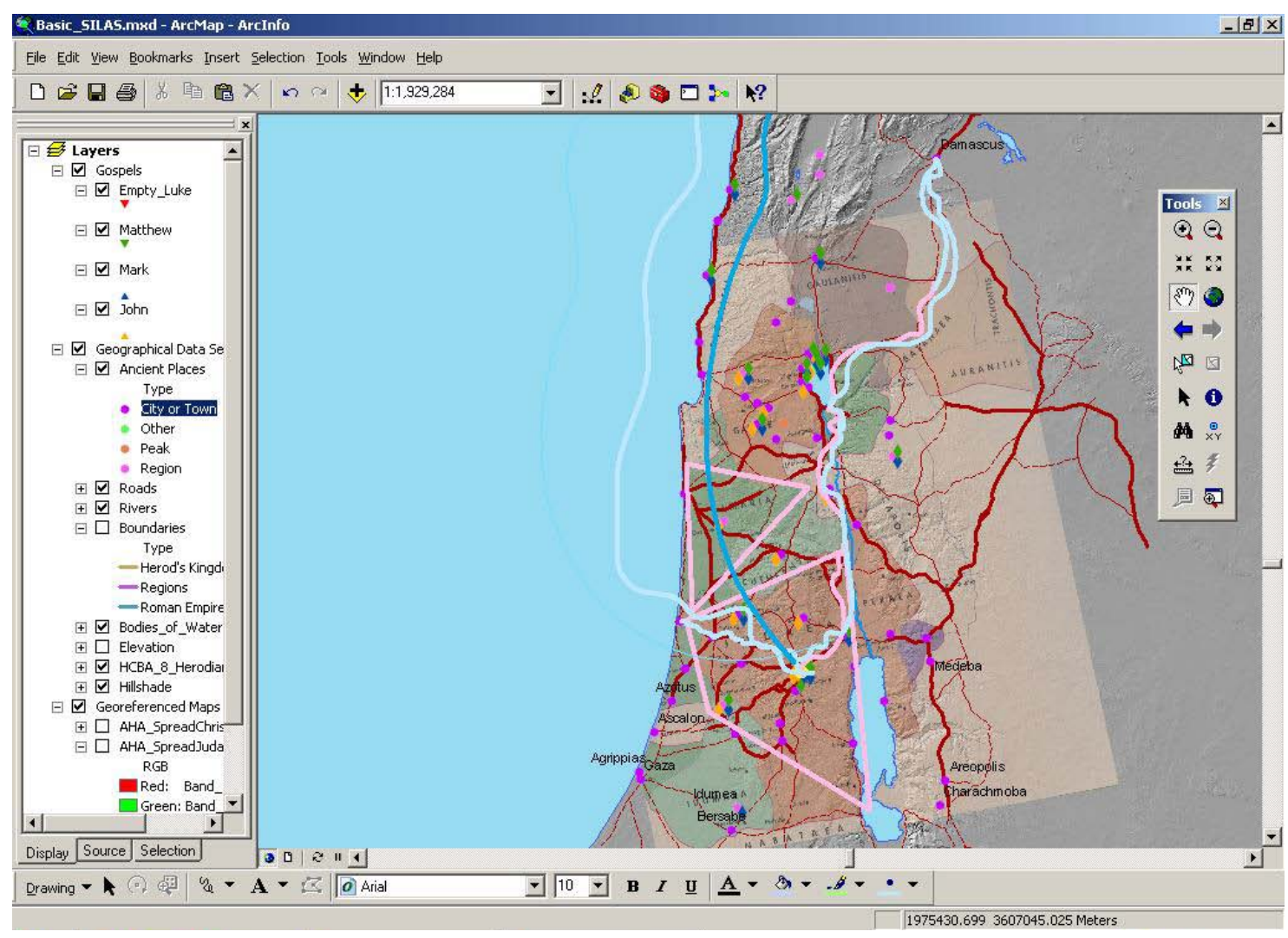

Figure 8 Screenshot from in-class exercise using ESRI's ArcMap

All students were given SILAS map layers, which included ancient city names, bodies of water, Roman roads, a hillshade of the terrain, and a scanned map layer from the HarperCollins Bible Atlas that depicted biblical regions. Students were taught how to turn layers off and on, and how to move the order of layers in the table of contents. They were also taught how to set the transparency of a layer.

In Figure 8, a two-student group mapped the journeys of the apostles, using the "curvy" line option because it looked more natural. The students chose colors to represent various apostles and their respective travels. Other student groups chose to draw straight lines, and most chose a color scheme that highlighted different parts of the story as related in Acts.

While monitoring the student groups, I observed the students' tendency to zoom in on a vector point until the background raster hillshade was pixilated. They would then place a point or line, in an effort to be as precise as possible. In a later test trial of the SILAS.ST interface using the same exercise, I had a peer in the MS GIS Program map out a fictional journey. The MS GIS student never zoomed in on the map display after the point was highlighted by the Find tool. Whether this was a function of trained habit or lack of familiarity with Google Earth, I was surprised she did not zoom in on the data layer to draw a line. Because of the limited accuracy of the place name points, students should be advised not to zoom in past a certain extent.

From this observation of different navigation and zooming practices, it might be advisable to limit the zooming options or set extents on individual layers. In the following subsections, a discussion on accuracy and scale is covered. These are important 
concepts in the design and organization of the metadata. The final metadata could work in tandem with the user interface to better inform students of the limitations of zooming, with regards to data accuracy.

I also observed that students were interpreting the terrain layer for clues about its actual ground cover. For example, when looking for "the countryside," students looked for relatively flat areas on the hillshade terrain layer. For forested areas, students looked for areas near hill sides and water bodies. I do not know if such interpretations are valid using that terrain model, but these would be matters to discuss within the metadata that accompanies a given map layer. Included within the original SILAS database were two 150m EarthSat NaturalVue Global Landsat mosaics of Europe and Africa. Due to the large file size (2.21 GB), they were excluded from the SILAS data layers provided to students during this course. These natural color Landsat mosaics would be better suited for interpreting ground cover, though additional caution would be needed because they are not as current or as high a resolution as the satellite images students are accustomed to in Google Earth.

\subsubsection{Proposed Toolbars and Interface}

The four toolbars created for specific student tasks were based on observations from the spring 2009 course. The Explore Data toolbar (Figure 9) contains a number of exploratory tools that students will be familiar with from using applications such as Google Earth. I purposely put the zoom in and zoom out tools towards the center, in order to emphasize the pan and identify tools before zooming in and out of the set map extent of the Roman Empire. "Bookmarks" affords an option to bookmark an extent so a specific detail can be revisited or shared among student users. This is useful if students determine an ideal extent for viewing their map layers. Options to set transparency levels for individual layers are also available on the toolbar. These tools were not part of the original collection of exploratory tools.

\section{Figure 9 SILAS.ST toolbars, 'Explore Data'}

The time necessary to learn how to edit features within ArcMap is too much for an introductory humanities course. It was suggested by my advisor that drawing options should be available in place of the editing tools. The Hand Draw toolbar was created with a range of drawing options, as seen in Figure 10. Traditional editing would require creating a new empty shapefile in ArcCatalog, and then editing in the features in ArcMap. With the drawing options, points, lines, polygons and text can be drawn and then exported as a layer file or shapefile that can be saved and shared. While options for adding fields and attributes are absent from the drawing options, the editing toolbar and ArcCatalog are still available on the lab workstation computers, if there is time for further editing instruction. 


\begin{tabular}{|l|l|}
\hline Hand Draw \\
\hline Drawing \\
\hline
\end{tabular}

Figure 10 SILAS.ST toolbars, 'Hand Draw'

The final assignment for my client's course was for students to create their own atlas page. Anticipating that my client would want to use SILAS.ST for this particular assignment in the future, the "Create Atlas" toolbar contains all the necessary tools and options for students to customize an atlas page (Figure 11). A few map templates are available, but from observing students' use of the ArcMap software, it seems that most students are comfortable taking the creative initiative.

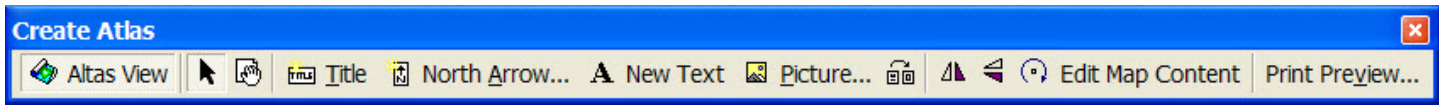

Figure 11 SILAS.ST toolbars, 'Create Atlas'

The out-of-box ArcMap 9.3 software does not give users the ability to edit metadata; instead users must access it through ArcCatalog. To encourage metadata to be read and edited on a more regular basis, both options of reading and editing are available through a toolbar in ArcMap called SILAS.ST Map Information (Figure 12). Within SILAS.ST, metadata is referred to as "map information" because metadata may not be a familiar term to humanities students.

\section{\begin{tabular}{|l|r|}
\hline SILAS.ST Map Information \\
圆 View Map Information
\end{tabular}}

Figure 12 SILAS.ST toolbars, 'Map Information’

Over the course of the project we have discussed whether the "layers" in ArcMap should be called "maps." Conceptually in ArcMap, all data sources listed in the table of contents are thought of as individual layers that overlay one another to compose the map. Unfortunately the correct term for each data set "layer" in ArcMap is more specific, such as a shapefile, feature class, or raster. "Layers" in ArcMap are essentially symbology templates that accompany the shapefile or feature class. In the final document, the terminology I use for humanities students will not be consistent with the ArcGIS vernacular.

\subsection{Initial Construction of Metadata}

The SILAS.ST metadata contents and organization were initially modeled off two sources: one that targeted the larger contextual and evaluative questions my client wanted her students to be aware of, and the other the base structure for data documentation. SILAS.ST uses maps from the David Rumsey Map Collection. The Rumsey Colllection's identifying fields are very thorough, so some were included to help document the original and digital information of historic maps. Other map collections were considered for their 
organization of metadata documentation, particularly where the Rumsey Map Collection fields were not open-ended enough to meet my client's requirements.

Successful compilation of metadata will allow the reader to easily qualify an information source (Schultz et al, 2008). Basic information should be included, such as the origination of the data, the geographic extent, and the representative time period. Data quality is also important, and it is helpful to know how the information was compiled and how it was brought into GIS. The "reliability" of the metadata is related to quality, such as who updated it, how often and how they used the data. Other suggestions include spatial reference information (projections and coordinate systems), distribution information, availability of the data, compliance with copyright, and the individual attribute details to help decode tabular data (Schultz et al, 2008). For the purpose of teaching students about historic data and using data in GIS, my metadata standard will focus more on the identification and qualification of source data. The table below (Table 8) summarizes all the different documentation standards this chapter covers. The final SILAS.ST metadata standard is included in the last column. 
Table 8 'Metadata' Comparison

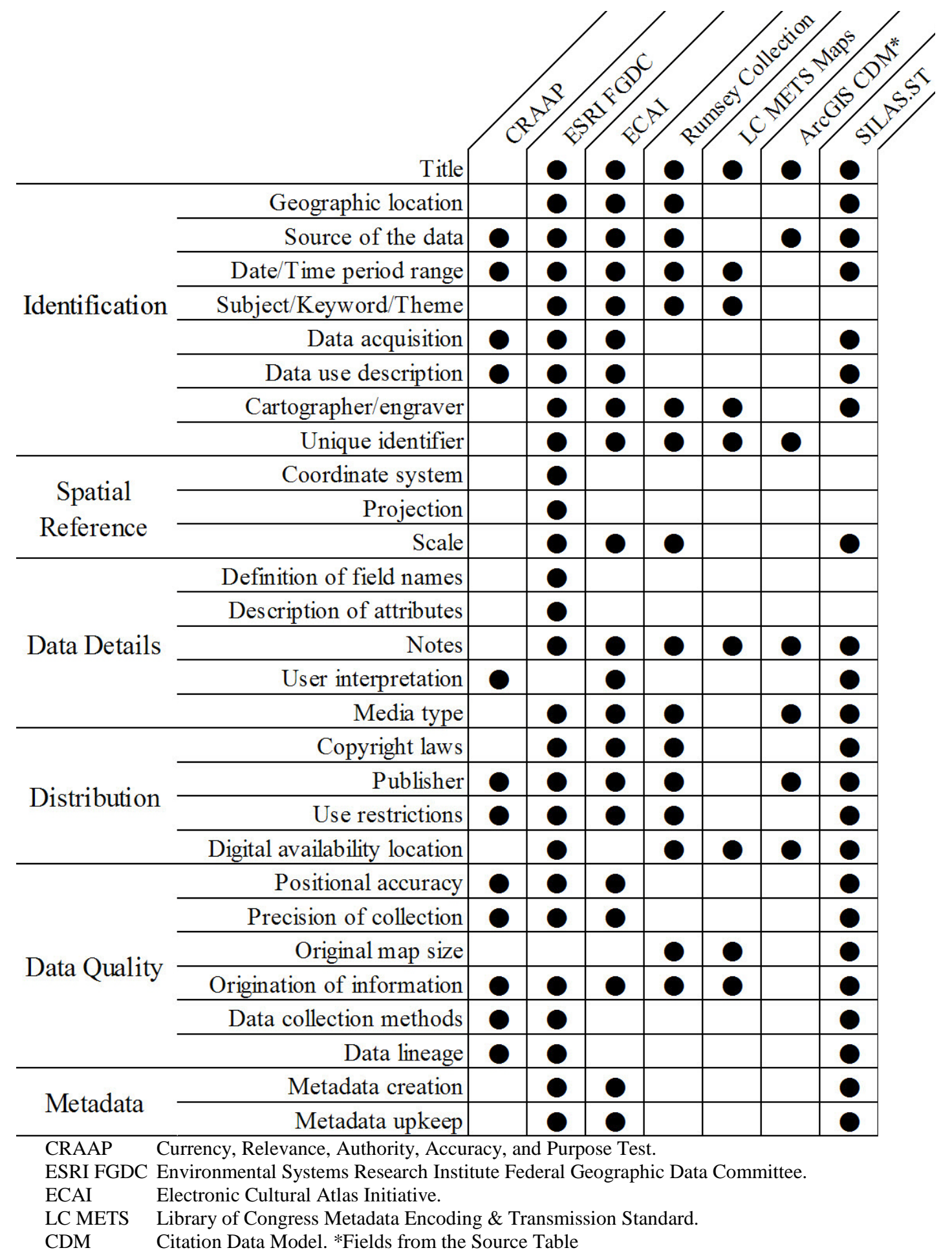

This table is comprised of the recommended "categories" outlined by Richard Schultz et al., (2008) with additional quantifiers commonly found in select metadata documentation sources. While the documentation standards included in the table would not all be considered traditional, standards-based metadata, they do contribute to the 
elucidation and evaluation of data. This table is intended to highlight areas of similarity and divergence. As such, a perfect match across categories is not desired.

In considering the table of documentation and evaluation standards, I focused on developing the following for SILAS.ST:

- A collection of fields that draws out information and interpretation from a variety of sources SILAS.ST may contain in its database.

- Metadata text fields that qualify a data source for research, based on content and "accuracy" of the data source.

- The ability to host a discussion that challenges and enriches the information each semester it is used.

- A balance of subjective and objective information.

- A metadata editor that is not a one-time reference.

- An efficient design (all encompassing fields, forms and tabs) that limits redundancy.

\subsubsection{CRAAP Test \& the FGDC FAQ}

As noted above, the CRAAP (Currency, Relevance, Authority, Accuracy, and Purpose) Test was introduced to my client's class early in the semester by Shana Higgins, a University of Redlands reference librarian, as a way to evaluate library information that students might use for their research. The CRAAP Test is particularly useful for information found on the Web, as indicated in the table below (Table 9). This method of evaluation is similar to that of a historian's approach to evaluating historical sources because it prompts the researcher to be critical of the quality and original purpose of a given body of information. The categories of the CRAAP Test, along with accompanying questions, are straightforward and appropriate for an undergraduate audience. With some adjustments and customizations to better handle both GIS data processing and historical context, the CRAAP Test affords a useful vetting tool for the historical GIS sources SILAS.ST contains.

Table 9 CRAAP Test Components

\begin{tabular}{|c|c|}
\hline Component & Prompts \\
\hline \multirow{4}{*}{$\begin{array}{l}\text { Currency: The } \\
\text { timeliness of the } \\
\text { information. }\end{array}$} & When was the information published or posted? \\
\hline & Has the information been revised or updated? \\
\hline & Is the information current or out-of date for your topic? \\
\hline & Are the links functional? * \\
\hline \multirow{5}{*}{$\begin{array}{l}\text { Relevance: The } \\
\text { importance of the } \\
\text { information for your } \\
\text { needs. }\end{array}$} & Does the information relate to your topic or answer your question? \\
\hline & Who is the intended audience? \\
\hline & $\begin{array}{l}\text { Is the information at an appropriate level (i.e. not too elementary or advanced } \\
\text { for your needs)? }\end{array}$ \\
\hline & $\begin{array}{l}\text { Have you looked at a variety of sources before determining this is one you will } \\
\text { use? }\end{array}$ \\
\hline & Would you be comfortable using this source for a research paper? \\
\hline
\end{tabular}


Table 9 CRAAP Test Components (Continued)

\begin{tabular}{|c|c|}
\hline Component & Prompts \\
\hline \multirow{6}{*}{$\begin{array}{l}\text { Authority: The source } \\
\text { of the information. }\end{array}$} & Who is the author/publisher/source/sponsor? \\
\hline & Are the author's credentials or organizational affiliations given? \\
\hline & What are the author's credentials or organizational affiliations given? \\
\hline & What are the author's qualifications to write on the topic? \\
\hline & Is there contact information, such as a publisher or e-mail address? \\
\hline & $\begin{array}{l}\text { Does the URL reveal anything about the author or source? examples: .com } \\
\text {.edu .gov .org .net * }\end{array}$ \\
\hline \multirow{6}{*}{$\begin{array}{l}\text { Accuracy: The } \\
\text { reliability, } \\
\text { truthfulness, and } \\
\text { correctness of the } \\
\text { informational content. }\end{array}$} & Where does the information come from? \\
\hline & Is the information supported by evidence? \\
\hline & Has the information been reviewed or refereed? \\
\hline & $\begin{array}{l}\text { Can you verify any of the information in another source or from personal } \\
\text { knowledge? }\end{array}$ \\
\hline & Does the language or tone seem biased and free of emotion? \\
\hline & Are there spelling, grammar, or other typographical errors? \\
\hline \multirow{4}{*}{$\begin{array}{l}\text { Purpose: The reason } \\
\text { the information exists. }\end{array}$} & $\begin{array}{l}\text { What is the purpose of the information? to inform? teach? sell? entertain? } \\
\text { persuade? }\end{array}$ \\
\hline & Do the authors/sponsors make their intentions or purpose clear? \\
\hline & Is the information fact? opinion? propaganda? \\
\hline & $\begin{array}{l}\text { Does the point of view appear objective and impartial? Are there political, } \\
\text { ideological, cultural, religious, institutional, or personal biases? }\end{array}$ \\
\hline
\end{tabular}

Key: * indicates criteria are for Web only

At the suggestion of my advisor, the ESRI (Environmental Systems Research Institute) FGDC (Federal Geographic Data Committee) FAQ (Frequently Asked Questions) section style sheet was also considered. This collection of questions prompts users to assess the GIS data they are documenting (Table 10). The FGDC FAQ also includes technical questions and better informs the user of the state of the digital GIS data. This style sheet is available in ArcCatalog.

Table 10 ESRI FGDC FAQ

Frequently-asked questions:

How should this data set be cited?

What geographic area does the data set cover?

What does this data set What does it look like?

describe?

Does the data set describe conditions during a particular time period?

What is the general form of this data set?

How does the data set represent geographic features?

How does the data set describe geographic features?

Who are the originators of the data set?

Who produced the data set? Who also contributed to the data set?

To whom should users address questions about the data?

Why was the data set created? 


\section{Table 10 ESRI FGDC FAQ (Continued)}

\begin{tabular}{|c|c|}
\hline \multicolumn{2}{|r|}{ Frequently-asked questions: } \\
\hline \multirow{2}{*}{$\begin{array}{l}\text { How was the data set } \\
\text { created? }\end{array}$} & Where did the data come from? \\
\hline & What changes have been made? \\
\hline \multirow{5}{*}{$\begin{array}{l}\text { How reliable are the data; } \\
\text { what problems remain in } \\
\text { the data set? }\end{array}$} & How well have the observations been checked? \\
\hline & How accurate are the geographic locations? \\
\hline & How accurate are the heights or depths? \\
\hline & Where are the gaps in the data? What is missing? \\
\hline & $\begin{array}{l}\text { How consistent are the relationships among the data, including } \\
\text { topology? }\end{array}$ \\
\hline \multirow{7}{*}{$\begin{array}{l}\text { How can someone get a } \\
\text { copy of the data set? }\end{array}$} & Are there legal restrictions on access or use of the data? \\
\hline & Who distributes the data? \\
\hline & What's the catalog number I need to order this data set? \\
\hline & What legal disclaimers am I supposed to read? \\
\hline & How can I download or order the data? \\
\hline & Is there some other way to get the data? \\
\hline & What hardware or software do I need in order to use the data set? \\
\hline Who wrote the metadata? & \\
\hline
\end{tabular}

\subsubsection{David Rumsey Map Collection}

In considering the types of data sources available to students in SILAS.ST, and in an effort to make the metadata as interoperable as possible, I borrowed some of the media information fields from the David Rumsey Map Collection. The David Rumsey Map Collection is an impressive digital map collection, including historical atlases, globes, maritime charts, and a variety of separate maps, for example, those included in or preserved as manuscripts. Rumsey’s media information fields thoroughly document the digital maps using an exhaustive list of fields. This includes publication information, original size and scale, titles and digital data details, like resolution size, format, and file name. Rumsey's objective documentation method makes it easy for the user to find the original source or download and share the image under the creative commons license.

\subsubsection{Library of Congress Map Collection}

There are a variety of ways of documenting maps, but no single and widely accepted proper way. The Library of Congress (LOC) uses a very thorough and complex metadata format known as the Metadata Encoding and Transmission Standard (METS), developed by the Digital Library Federation. METS is comparable to the FGDC standard, though it is not solely focused on geographic information. On both the LOC Map Collection website and the sample map document referred to on the METS website, the displayed information for maps is limited. While more information may exist for each map stored using METS documentation, only limited information is available in the online display (Table 11). Rumsey, in turn, includes 39 fields of documentation for each online map. The LOC in turn uses only 10 fields consistently, although the LOC makes extensive use of their Notes section in adding further detail. The LOC METS for Maps fields are 
included in Table 8. The online LOC Map Collection provides a blanket rights and reproductions page, as well as information for where to get a copy of the digital data. For online display, the LOC keeps the lowest common denominator information consistent among all maps. It also simplifies some information to reduce redundancy. Although this might also be out of necessity, as their collection has more than 4.5 million items, of which only a small fraction are scanned and available online. In contrast, the Rumsey Collection boasts over 20,000 maps and images that are all available online, reflecting a significant digitization effort. The lengthy format of documentation practiced by Rumsey may not be as easily managed, but it has superior search capabilities.

\section{Table 11 Library of Congress Map Collection Documentation}

\begin{tabular}{|c|c|}
\hline \multicolumn{2}{|c|}{ Library of Congress Map Collection Sample } \\
\hline Palestina, siue Ter & $\begin{array}{c}\text { Sanctæ descriptio / excudebat Joannes Joansonius. } \\
\text { Jansson, Jan, 1588-1664. }\end{array}$ \\
\hline OTHER TITLES & Palestina, sive Terræ Sanctæ descriptio \\
\hline CREATED/PUBLISHED & Amstelodami : [s.n., 1650?] \\
\hline \multirow{5}{*}{ NOTES } & Relief shown pictorially. \\
\hline & Oriented with north to the left. \\
\hline & $\begin{array}{l}\text { Includes an inset view of Jerusalem and } 18 \text { indexed biblical } \\
\text { scenes at top and bottom of sheet. }\end{array}$ \\
\hline & $\begin{array}{l}\text { Exhibition: Jordanian Display, Library of Congress, } \\
\text { Washington, D.C., May 25-27, } 2005 .\end{array}$ \\
\hline & Scale $[$ ca $1: 600,000]$ \\
\hline \multirow{5}{*}{ SUBJECTS } & Bible.--O.T.--Geography--Maps--Early works to 1800. \\
\hline & Palestine--Maps--Early works to 1800. \\
\hline & Israel--Maps. \\
\hline & Palestine. \\
\hline & Israel. \\
\hline MEDIUM & 1 map : col. ; 27 x 56 cm. \\
\hline CALL NUMBER & G7481.2 1650 .J3 \\
\hline REPOSITORY & $\begin{array}{l}\text { Library of Congress Geography and Map Division } \\
\text { Washington, D.C. 20540-4650 USA }\end{array}$ \\
\hline DIGITAL ID & $\begin{array}{l}\text { g74812 ct001380 } \\
\text { http://hdl.loc.gov/loc.gmd/g74812.ct001380 }\end{array}$ \\
\hline
\end{tabular}




\subsubsection{ECAI Metadata}

In Historical GIS: Technologies, Methodologies and Scholarship, Ian Gregory specifically acknowledges the efforts of the Electronic Cultural Atlas Initiative (ECAI) for their method of documenting sources. ECAI is comprised of scholars from around the world who are working to create a virtual atlas of cultural information. The project emphasizes both spatial and temporal information. The documentation standard used by ECAI is composed of the Dublin Core Standard, a widely used metadata standard. Additional ECAI fields account for the contextual footprint of the data (Gregory \& Ell, 2007). This additional contextualization makes the metadata more usable for ECAI purposes (Appendix A).

The ECAI metadata standard is very thorough, and detailed descriptions assist the user in accurately and adequately completing included fields. The Coverage field is intriguing because it documents both spatial and temporal attributes under one name (Coverage). For historical purposes, the SILAS.ST metadata may separate the content of Coverage into two separate categories, as time and place can be ambiguous or conflicted, warranting separate discussions. The ECAI Relation category is also distinctive from the other metadata and document standards discussed in this paper. Using defined relations, such as mechanical, versions, inclusions, citations and physical, I appreciate how this field acknowledges a larger body of work that would be relevant in interpreting the fragmentary piece that is being evaluated and documented.

\subsection{Related Projects in Historical GIS: Anne Knowles \& Charlie Frye}

As noted in the preceding section, there is a variety of ways to document sources, with benefits to each method. In addressing the needs of my client, I placed greater emphasis on data identification, attending to both quality of the source, and quality within GIS. In the development phases of SILAS.ST I was able to speak with scholars in the field of historical GIS. Although SILAS.ST explicitly focuses on the pedagogical methods used in historical GIS, these conversations were invaluable.

\subsubsection{Historical Holocaust Database}

On March 9, 2009, my advisor and I had a phone conference with Anne Knowles, a professor of historical geography, and her research assistant Alex Yule, both from Middlebury College, in Middlebury, Vermont. Knowles and her assistant are currently in the process of creating a digital repository of information about Auschwitz, the largest concentration camp established by Nazi Germany. The project uses diaries, memoirs, documents, and large scale maps to document death marches from Auschwitz. For these scholars, developing a documentation standard that can account for the variety of sources being used is particularly important.

Common to both projects is the question of how to assess and document "uncertainty." In her Auschwitz project, Knowles has chosen to incorporate fields that assign a Likert-like scale of values to gauge the uncertainty of the data. At the time of our discussion I in turn was still struggling with how to categorize accuracy. In my first attempt, users were required to fill in a "yes," "no" or "unknown" to gauge the root mean square error (RMSE) value from georeferencing. I knew students would not be able to 
look at an RMSE value and know if it was acceptable, so I also experimented with a scaling of high, medium or low to assess the "acceptability." The "acceptability" of the source would reflect the student's perception of the digitization and cartographer's accuracy (Figure 13).

Georeference Error:
RMSE Value
Acceptable Value? Yes $\checkmark$
See Accuracy for information on digitization

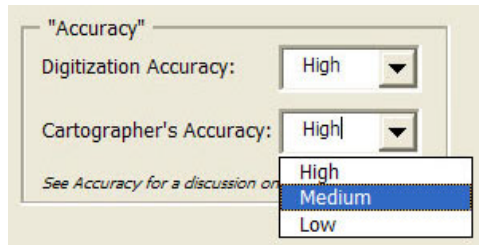

Figure 13 Documenting accuracy, first and second attempt

In contrast to a Likert-like scale of accuracy, my users would not have a range of values to assign. Rather the concept of accuracy and uncertainty during this phase of the project was limited to georeferencing induced error. Both RMSE and Likert methods of categorizing accuracy are quite one-dimensional. Likewise, deriving meaning from a scaled value does not grant much insight to the reader. The advantage of this gauged method is its simplicity. In addition, a detailed explanation of the values could help inform the user of the proper value to assign. This explanation would also help reduce redundancy in metadata entry, provided accuracy could be expressed as a value.

In an effort to accommodate a more in-depth discussion of accuracy, I included in my first metadata draft two text fields that questioned data lineage and accuracy. Each required a detailed response from the user (Figure 14).

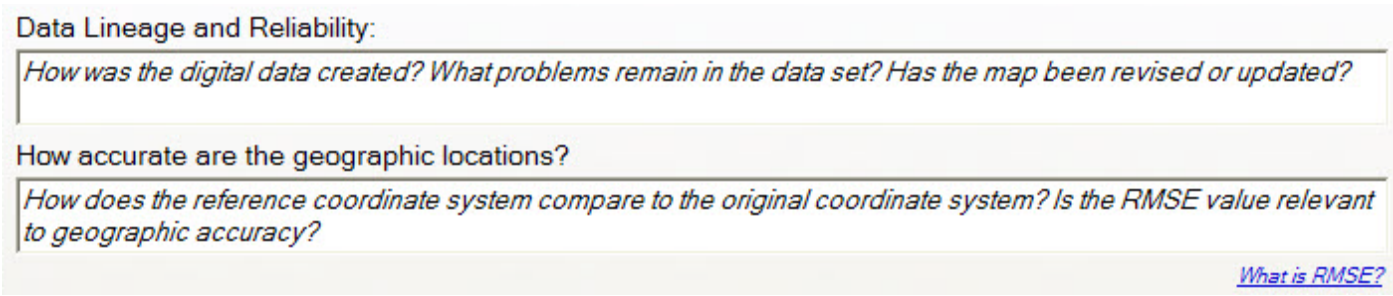

Figure 14 Documenting accuracy and data lineage, first attempt

In the end, the nature of the project must shape the focus of the metadata collection method. The aim of SILAS.ST is not reducing redundancy or aiding in data discovery. Rather, the SILAS.ST metadata is to be used as a pedagogical tool for learning to document and use historical sources within GIS. For Knowles' project, streamlining a documentation method to make data entry more efficient takes priority.

These projects also share the many challenges of documenting duration, multiple place names for a single location, and scale. However, the motivation underlying Knowles' project again is different. Her objective is to preserve history, with an eye to database management and efficiency. The questions posed relate to how a historian can record data so it will be useful to future historians and researchers using the metadata. The purpose of SILAS.ST is to teach students to challenge and question conventional readings of history by considering the geography. Ideally, future students using SILAS.ST data will have access to the written processes and methodologies of digitizing and using that historical source within GIS. 
In discussing the pros and cons of various methods, two different "types" of information that could be included within historical GIS metadata were identified. There is the basic source and citation information, as well as the basic geographic and temporal data, that is standard in metadata. The second type of information is more subjective and provides information on the interpretation of the source. This includes how it was used and why it was made. These questions are similar to those posed in the CRAAP Test in Table 9. This interpretative section would not be useful in meeting the aims of Knowles' project, as it is not traditional "metadata.” However, for SILAS.ST, this interpretative documentation can be researched and recorded by students, then revisited by future students who can revise and rethink its content. Ideally the collective knowledge contained within the metadata will accrue, bringing to light many questions and insights about the data being used.

\subsubsection{The ArcGIS Citation Data Model and Method}

The ArcGIS Citation Data Model (CDM) was created by ESRI's Charlie Frye to methodically link bibliographic information to geographic features in ArcGIS using a database schema. This method is different from metadata because it links information down to single geographic features, using a system of joins and relates of tabular data, versus documenting information of an entire layer (Frye, 2008). Within the database, as shown below in Figure 15, a single table stores all of the bibliographic information sources identified in the geodatabase assigning a unique identifier key to each reference (Src_ID). Metadata is implicit in the organization of the geodatabase.

\begin{tabular}{|c|c|c|c|c|c|c|c|}
\hline \multicolumn{8}{|c|}{ 囲 Attributes of Sources } \\
\hline & Src_ID & type & Author & PubYear & \multicolumn{3}{|c|}{$\begin{array}{lc}2 & \text { Titte } \\
\end{array}$} \\
\hline & 1 & Map & Sir Thomas Hyde Page (Lieutenant) & 1845 & \multicolumn{3}{|c|}{ A klan of the action at Bunkers-Hill, on the 17th. of June, 1775 , between His Majesty's troops under the cc } \\
\hline & 2 & Map & Sir Thomas Hyde Page (Lieutenant) & 1775 & \multicolumn{2}{|c|}{ Boston, its environs and harbour, with the rebele worke raised against that town in 1775 , from the observ } & \\
\hline & 3 & Map & Sir Thomas Hyde Page (Lieutenant) & 1777 & \multicolumn{3}{|c|}{ A klan of the town of Boston, with the intrenchments etc. of His Majestys forces in 1775: From the observ } \\
\hline & 4 & Book & Eacon, Edwn M. & 1921 & \multicolumn{2}{|c|}{ Rambles Around Old Boston } & \\
\hline & 5 & Periodical & Balfour, David M. & 1884 & \multicolumn{2}{|c|}{ The Taverns of Boston in Ye Olden Time, "The Bay State Monthly", Voume II. No. 2, November, 1884} & \\
\hline & 6 & Map & Item 2 of 12, Peter Force Collection & 1775 & \multicolumn{3}{|c|}{ Battle of Bunker Hill. } \\
\hline & 7 & Map & Sir Thomas Hyde Page (Lieutenant)? & 1775 & \multicolumn{3}{|c|}{ Rough draft of Charlestown, in water colour. } \\
\hline & 8 & Map & Edwards, Ben L. & 2004 & \multicolumn{2}{|c|}{ Waking Boston Map } & \\
\hline & y & Hook & Ward, Christopher & 1952 & \multicolumn{2}{|l|}{ Ine War of the Revolution } & \\
\hline & 10 & Map & Aitken, Robert & 1775 & \multicolumn{3}{|c|}{ A rew and correct plan of the town of Boston } \\
\hline & 11 & Мap & Unknown & 1775 & \multicolumn{2}{|c|}{ A Mlap of 100 miles round Boston. } & \\
\hline & 12 & Map & Unknown & 1775 & \multicolumn{3}{|c|}{ A Map of forty miles north, thirty miles west, and twentyfive miles sourh of Boston, including an accurate } \\
\hline & 13 & Map & Beaurain, crevalier de & 1776 & \multicolumn{3}{|c|}{ Carte du port et havre de Boston avec les côtes adjacentes, dans laquel on a tracée les camps et les retr: } \\
\hline & 14 & Map & Bellin, Jacques Nicolas & 1764 & \multicolumn{3}{|c|}{ Plan de la ville et du port de Boston; capitale de a Nouvelle Angleterre } \\
\hline & 15 & Map & Unknown & 1775 & \multicolumn{3}{|c|}{ Boston, S. West part. No. 25} \\
\hline & 16 & Map & De Costa, J. & 1775 & A flan of the town and harb & ton and the country adjacent with the road from Boston to Concord & \\
\hline & 17 & Map & Hills, John & 177 & Boston Harbour, with the su & etc. & \\
\hline & 16 & Map & Jefferys, Thomas & 1771 & A map of the most inhabited & Wngland, containing the provinces of Massachusete Bay and Nev & \\
\hline & 19 & Map & Sir Thomas Hyde Page (Lieutenant) & 1776 & A flan of the town of Bostor & virons, with the lines, batteries, and incampments of :he British an & \\
\hline & 20 & Map & Sir Thomas Hyde Page (Lieutenant) & 1777 & A plan of the town of Bostor & intrenchments etc. of His Majesty's forces in 1775 , frcm the observ & $\mathrm{v}^{2}$ \\
\hline$<$ & & & & & & $>$ & \\
\hline & Recor & $14 \mid$ & Show: $\longdiv { \text { All } }$ & & ecords ( 0 out of 33 Selected) & Optiors - & \\
\hline
\end{tabular}

Figure 15 Example source table, from the ArcGIS CDM (Frye, The ArcGIS Citation Data Model and Method, 2008)

The cross-referencing structure of the CDM ensures efficient use of sources, while establishing the fidelity of the sources. Each object within a feature class can reference up to three supporting sources in the table along with one conflicting source, should one exist. Limiting the number of reference sources follows a modern cartographic practice of determining what map information (place name, geographic feature name) is in the public 
domain. Three or more inclusions in modern day maps make the name part of the public domain (Frye, 2008). In the picture below (Figure 16), Frye provides an example of an object in a feature class layer linked to the supporting sources table. This table can be accessed while working with the data in ArcMap.

\begin{tabular}{|c|c|c|}
\hline Attributes & & {[} \\
\hline \multirow{2}{*}{$\begin{array}{c}\text { - LandCover } \\
-280\end{array}$} & Property & Value \\
\hline & \multirow{8}{*}{$\begin{array}{l}\text { OBJECTID } \\
\text { Src_ID } \\
\text { type } \\
\text { PageNum } \\
\text { Author } \\
\text { PubYear } \\
\text { Title } \\
\text { Publisher } \\
\text { PubLocation }\end{array}$} & 36 \\
\hline \multirow{8}{*}{$\begin{array}{l}\text { Sources } \\
+36 \\
\text { Sources } \\
\text { Sources } \\
\text { Sources } \\
\text { BuildingsAnno } \\
\text { Wharfs_Dock: } \\
\text { Land_CoverAn }\end{array}$} & & 31 \\
\hline & & Map \\
\hline & & 1 \\
\hline & & Price, William \\
\hline & & 1769 \\
\hline & & A new plan of ye great tow... \\
\hline & & Price, William \\
\hline & \multirow{6}{*}{$\begin{array}{l}\text { Library } \\
\text { Libr_ID } \\
\text { URL } \\
\text { Notes } \\
\text { DateObtai... } \\
\text { SrcLevel }\end{array}$} & \multirow{6}{*}{$\begin{array}{l}\text { Harvard Map Library } \\
\text { G3764.B6 } 1769 \text {.P7 } \\
\text { http://maps.bpl.org/id/06_... } \\
\text { Better copy than LOC (SrcI... } \\
\text { 1/2/2008 } \\
\text { Secondary - Digital Copy (... }\end{array}$} \\
\hline & & \\
\hline & & \\
\hline & & \\
\hline$>$ & & \\
\hline 1 features & & \\
\hline
\end{tabular}

Figure 16 Example object in a feature class, which sources listed, from the CDM (Frye, The ArcGIS Citation Data Model and Method, 2008)

What I appreciate about Frye's Citation Data Model design is that features can be queried by the number of supporting sources. Directly addressing the question of historical certainty, the more supporting sources, the greater the confidence in the feature. When I met with Frye, we discussed how confidence can also be established by contextualizing those sources and critiquing them. That is considering the intent of the cartographer, and his or her credibility, when using sources for historical research. Frye suggests that the three source fields could be used to register high, medium and low confidences, and that low confidence sources could not be listed as the primary source. The CDM also includes a notes field in both the source table and feature layer table, accommodating insights and information that might help qualify a source or feature. One of Frye's observations about the wealth of information available to current day researchers is that so little of this information can be integrated and validated. By applying the CDM to GIS research, a variety of data sources can be incorporated, validated, easily maintained and shared. For an individual or a group of researchers interested in using GIS for historical research, the CDM is a practical data management model.

\subsubsection{Requirements differences}

Because of the limited resources of biblical research and the nature of the assignments my client expects her students to accomplish and understand, SILAS.ST in turn focuses 
on the few resources available and draws out as much information and interpretation as possible. Hosting a discussion on the use and interpretation of a source is of greater importance then efficient database design, although the benefits of efficient design are applauded. While on a larger scale, and with a more resource-rich topic, the CDM might be appropriately implemented, Frye distances the CDM from feature level metadata because his efforts are focused on linking bibliographic information to layers. This is different from the SILAS.ST goal of documenting “data about data.” Equally significant is the issue of metadata being treated as a one-time reference. After it is filled out, it is often ignored. The fact that metadata is largely available for editing and viewing only in ArcCatalog accentuates this. The goal of SILAS.ST is to make metadata readily available, facilitating access and updates on a more regular basis.

\subsection{Student Critique}

Once a full prototype with initial feedback from my advisor and client was complete, it was time to evaluate the SILAS.ST prototype by conducting a learning exercise with my client and advisor's students. The students who enrolled in Lillian Larsen and Diana Sinton's three-hundred level undergraduate religion course, Historical Search for Jesus, were the ideal audience because they had discussed the complications of historical biblical research and had worked briefly with ArcMap and historical maps. I had initially planned testing a more complete version of SILAS.ST, but due to the limited time available before the candidate students left for the summer, I had them critique a design prototype of the metadata.

\subsubsection{Evaluation Method}

The first part of the teaching demonstration introduced the aim of SILAS.ST and how it compared to the version of SILAS to which students had already been introduced. To ensure that students understood the fields on accuracy and data reliability, they were presented with a series of screen shots that depicted the process of bringing a source into GIS. This progressed from the initial scan, to georeferencing, to digitizing into vector data. Causes of distortion in processing the data were highlighted, so that students could grasp the relative "accuracy" of digitized data. Using two maps that the students had seen and discussed in class and a printout of each tab of the SILAS.ST metadata editor prototype design (Figure 18), I posed a series of questions that prompted students to think critically about the information that had been presented. On the series of printouts, they were asked to note what was successful and what needed further clarification. They were also invited to give suggestions for further improvement. They were then allotted fifteen minutes to individually go through all of the pages and mark up the fields and labels. 

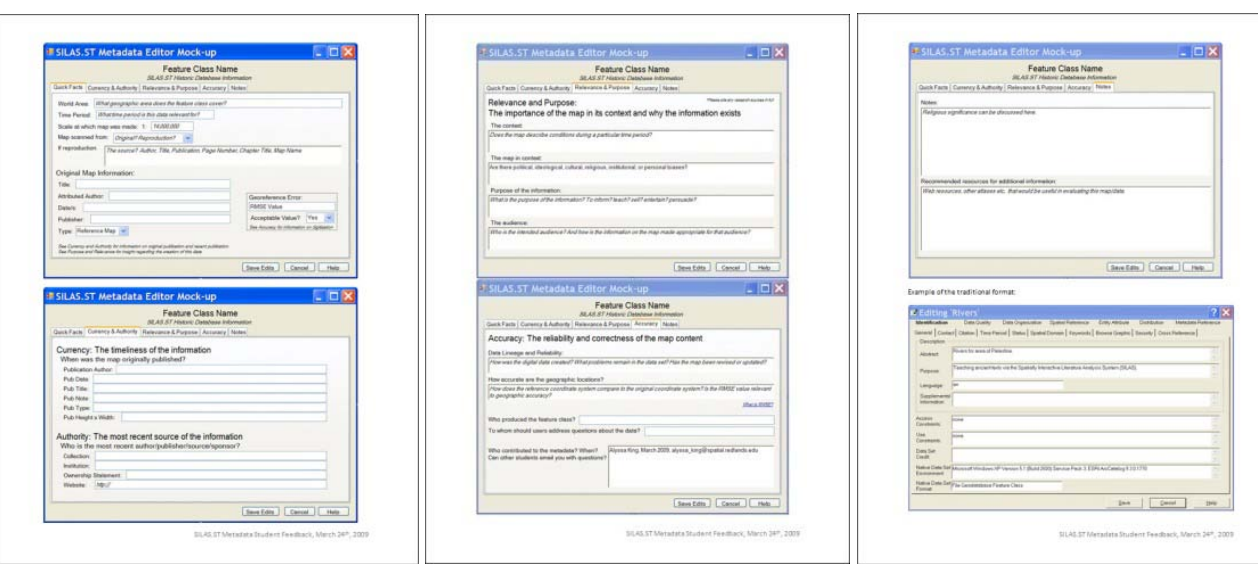

Figure 17 SILAS.ST prototype tabs to be critiqued by students

\subsubsection{Discussion}

After the students had read and marked-up the metadata, an open discussion proceeded page by page. The most frequent comments and suggestions pertained to language as, in most cases, it was the language that intimidated the students. For example, when the SILAS.ST metadata field asked students to fill in who produced the feature class layer, they did not know what "feature class layer" meant. In some cases, the language was inconsistent, referring to the map, the layer, the information and the data, which, depending on the context, referred to something in particular.

The most common issue students had with the metadata was the RMSE. It was mentioned on the first tab (Figure 13) and in one of the text fields when discussing accuracy (Figure 14). Discussing accuracy based on a single value appealed to them, and they suggested that qualifying accuracy with text versus a numerical value would be simpler and of better use.

\subsubsection{Results}

In general, the students were very appreciative of the metadata and thought it was a useful documentation tool. Once the individual marked-up printouts of the metadata were collected and read, each student's comments were considered, and many of their suggestions were included in a newer draft of the metadata. Overall, most suggestions targeted the language and many students asked for clarification of titles and question prompts. Students also made helpful suggestions regarding the organization of the fields, including the idea of combining fields (discussed below in section 4.6).

After applying the suggested revisions, and rearranging some of the fields, I presented this revised edition of the SILAS.ST metadata to the Bible Specialty Group at the Association of American Geographers (AAG) Conference in Las Vegas, Nevada on March 26, 2009.

\subsection{Metadata Candidate Designs}

Following the student critique and subsequent revisions, the SILAS.ST metadata had yet to be filled out in its entirety. A selection of sources for the final SILAS.ST metadata had 
been included: a map from the David Rumsey Map Collection, a map made by a student using Google Maps, and a map scanned and digitized from Michael Grant’s Ancient History Atlas. These three sources represent the various formats of sources that might be included in the future by my client and her students. With these sources in mind, I sat down with my client and advisor to attempt to fill out the metadata editor forms.

\subsubsection{Metadata Trial}

Each of the five tabs with fields was individually evaluated, according to the following four criteria:

- Relevance to a student documenting a historical source

- Availability of the information

- Ease with which a student could acquire the information

- Metadata's ability to satisfactorily document the variety of sources, outlined earlier

The original metadata form was divided into five sections (Figure 19) with Quick Facts, Origin and Authority, Relevance and Purpose, Accuracy, and Notes, all loosely derived from the CRAAP Test sections (Table 9). Of all these tabs, the Quick Facts (Figure 19) has undergone the most revisions because of the attempt to identify and qualify the sources on one page. The concept of scale, and how to document it, took up a majority of the metadata trial meeting. Scale represents a tricky crossroad between GIS and humanities vernaculars, similar to the term "Accuracy." Both scale and accuracy are discussed in section 4.6. 


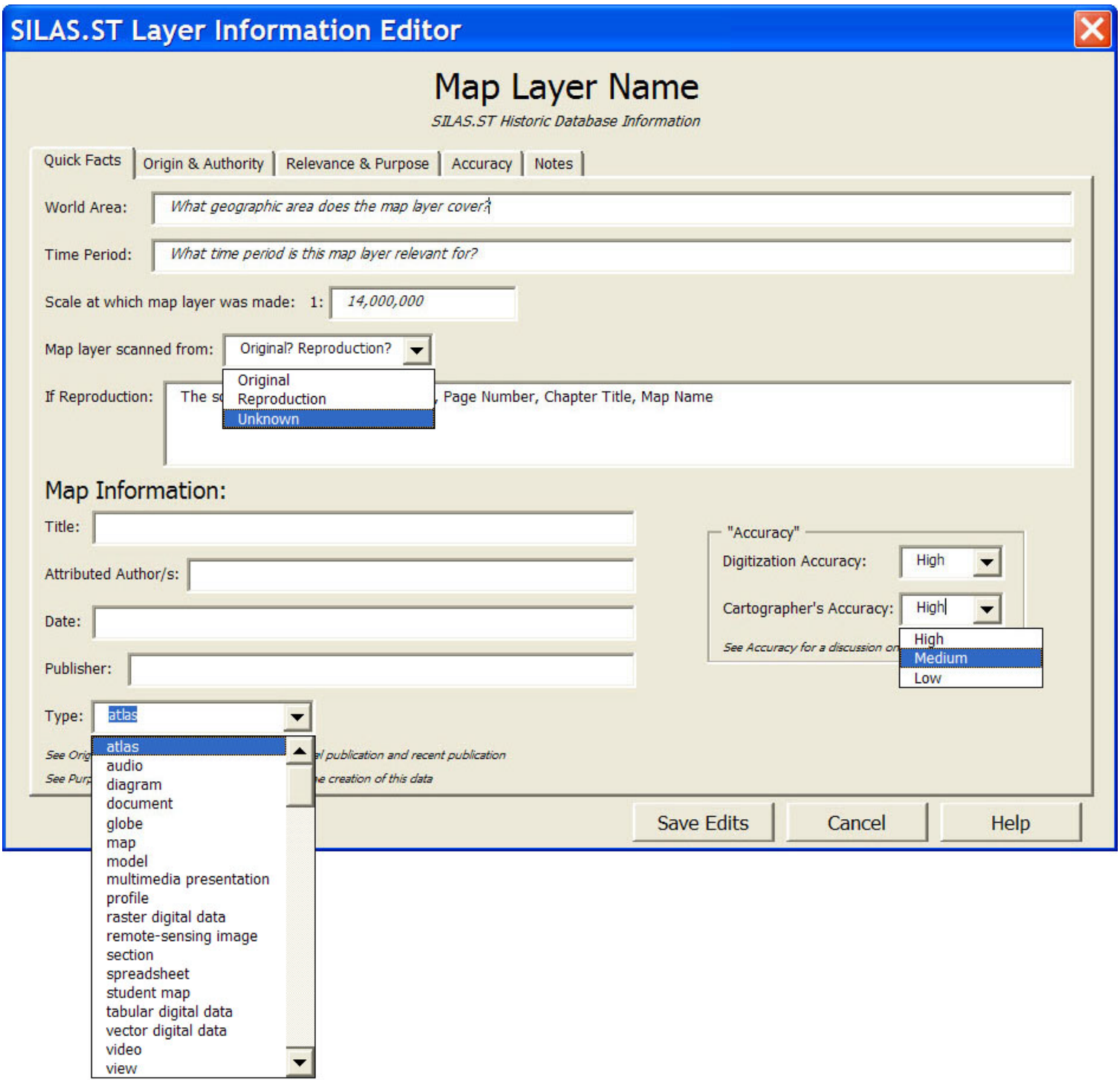

Figure 18 Metadata trial, 'Quick Facts’ tab with dropdown boxes

Another tricky section on the Quick Facts tab was identifying the map type (Figure 19). On this form, a partial list of cartographic materials as determined by the AngloAmerican Committee on Cataloguing of Cartographic Materials (Association American Library, 1982), and some additional materials relevant to SILAS.ST, were included for use in identifying the map type. This approach was inspired by Rumsey’s Map Collection Media Information that has a space identifying the media type. After several attempts to compose a complete list that would not overwhelm the students, it was suggested that the list be refined and simplified. When documenting the scanning and reproduction of a map, it became clear that the field would mean something different in the context of a student-made map, as opposed to any other map source. This became apparent when considering the Origin \& Authority tab (Figure 20), which requires publication information not applicable to a student made map. My advisor and client suggested that there be a way to specify from the outset whether the map was student-made, inorder to customize the fields to better fit the different contexts. 
Map Layer Name

SILAS.ST Historic Database Information

Quick Facts Origin \& Authority $\mid$ Relevance \& Purpose | Accuracy | Notes |

Origin: What is the original publication information?

Publication Author: 1

Publication Date:

Publication Title:

Publication Type:

Publication Language:

Publication Height $x$ Width:

Has the map content been revised or updated?

Authority: Who is the most recent author/publisher/sponsor?

Name:

Collection:

Institution:

Ownership Statement:

Website: http://

Figure 19 Metadata trial, 'Origin \& Authority'

The Origin \& Authority tab was modeled after the David Rumsey Media Information fields, which thoroughly document original publication information and recognize the ownership of material. As described above, this would not be appropriate for a studentmade map, and, as later pointed out by Charlie Frye, not all maps are published. Some maps on Rumsey's site were from manuscripts. From Frye's experience, other singleton maps also exist, and this would not be an appropriate way of documenting them.

My client and advisor were confused by my concept of authority. In the lower portion of the tab, I suggested that authority belonged to the author, publisher or sponsor. The purpose of documenting "authority" was to have students document from where they had acquired the information. It was suggested that the title of this section be revised to include owner, distributor and publisher. This section would not be applicable to a student-generated map, and so an alternative was proposed specifically for studentgenerated maps, as seen in Figure 21.

Figure 20 Citation requirement for a student-made map 
The language was changed to recognize that student-made maps could be used and later published, after a semester course is completed. This citation requirement for student maps will be useful for my client if she decides to publish any of her student's maps in the future.

The Relevance \& Purpose tabs had the least revisions, and were generally well received by students during the student critique. Students recognized that additional research would be required to fill out the text boxes (Figure 22), but they understood the value of the information when evaluating a map for use. These fields were modeled on the CRAAP Test components and tailored to accommodate historical sources.

\section{SILAS.ST Layer Information Editor}

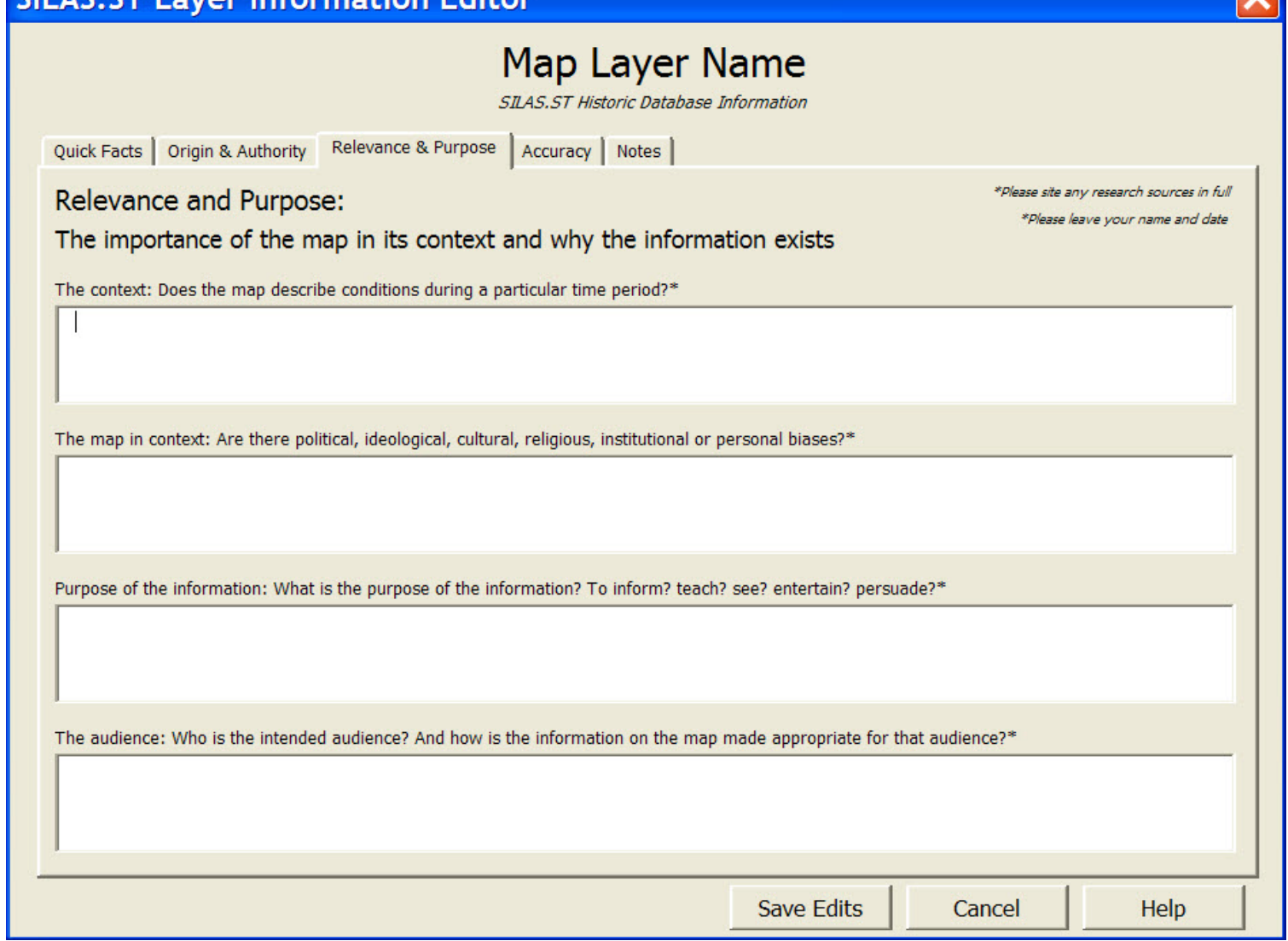

Figure 21 Metadata trial, 'Relevance \& Purpose'

It is logical to follow the Relevance \& Purpose section with a tab discussing the accuracy of the information. Accuracy in GIS, let alone history, is an ambiguous concept, and unattainable no matter how thorough one's method. This is discussed at length in section 4.6. From the metadata trial, it was suggested that the terms "accuracy" and "correctness" be used carefully because they are open to interpretation by the student (Figure 23). For the title, emphasizing "relative reliability” of the information versus the correctness would be a better practice in terminology for students. 


\section{SILAS.ST Layer Information Editor}

\section{Map Layer Name}

SILAS.ST Historic Database Information

Quick Facts | Origin \& Authority | Relevance \& Purpose Accuracy | Notes |

Accuracy: the reliability and correctness of the map

Accuracy of the Original Map: How was the original map created? Could the relevance and purpose of the map affect accuracy?

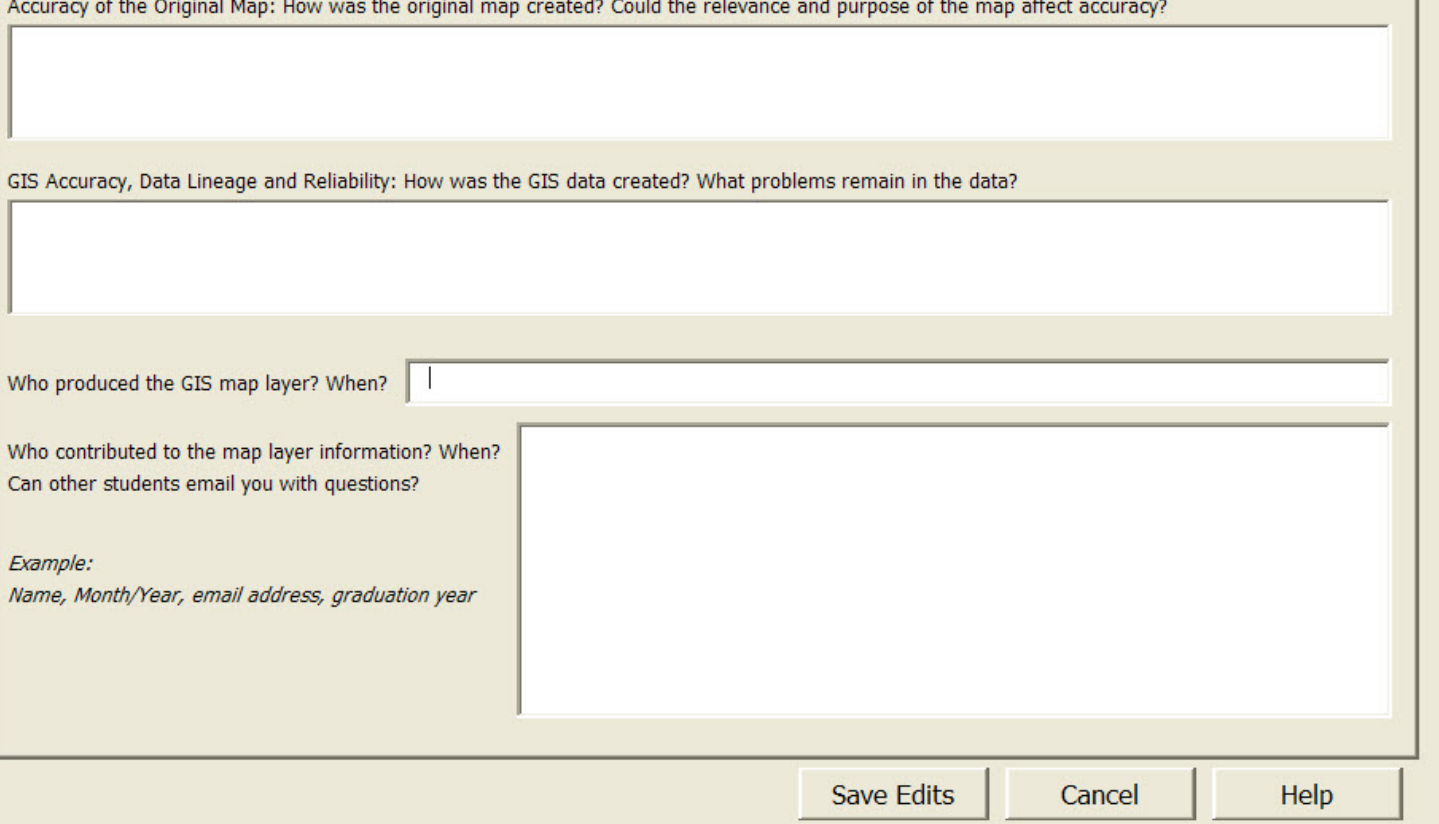

Figure 22 Metadata trial, 'Accuracy'

From the ECAI metadata standard discussed earlier (Section 4.2.4), the concept of Relation was a thoughtful way of acknowledging a larger body of work. This is useful if the larger body of work is relevant to the study of the individual layer or map. In general, an open-ended section that could accommodate notes and comments not required in the previous tabs would be useful for all types of sources (Figure 24). 


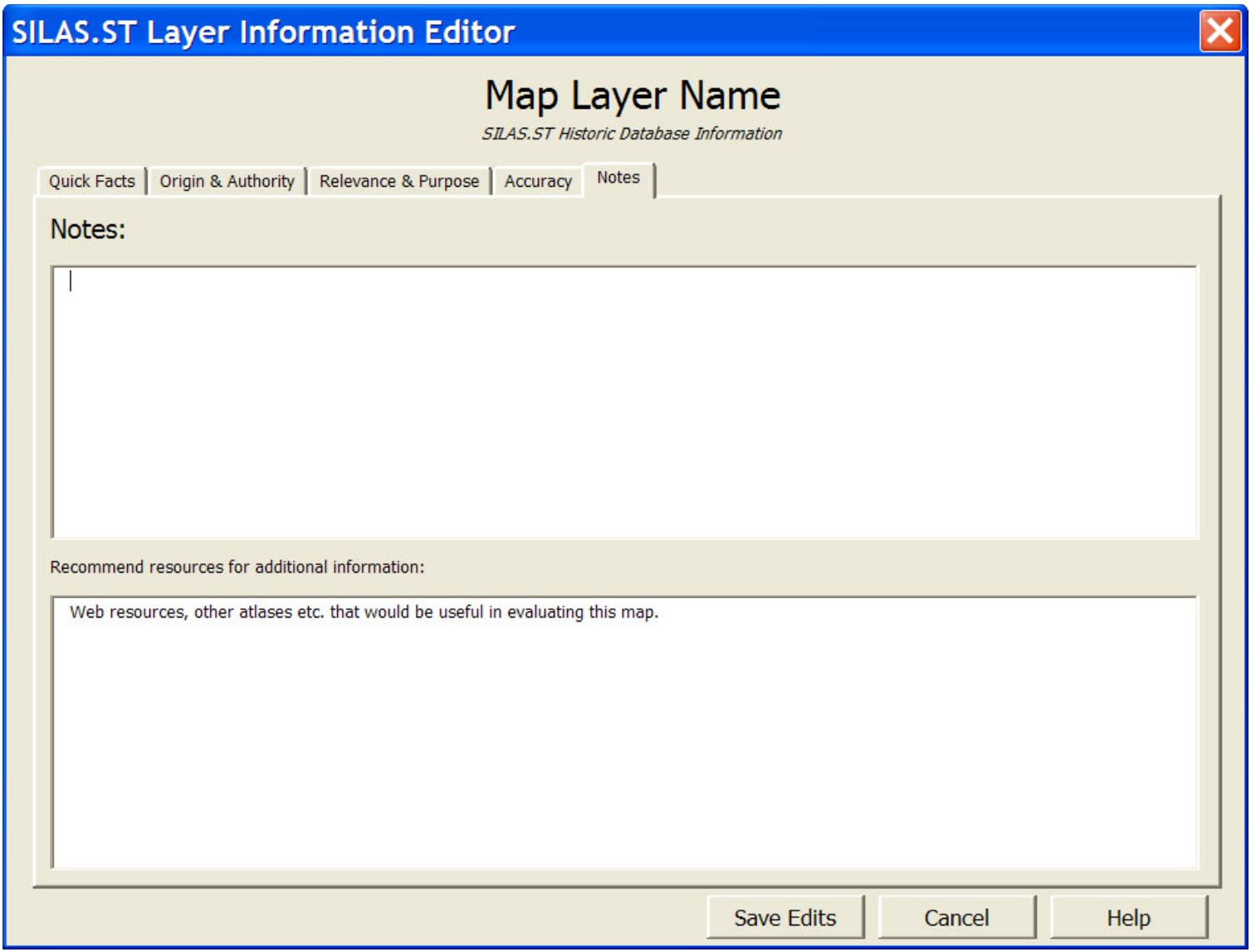

Figure 23 Metadata trial, 'Notes'

The open-endedness of this section makes it difficult to standardize what is included. The "Notes" tab's purpose is to accommodate a variety of sources, and useful documentation for students. As with the Relevance \& Purpose tab, this concept was also well received and has undergone few revisions.

\subsection{Metadata Contents and Discussions}

\subsubsection{Uncertainty \& Accuracy}

Issues involved with helping students recognize uncertainty and understand the inherent difficulty of ascertaining accuracy in historical research, fueled the creation of the SILAS.ST metadata. When students encounter discrepancies between data sources when overlaying them in ArcMap, it is helpful to have documentation available so students can begin to tease out the differences they encounter. Discrepancies between sources could stem from different map making practices, or the intent of the cartographer.

In The Nature of Uncertainty in Historical Geographical Information (2002), Plewe discusses the process of representation, and how it is never a perfect replication of reality. His definition of the conceptual modeling of a place or entity is applicable to how students think about place (as I have observed). His first level suggests a direct correspondence to a particular real place or entity, similar to Google Maps' ability to pinpoint candidate places "exactly" when the user supplies a name. Students are willing 
to accept points as representing cities in Google Maps, and this concept easily transfers outside of Google. This was epitomized one evening when a student used his iPhone to search for the coordinates of a city so that he could be exact in drawing a point onto a small scale paper map. For students accustomed to the exactness of finding only single points on Google Earth, understanding that a name might also reference a defined area, or a loosely defined region, is challenging.

Plewe's subsequent two levels of conceptualization are more difficult to visualize, yet they are critical for understanding historical texts and maps. The first level is the artificially constructed places that are recognized publicly, such as countries or groups of islands. The next level describes places as purely conceptualized or recognized patterns, such as storms or cultural regions (Plewe, 2002). According to Plewe, reality is not uncertain, just extremely complex.

Uncertainty is inherent in any conceptualization of reality and can create problems of incompleteness, incoherency, and ambiguity. In historical records, these problems are part of documenting reality and stem from interpreting that documentation over time (Plewe, 2002). One example is the limitation of an initial observance (measured or sensed by a person) that is recorded, and that person's (or instrument's) ability to be as exact and precise as possible. In pre-survey era maps, space was malleable, and that recorded observance may be ambiguous (Frye, 2009). Before the invention of precision instruments, maps were a mental construct of space. For instance, the further away one is from a place, the bigger that conceptual "place" may become. One's direction of approach and one's orientation will also influence one's perception of that space. For example, maps of the Holy Land suggest that greater effort was expended in detailing particular features.

Once data has been recorded, the data is then retrieved through research and firsthand observances. Observances and records may not be adequately preserved, may be biased, or may not be located in the same time and place (Plewe, 2002). Frye suggests that in historical sources, it is the strength of the argument that tends to indicate accuracy; otherwise, no such measure exists, or can be known. The accuracy and certainty of accumulated evidence can vary widely based on the sources. As time ellapses, a lack of reference on the reader's part can limit what the reader understands. For example, when using the bible as a source, it is undoubted that place names, geographic features and measurement standards have changed (Plewe, 2002).

It is important that the reader and user of the information understand these causes of uncertainty. Plewe has identified three types of assertions a person can make regarding historical sources: unknown, imprecise or inaccurate assertions (2002). In my work, I hope students will 1) recognize and make these assertions when reviewing or making maps, and 2) record them in metadata for future users. It is important that students understand the causes and forms of uncertainty. I have designed the Relevance \& Purpose tabs to accommodate student observations and assertions.

\subsubsection{Scale \& Resolution}

Scale and resolution were the most difficult concepts to document. Beyond knowing the actual map scale and image resolution, making these numbers meaningful to students was not easy. Because they are familiar with Google Earth, and its ability to zoom and preserve resolution at each fixed extent level, students did not initially understand how 
information in GIS differs. Despite the similarity of functions, looking at data sources in Google Earth and ArcGIS is not the same. There are limitations to the malleability of GIS sources. As noted above, while using ArcMap to place a point, students would zoom in as close as possible. As a result, the background 90 meter SRTM Shaded Relief resolution became pixilated. In one instance a student zoomed in on a junction of roads that from afar appeared to connect at one node. Due to poor digitizing practices, moving beyond the extent to which the roads were digitized, the roads no longer met, or even connected. In digitizing historical maps and bringing them into an interactive environment, we cannot preserve the physical limitations of the original source or how the cartographer intended that source to be used, only the information itself.

What is the best way to inform Google Earth-era students of an ideal extent range? A specific extent threshold preserves the original quality of the physical source, and unlike Google Earth, better quality at larger extents is not always available. This is also true with quality and accuracy, they diminish after a certain extent when there are no zooming constraints. Initially, the metadata asked for the extent at which the map was made, but it became apparent from the student critique that they did not know 1) how to find that information, and/or 2), how to interpret it. A revision to the metadata asked students to identify how far they could zoom in before the quality of the map information was lost. During the metadata trial, it became clear that even this question was too open-ended. Describing extents and determining when the extent diminishes quality was hard for students to determine. A combination of an objective, "what is the extent," and subjective, "what is the best scale to view," were suggested by my advisor.

In turn, Charlie Frye suggested a grouping of measurements, both subjective and objective (Figure 25). According to Frye, few understand the difference between scale and resolution, but when they are paired, one gains a better sense of both (Frye, 2009). Knowing the method and purpose of preservation is also important. For example, was it a research quality scan?

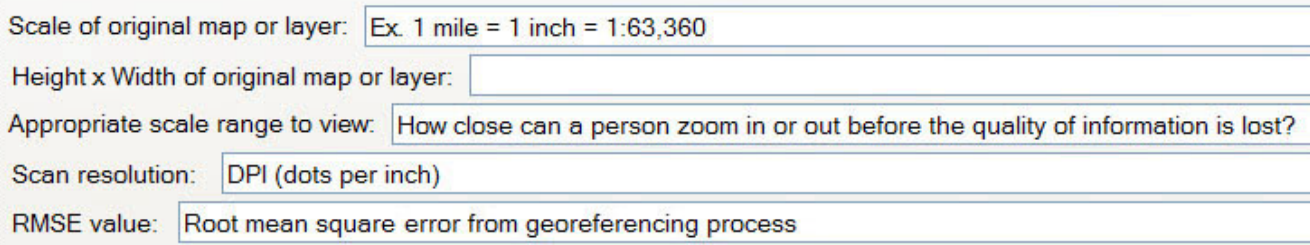

Figure 24 Documenting scale and resolution

\subsubsection{Map Documentation}

Charlie Frye likewise suggested that I differentiate between the publisher and the cartographer. Originally, SILAS.ST did not include a space to note the cartographer, as cartographers have lost prominence in the making of modern maps. With historic maps however, the cartographer often represents a certain school of thought or tradition in map making that may qualify a map towards a certain use. Vernaculars of geographers and cartographers will vary depending on their background. Frye notes that a historical map may have many lineages and may have undergone many revisions and updates. When researching the cartographer and his map, it is helpful to think of how he gathered his information, whom he borrowed information from, and how well he knew the geography. 
With some historical maps it is possible to identity a "better" lineage, determined by which cartographer produced more reliable information.

Having an ownership statement is important for protecting the validity of the SILAS.ST project. I realized this early on when I was unable to get publisher permission to include material from modern atlases in SILAS.ST. Figuring out how to document ownership, including student ownership, took some time. The SILAS.ST metadata initially required an ownership statement from the students because students do have ownership of their work completed for a course. Frye suggested calling it a citation requirement, which might better describe the information my client would want from the students. Non-student-made maps have varying forms of ownership, and Frye suggested a combo box that gave examples of different ownership statements, such as privately owned, licensed or part of the public domain.

When students are looking at the accumulated evidence behind a map, it is important that they consider if it reflects due diligence or opinion of information. Frye also pointed out that there are many ways of documenting sources. The SILAS.ST method of recording both factual and ambiguous information is a healthy practice. Using an interdisciplinary collaboration when building a database is optimal because it preserves the humanities features of GIS, which otherwise may be left out. It will be interesting to see how SILAS.ST metadata is approached by the different disciplines represented by students.

\subsection{Final SILAS.ST Metadata Model Summary}

The methodology behind my design choices of SILAS.ST culminates in this section, which outlines the finalized design choices for the SILAS.ST metadata. Figure 26, shown below, pops-up when a layer in the table of contents is selected and the edit Map Information (Figure 12) is clicked. 


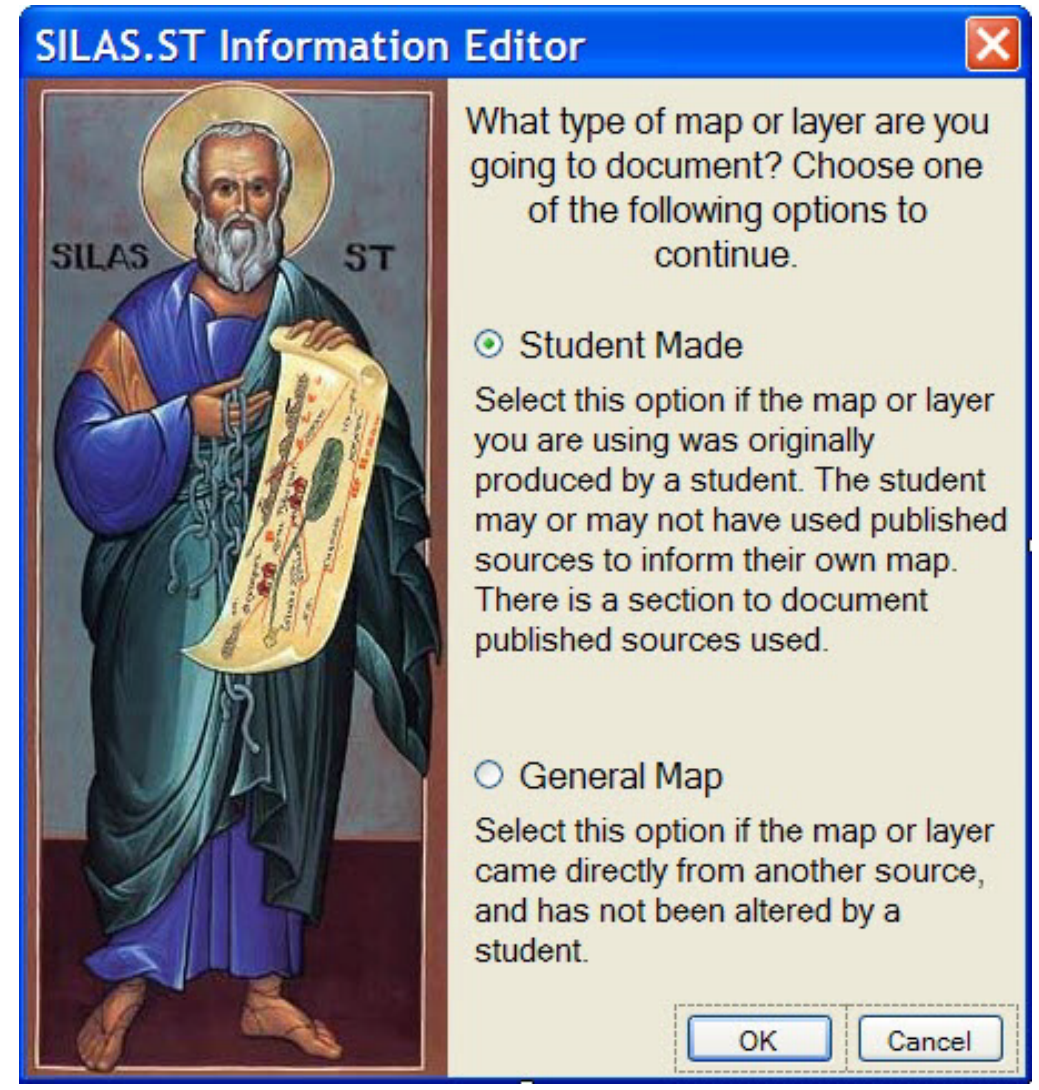

Figure 25 Final design, initial window

From this window, users decide which type of map they have, as the two different forms are comprised of questions and required information pertinent to the type of map. The first option is for maps made by students, and includes space for students to acknowledge use of materials already published elsewhere that inform the selection and content of their own maps. The second option is for everything else, with none of the information altered or generated by students.

\subsubsection{Student Made Maps}

Compared to the prototype Quick Facts tab seen earlier (Figure 19), the final form kept some of the same elements, but the organization was rearranged for consistency of presentation. In the first group, the identification information covers the types of information a student might seek out when deciding what to include in their map. 


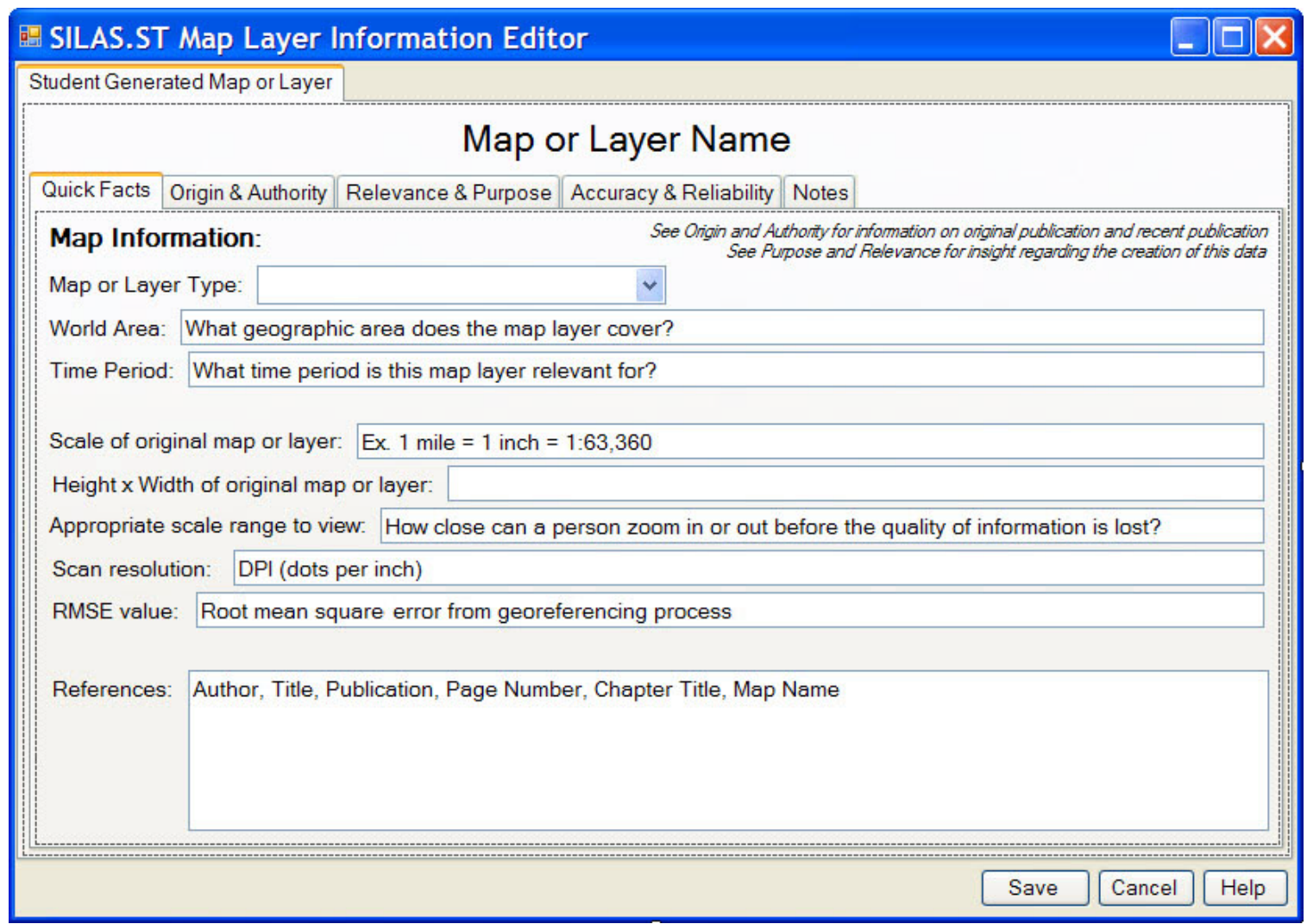

Figure 26 Final SILAS.ST Map Information design, ‘Quick Facts’, student version

The second grouping helps qualify the information by providing the scale and detail of the map and by indicating whether the map or layer would be appropriate for the study area the student has set. The second grouping also informs the student of the appropriate extent/scale range to use in viewing and working with the map layer. The last grouping identifies the sources the student used and where the student obtained information. This information helps qualify the student map or layer.

The Origin \& Authority tab (Figure 28) documents the student producer and basic documentation information regarding the source and usage permits. The Authority section reminds students that they have a claim to the map they produced. Acknowledging these citation rights simplifies any future inclusion of student produced maps for publication by my client. 


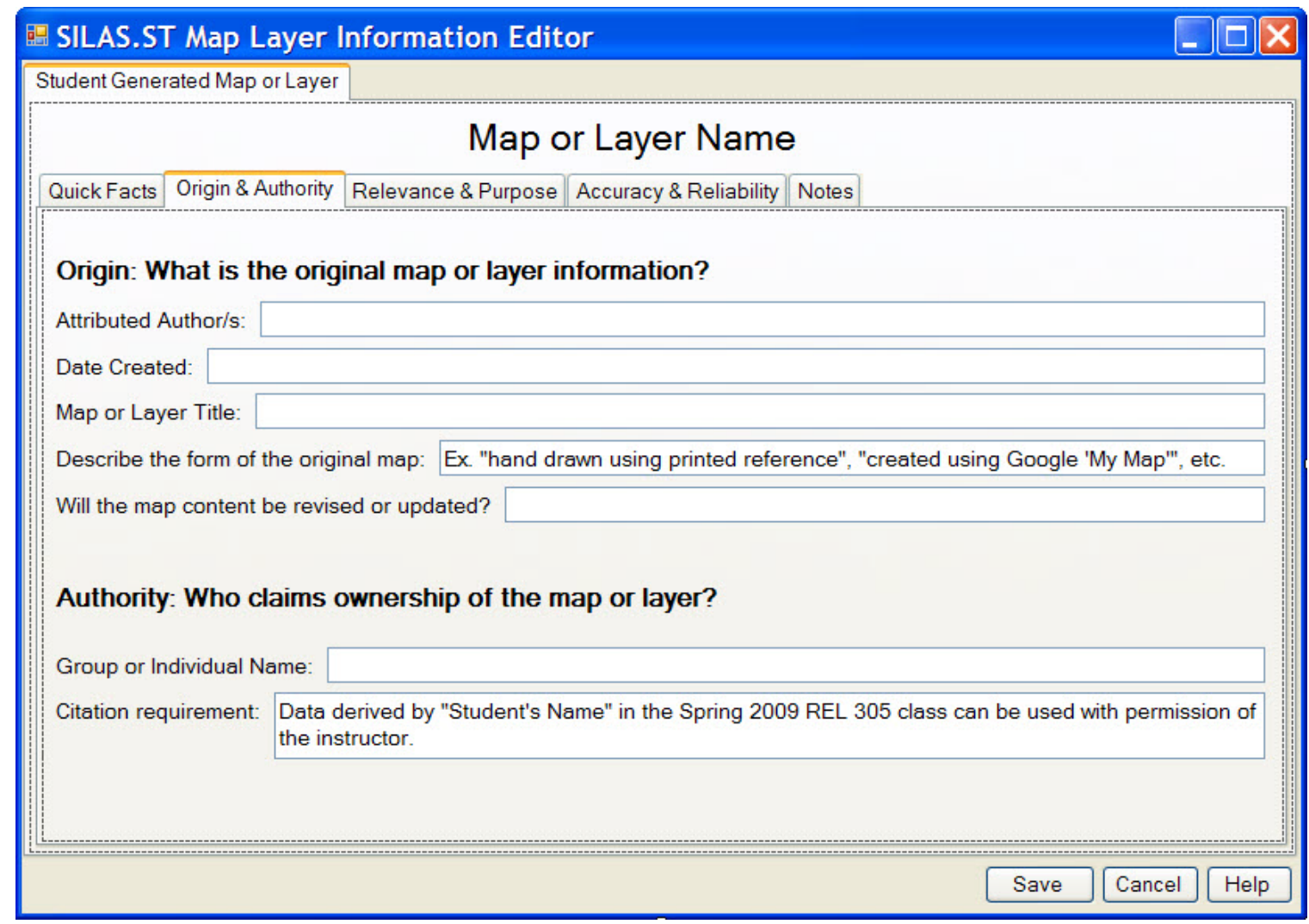

Figure 27 Final SILAS.ST Map Information design, 'Origin \& Authority', student version

The Relevance \& Purpose section (Figure 29) changed little during the revision process, as it was well accepted by both students and my client. Some of the fields will require research by the student, along with their interpretation of the information. I asked that students leave their name and any sources they used so future students can add to the information over time. 


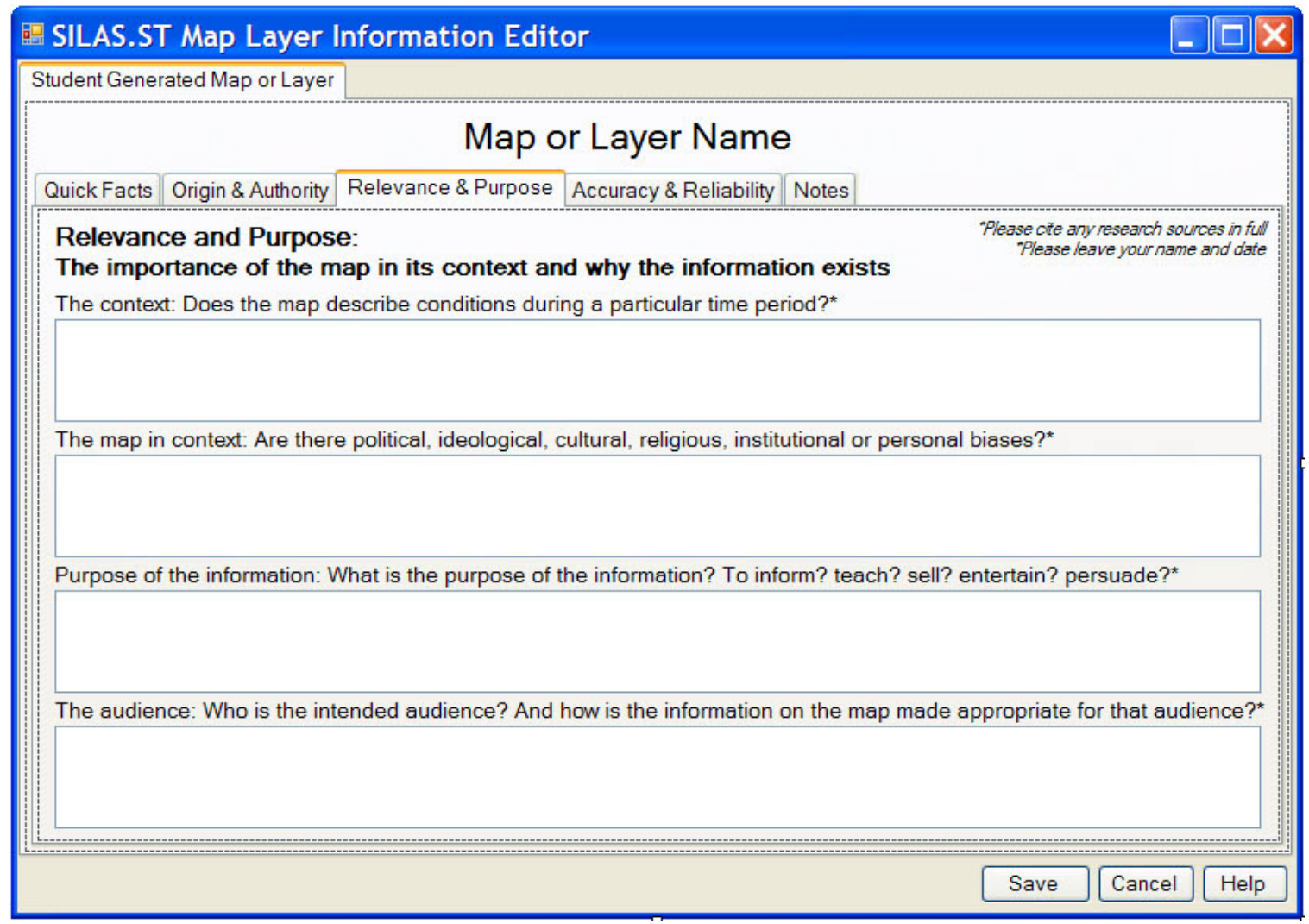

Figure 28 Final SILAS.ST Map Information design, 'Relevance \& Purpose', student version

The Accuracy \& Reliability section (Figure 30) of the metadata was the least user friendly to someone who has never worked with or processed GIS data. In this section students had trouble understanding how to answer my questions and how to go about finding information. They requested that I change some GIS specific language. Taking one student's suggestion, I combined what students had learned in the Relevance \& Purpose section and applied it to determining the "relative reliability" of information. This made the tab more accessible to students. Nonetheless, the field requesting information on data lineage and processing will need to be filled out by someone familiar with GIS. It is important that the documentation of data lineage and processing is written so non-GIS readers can understand how the original information was manipulated to be ready for use with GIS. 


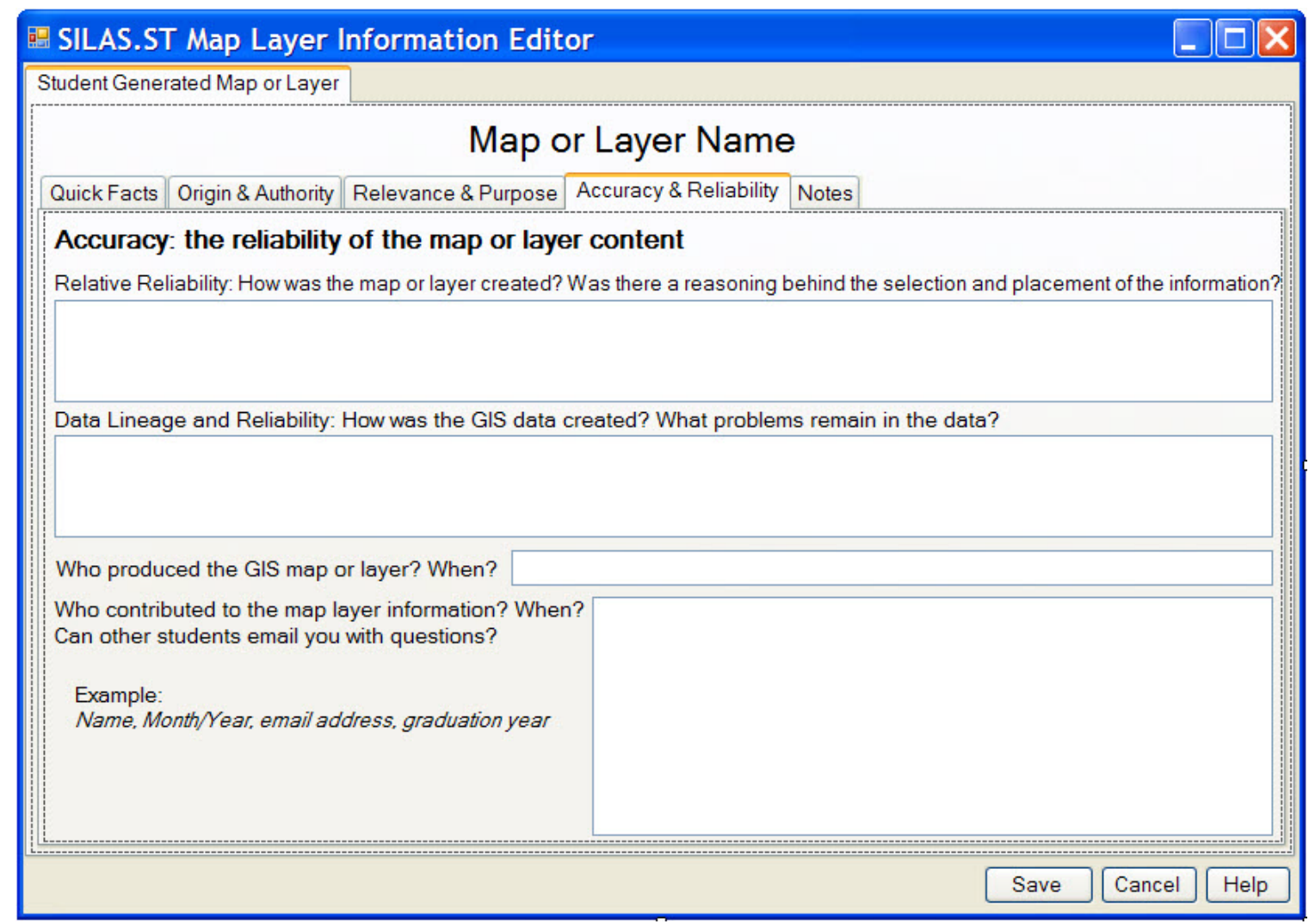

Figure 29 Final SILAS.ST Map Information design, 'Accuracy \& Reliability', student version

Students liked the idea of "signing off" on their contribution to the metadata information. One student suggested that in addition to the optional email address, students include the year of graduation, as Redlands specific email addresses expire a year after students graduate.

The Notes tab (Figure 31) was well received by students and my client, and no additional changes were suggested. This tab, and the Relevance \& Purpose, and Accuracy \& Reliability tabs remain the same for the general map option that is discussed in the next section. 


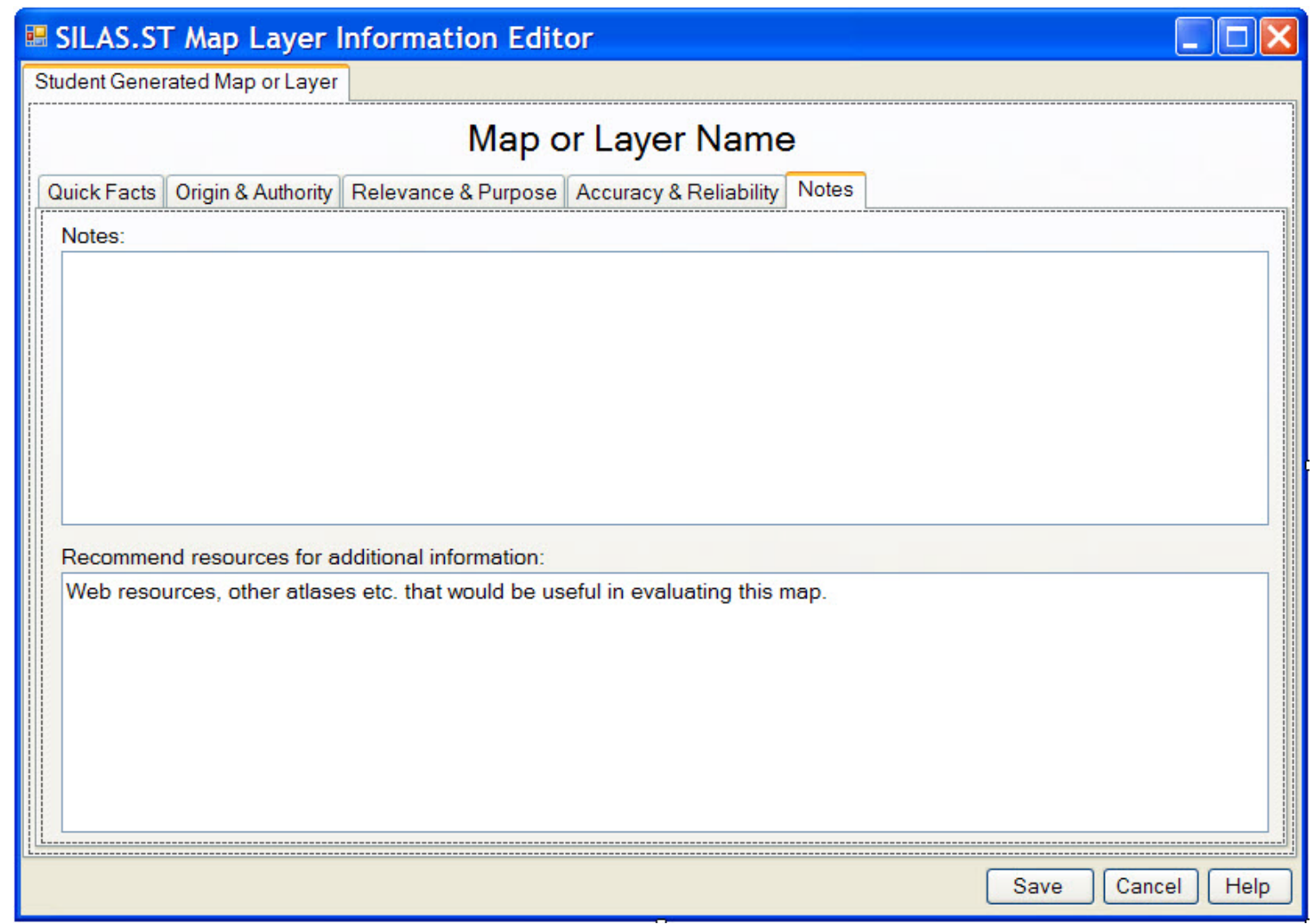

Figure 30 Final SILAS.ST Map Information design, 'Notes’, student version

\subsection{2 “Published” Maps}

Initially I differentiated between student maps and all other maps under the assumption that all other maps, specifically historic maps, would be published. Thus, this section was specifically for "published” maps. However, not all maps that have been preserved come from published sources (Frye, 2009). As noted previously, online collections, such as that of David Rumsey, include "unpublished" maps, in the form of folios and manuscripts. The section title was thus adjusted to "General Maps”, specifically excluding only student-made maps.

The major differences between the two Quick Facts tabs are 1) the addition of a source website and 2) the reference field was moved up to emphasize that the map or layer came from an outside source (Figure 32). 


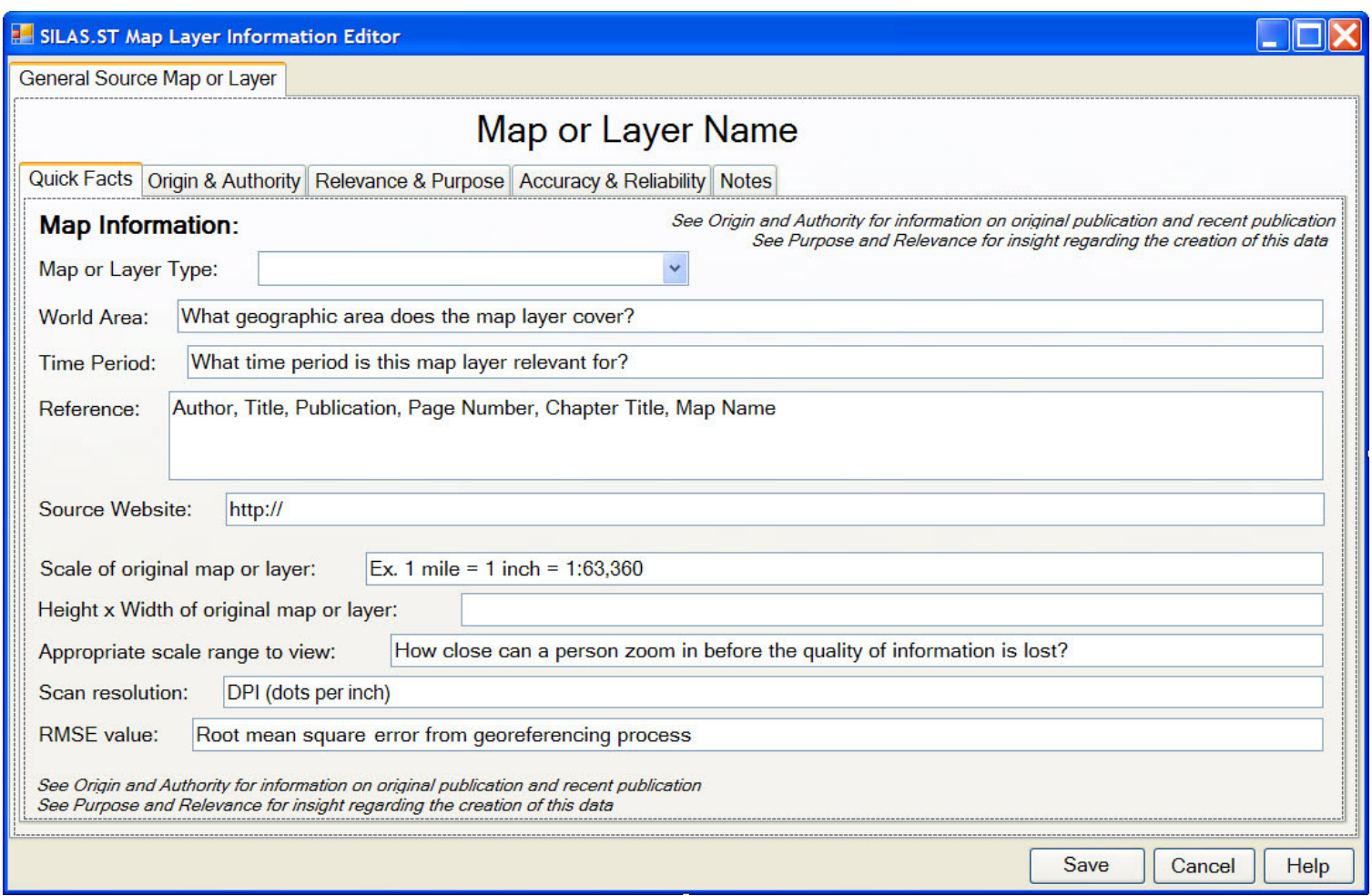

Figure 31 Final SILAS.ST Map Information design, ‘Quick Facts’, general version

The tab that underwent the most changes from the student version was the Origin \& Authority tab, which no longer caters to student-made maps (Figure 33). This tab has place holders for important information that is required in documenting an independent source. This includes reference information for future students to find the original paper or digital source. This tab is also designed to teach students to recognize authority in a more official way, requiring that students identify an ownership statement and its granted use cases. 


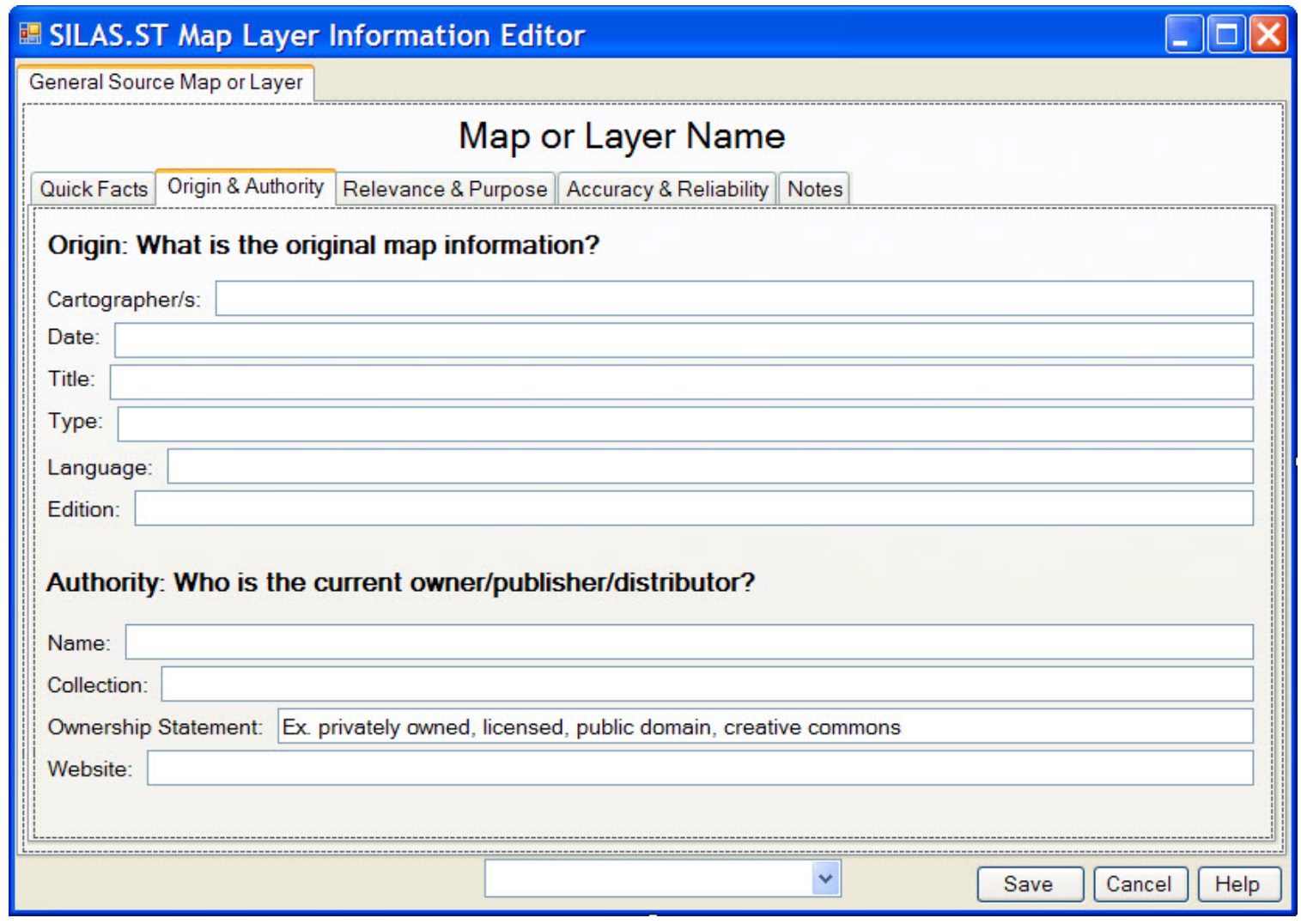

Figure 32 Final SILAS.ST Map Information design, 'Origin \& Authority', general version

The last three tabs-- Relevance \& Purpose, Accuracy \& Reliability, and Notes-remain the same for both types of maps. These last three tabs were appropriate for documenting both student-made and general maps.

\subsubsection{Summary}

Considerable effort went into the design of the metadata presented in this chapter. The final evaluation, however, will occur when students fill out each metadata tab and conduct research for background information and context. This will happen when my client decides to integrate SILAS.ST into her courses.

Given all the consideration that has gone into making the metadata accessible to students, both by using a general (non-GIS) language and balancing the amount of objective and subjective map information they need to research and consider, I am confident SILAS.ST will be a helpful tool for my client. 



\section{Chapter 5 - Implementation}

\subsection{Project Plan}

Over the course of 11 months, I have attempted to follow the various tasks outlined in Chapter 3. The actual schedule of project development is included below (Figure 34). Upon completion of these tasks, the final application and MIP was submitted in fulfillment of the University of Redlands MS GIS Program's requirements by August 2009.

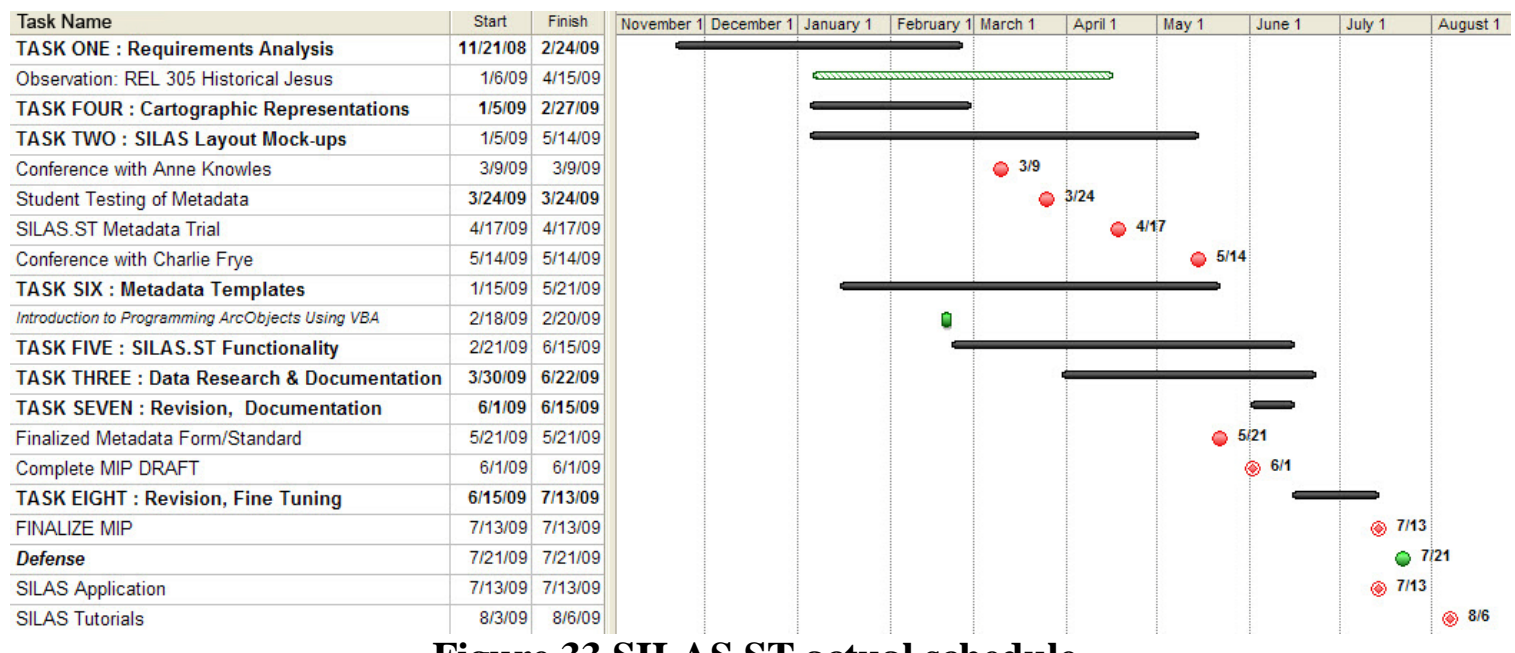

Figure 33 SILAS.ST actual schedule

Changes to the schedule occurred for a number of reasons. During the planning phase of the project I decided to extend the requirements analysis to include my observations from the undergraduate class co-taught by my client and advisor. Opportunities for insightful conversations also arose, such as my conversations with Anne Knowles (Middlebury College) and Charlie Frye (ESRI) that had not been anticipated. Much of the project work that I had planned on completing during the year was minimized due to the demands of the MS GIS program courses and homework. The final timeline shown in Figure 34 reflects a reordering of tasks according to when certain resources became available and the shifts in prioritization that happened as project development got underway.

\subsubsection{Task One: Requirements Analysis}

The first task was to draft a list of desired functionalities to go over with my advisor, along with the technical requirements for each component. After discussions with both my advisor and client, I assembled a prioritized but tentative list of functions. As noted above, to help better understand and address my client's needs, I regularly attended her three-hundred level undergraduate course, Historical Search for Jesus. This course "[explored] the complex social, cultural and historical fabric of the search for the Historical Jesus. Placing canonical and extra-canonical texts in conversation, [students 
located] the Jesus narratives within their Jewish and Greco-Roman rhetorical and imperial frame, and attended to the wide-ranging interpretative agendas that have shaped the reception of 'Jesus' in both ancient and modern 'afterlives' (Larsen, 2009).” This class provided a great opportunity to monitor and gauge the student's abilities to navigate the ArcMap software and decide what components should assume a top priority.

The final assignment for the Historical Search for Jesus course was an atlas page that explored the geographical component of a proposed question that each student independently derived. Students could use any method of creating a map, including digitally produced with ArcMap or PowerPoint or hand sketched. Diana Sinton and others from the University's Information Technology Services (ITS) provided additional help to students if they wanted to produce a map using ArcMap. On the final class day, each student presented his or her map and discussed with the class the accomplishments and challenges of mapping and researching their topic. Ultimately the students did use a variety of methods to create their final maps. This range included hand drawn maps depicted from an oblique angle, to "photoshopped" maps with added overlays (Figure 35).

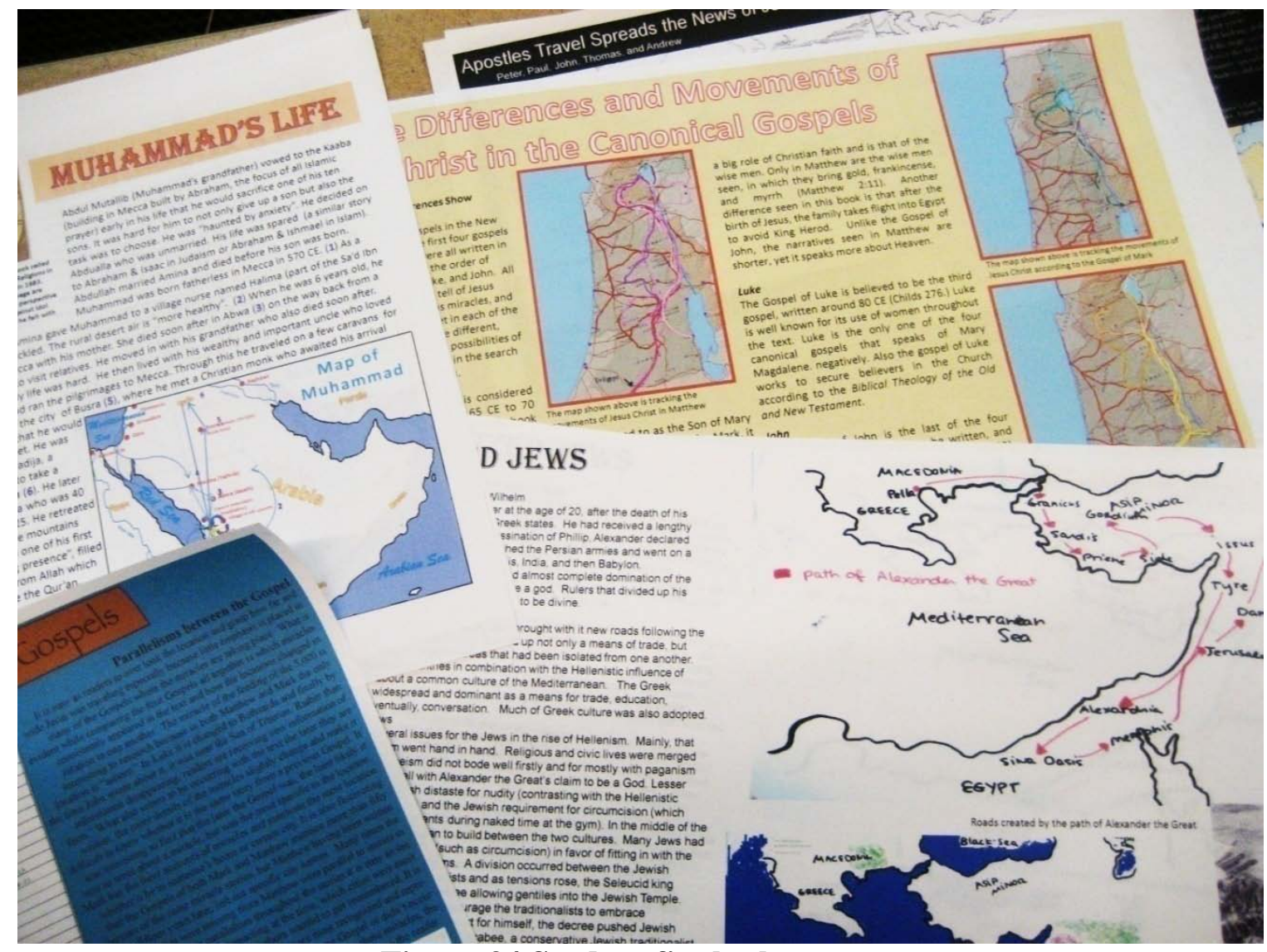

Figure 34 Student final atlas pages

In the end, several students used ArcMap to construct their atlas page, which required meeting with one of the professors to get the necessary data layers. Several students who chose not to use the software expressed frustration at not being able to save the document they had assembled on the workstation computers in Lewis Hall. 
Unfortunately these University computers are refreshed to the standard "image" every night and no files can be saved on the hard drives. Students did have the option of saving their map document on an external drive, but because of the added difficulty of acquiring data and the ArcMap interface not being easy for a first time user, students chose other options for composing their atlas page.

One student chose not to use ArcMap because she had a unique symbolization scheme that she could not replicate using the software. Her symbol was composed of overlapping circles and the relative sizes represented the number of artifacts found from different time periods (Figure 35). She chose to hand draw her map, using a printed base map. For clarity, she later scanned her maps and used photo editing software to type in text.

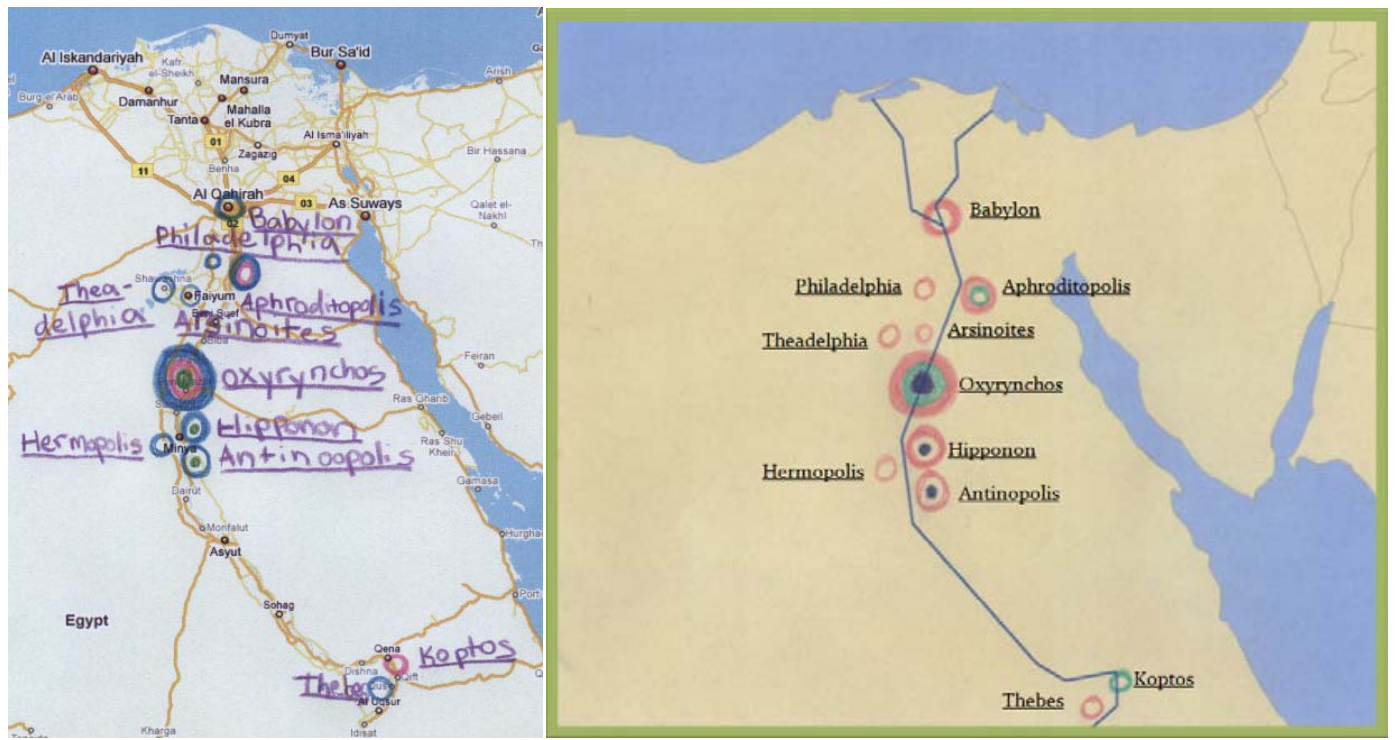

Figure 35 Student's unique symbolization, draft and final map

During the final discussion on the atlas project, many students expressed interest in using the ArcMap software if they were given the same assignment again. They regretted not taking the time during the final weeks to gather the data, compose the page, and bypass the data saving issues.

The observations I gathered from the class helped me to revise my functional and non-functional requirements to focus on where students struggled conceptually with the topics in class and where they ran into problems with the software. I eliminated the wizard idea from my plans because I saw that adding layers and the general setting up of a map document was relatively easy for students. Although the wizard would have made data selection by geographic extent and temporal extent possible, I decided that the acquisition of data would be a good exercise for students. Without the wizard, students could decide for themselves the layers that would compose their maps, and thus evaluate the relative usefulness and appropriateness of the content. Designing and implementing a wizard would have little advantage objective-wise and would not have been of great use for my client. 


\subsubsection{Task Two: Cartographic Representations and Templates}

While Task One was underway and I was observing students, I generated some sample cartographic representations for student use, to determine if they would be a valuable component to the SILAS Study Tool. Students were creative in color coding lines, using very basic symbol options for different segments of the journey, and from this observation, I created two line symbols that would be useful for mapping journeys (Figure 36).

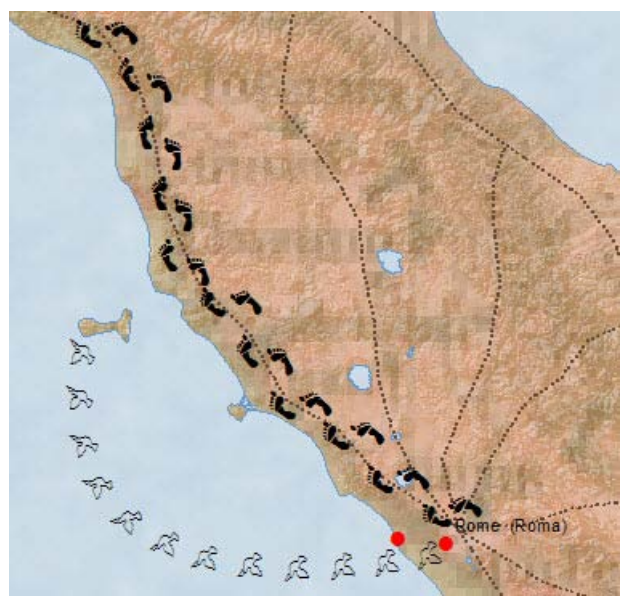

Figure 36 Custom symbols for journeys

This task was later moved to a lower priority as the project was underway, due to time and my vested interest in the metadata component of the project. The goal of the cartographic representations was to represent spatial uncertainty using symbols that could be adjusted to show varying levels of certainty (such as the floating point in Figure 37).

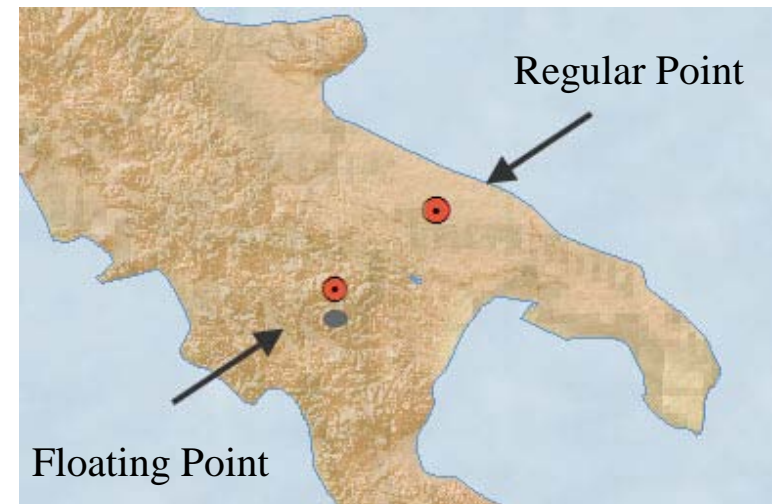

\section{Figure 37 Custom 'floating' point marker for places compared to a regular point marker}

I realized more information could be interpreted by the student from the metadata, and only visualizing the data would not be an effective way of getting at the pedagogy behind the uncertainty of historical data. Cartographic representations of uncertainty are a 
complex topic, and I would not have the time to serve the technique justice. I recommend this as a future project.

I also created three templates that can be accessed through the Create Atlas toolbar (Figure 38). These map templates were designed after viewing my client's REL 305 atlas assignments. There were common organizational themes amongst the map layouts, so I designed three templates for future students’ use.
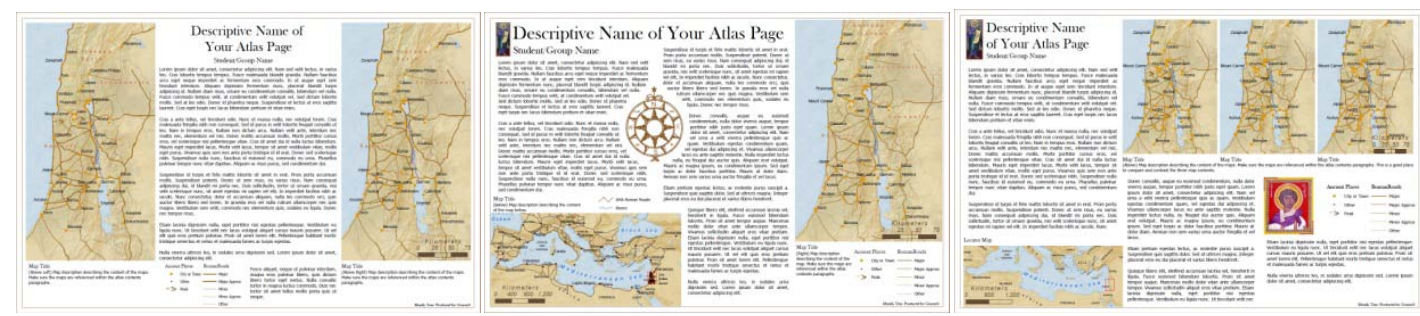

Figure 38 Atlas templates

\subsubsection{Task Three: SILAS.ST Layout Mock-ups}

Based on the requirements analysis and observations from my client's course, I created four different toolbars containing a variety of commands. They used the common out-ofbox commands but I carefully renamed and reorganized the commands to be better grouped on the toolbars. The Explore Data toolbar fulfilled many of the functional requirements outlined in my requirements analysis (Figure 39).

Explore Data

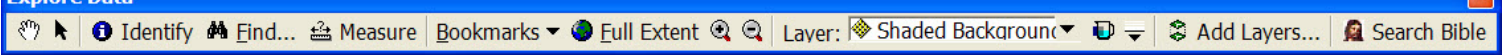

Figure 39 Final SILAS.ST ‘Explore Data’ toolbar

This toolbar contains full names of the commands, except for the transparency and swipe tools. The Add Layers command opens up the database with all the data layers, and the Search Bible opens up the SILAS Scripture Search, in which students can enter in names and places and full passages from the NRSV Bible are returned.

The Hand Draw toolbar helps students learn how to edit features and attributes (Figure 40). Most of the commands on this toolbar are familiar for students accustomed to PowerPoint or any software in which they can add drawn graphic elements. Students have the option to save their drawings as a layer for future use outside of their current map document.

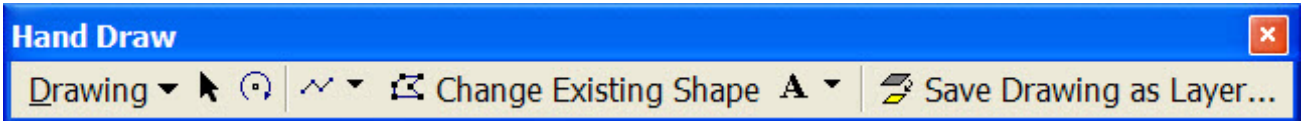

Figure 40 Final SILAS.ST 'Hand Draw' toolbar

One use case I identified for SILAS.ST is for students to create an "atlas page” of layers and drawings that they have compiled. Using the basic out-of-box map layout commands, I assembled a Create Atlas toolbar that contained the most common commands a student might use in creating a map for print (Figure 41). 
Figure 41 Final SILAS.ST ‘Create Atlas’ toolbar

One of the confusing aspects in ArcMap is switching the View between Data and Layout; the icon to indicate the switch is not very obvious. With the Create Atlas toolbar, students access the Layout View by clicking Atlas View. To switch back to the Data View, they click the Edit Map Content button.

The SILAS.ST Map Information toolbar does not use out-of-box ArcMap functions, instead there are custom buttons (using VB.Net) for viewing a custom stylesheet and editing metadata for any selected data layer in the table of contents (Figure 42).

SILAS.ST Map Information

$x$ View Map Information Edit Map Information

Figure 42 Final SILAS.ST 'Map Information’ toolbar

Throughout the process I shared and discussed with my advisor and client the content, titles and prompts contained within the metadata. Midway through the process I also had conversations with Knowles and Frye. Their perspectives were invaluable for the completion of Task Six.

I enrolled in the ESRI Instructor-led Introduction to ArcObjects (24 hours, on ESRI campus 2/18/09-2/20/09) and in addition completed the Getting to Know ArcObjects: Programming ArcGIS with VBA (30 hours, self study), before going into Task Four.

\subsubsection{Task Four: Student Testing / Metadata Temples}

I initially thought I had enough time to put together a functioning version of SILAS.ST before the undergraduate students left for summer break in May. However, the date for the evaluation of the metadata was moved earlier, and this moved the task forward from sixth to fourth. While some students were on campus for May term, my client's course ended mid-April, and her students were the ideal candidates for testing my prototype. The other conflicting factor was the annual meeting of the Association of American Geographers (AAG) during the last week in March; it would be valuable to have some proof of concept in regards to my metadata design for my presentation at the conference. To accommodate the conference and to avoid conflict with the final examination period of my client's course, we moved the evaluation to the last week of March. I had hoped to test all components within a regular ArcMap interface, but because of the earlier-thanplanned evaluation day, I chose to have students evaluate a prototype of my metadata. As discussed earlier, over the course of an hour I gave thirteen students a quick introduction to the purpose of the metadata and then let them evaluate and critique my work. A more detailed discussion and outline of the testing exercise is contained in section 4.4. 


\subsubsection{Task Five: SILAS Functionality}

I began testing the functionality of SILAS.ST after I completed the ESRI three day Instructor-led course Introduction to Programming ArcObjects Using Visual Basic for Applications (VBA). While the course content was still fresh, I further customized the buttons and the metadata form. I quickly found out that I was not prepared to complete some of programming I had set out to do, such as making metadata viewable and editable from within ArcMap. I initially sought help though the ESRI ArcGIS Desktop Discussion Conference Forum, which had a thread about implementing the IMetadataViewWindow Interface. The forum did not have a viable solution to the problem, so I contacted Steven Rozic of ESRI, who helped me with the programming. His solution worked perfectly, and he later contributed his code to the forum (ESRI, 2009).

The development of the Metadata Editor and stylesheet involved intense programming. I later found out that the metadata editor could not be completed using VBA as the underlying Component Object Model (COM) interface standard was nearly obsolete, and creating an ActiveX DLL was impossible with my versions of software. Additional help was required for programming, as the suggested alternative was to create a 'COM Visible' project using Visual Basic.NET (VB). I worked with Nathan Strout, of the Redlands Institute, who guided me through the process.

This was a larger task than I had anticipated. Making the project operable with ArcMap was not as straight forward as I had envisioned. Halfway through the process, I learned that the workstation lab computers would be installing the newest update of ArcMap, 9.3.1, while I was working with 9.3.0. Because the new version was not fully understood, I used a virtual machine (VM) to install 9.3.1 to a copy version of 9.3.0. I then tested my documents and templates, along with the VB project, to check for compatibility. Once tested, I updated to 9.3.1 on my laptop. The update was necessary to ensure compatibility on the lab workstations, and the update did not affect the VB project. By the end of this task, I had a functioning metadata editor and stylesheet on my laptop, but not on the Lewis Hall lab computers.

\subsubsection{Task Six: Data Research \& Documentation}

I included only sources that were representative of historical GIS projects in the final SILAS.ST database. To better showcase the interoperability of the metadata, I chose to add 1) a map from the David Rumsey collection, 2) a scanned map from an atlas, and 3) one map produced digitally by a student. Once the SILAS.ST metadata editor was complete, I created and documented the information for all sources in metadata, paying attention to detail and qualitative information that is useful for history students using the data. The metadata content and format is discussed at length in Chapter 4. The metadata I completed will be used as examples for my client's students in future course work.

I added to the original SILAS database, though I did not fill out the metadata for all the feature classes, due to time constraints. It will be a good practice for students to fill out the information, as my predecessor left enough information to trace back to the source of the data. Below is a table detailing what is included in the SILAS.ST database. 
Table 12 SILAS.ST Database Contents

\begin{tabular}{|c|c|c|c|c|}
\hline & Contents & Туре & Origin & Description \\
\hline \multirow{10}{*}{ 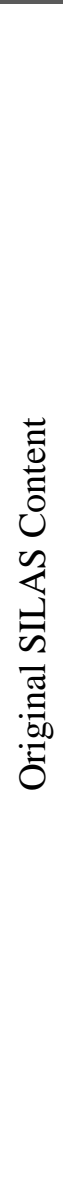 } & Rivers & Vector- Lines & $\begin{array}{l}\text { Unpublished } \\
\text { Material }\end{array}$ & Sections of the Jordan and Nile Rivers \\
\hline & Boundaries & Vector- Lines & $\begin{array}{l}\text { Unpublished } \\
\text { Material }\end{array}$ & $\begin{array}{l}\text { Regional boundaries (including the } \\
\text { boundary of the Roman Empire) }\end{array}$ \\
\hline & $\begin{array}{c}\text { Bodies of } \\
\text { Water }\end{array}$ & $\begin{array}{l}\text { Vector- } \\
\text { Polygons }\end{array}$ & $\begin{array}{c}\text { Unpublished } \\
\text { Material }\end{array}$ & Oceans seas as well as inland lakes \\
\hline & $\begin{array}{l}\text { Ancient } \\
\text { Places }\end{array}$ & Vector- Points & Barrington Atlas & $\begin{array}{l}\text { Includes } 40 \text { cities, towns, regions and } \\
\text { mountain peaks that are mentioned in the } \\
\text { four gospels as well as } 64 \text { other important } \\
\text { places named in maps included in the } \\
\text { Harper Collins Study Bible }\end{array}$ \\
\hline & $\begin{array}{l}\text { Palestine } \\
\text { Roman } \\
\text { Roads }\end{array}$ & Vector- Lines & Barrington Atlas & $\begin{array}{l}\text { Roman roads in the area of Palestine } \\
\text { digitized at the 1:500,000 scale from maps } \\
\text { in the Barrington Atlas of the Greek and } \\
\text { Roman World }\end{array}$ \\
\hline & $\begin{array}{l}\text { RE Pop } \\
\text { Places }\end{array}$ & Vector- Points & $\begin{array}{l}\text { ESRI Data \& } \\
\quad \text { Maps }\end{array}$ & $\begin{array}{l}\text { Contains over } 12,000 \text { modern populated } \\
\text { places within the extent of Roman Empire } \\
\text { that were clipped from “ESRI Data \& } \\
\text { Maps } 2007 \text { World, Europe, United States, } \\
\text { Canada and Mexico” }\end{array}$ \\
\hline & Countries & $\begin{array}{l}\text { Vector- } \\
\text { Polygons }\end{array}$ & $\begin{array}{l}\text { ESRI Data \& } \\
\text { Maps }\end{array}$ & Modern country boundaries \\
\hline & $\begin{array}{l}\text { RE Shaded } \\
\text { Relief }\end{array}$ & Raster & $\begin{array}{l}\text { ESRI Data \& } \\
\text { Maps }\end{array}$ & 90m SRTM shaded relief image \\
\hline & $\begin{array}{c}\text { Europe } \\
\text { EarthCover }\end{array}$ & Raster & $\begin{array}{l}\text { ESRI Data \& } \\
\text { Maps }\end{array}$ & $\begin{array}{l}\text { 150m EarthSat NaturalVue Global Landsat } \\
\text { mosaic of Europe }\end{array}$ \\
\hline & $\begin{array}{c}\text { Africa } \\
\text { EarthCover }\end{array}$ & Raster & $\begin{array}{c}\text { ESRI Data \& } \\
\text { Maps }\end{array}$ & $\begin{array}{l}\text { 150m EarthSat NaturalVue Global Landsat } \\
\text { mosaic of Africa }\end{array}$ \\
\hline \multirow{3}{*}{ 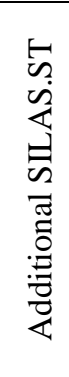 } & $\begin{array}{l}\text { Diaspora } \\
\text { Places }\end{array}$ & Vector- Points & $\begin{array}{l}\text { Student } \\
\text { Produced }\end{array}$ & $\begin{array}{l}\text { Student map of Diaspora Places as } \\
\text { gathered from three sources, originally } \\
\text { made in Google Maps }\end{array}$ \\
\hline & $\begin{array}{l}\text { RE Roman } \\
\text { Roads }\end{array}$ & Vector- Lines & $\begin{array}{c}\text { Ancient History } \\
\text { Atlas }\end{array}$ & $\begin{array}{l}\text { Roman roads in the area of the Roman } \\
\text { Empire, digitized at the } 1 "=200 \text { miles } \\
\text { scale from a map in Ancient History Atlas }\end{array}$ \\
\hline & $\begin{array}{l}\text { RE Greatest } \\
\text { Extent }\end{array}$ & Raster & $\begin{array}{l}\text { David Rumsey } \\
\text { Map Collection }\end{array}$ & $\begin{array}{l}\text { David Rumsey Map Collection map } \\
\text { showing the greatest extent of the Roman } \\
\text { Empire }\end{array}$ \\
\hline
\end{tabular}

All of the data is on an ArcSDE Enterprise database, which allows multiple students to simultaneously use and edit the data. Because the LENS server does not support ArcSDE, the ArcSDE database is hosted on the Redlands Institute server (Figure 43). Because of the few changes between the contents of the original SILAS and SILAS.ST database, I added the new feature classes and raster imagery to the original database created by Benzek. All of the other components are accessible on the LENS server, which is a shared folder location that faculty can access from across campus. During a semester course, students can access the data sets that the professor has stored in the ArcSDE database. Students have the option to save their map documents to the LENS server or 
personal thumb drives. Moving and saving data files will give students good practice with file management.

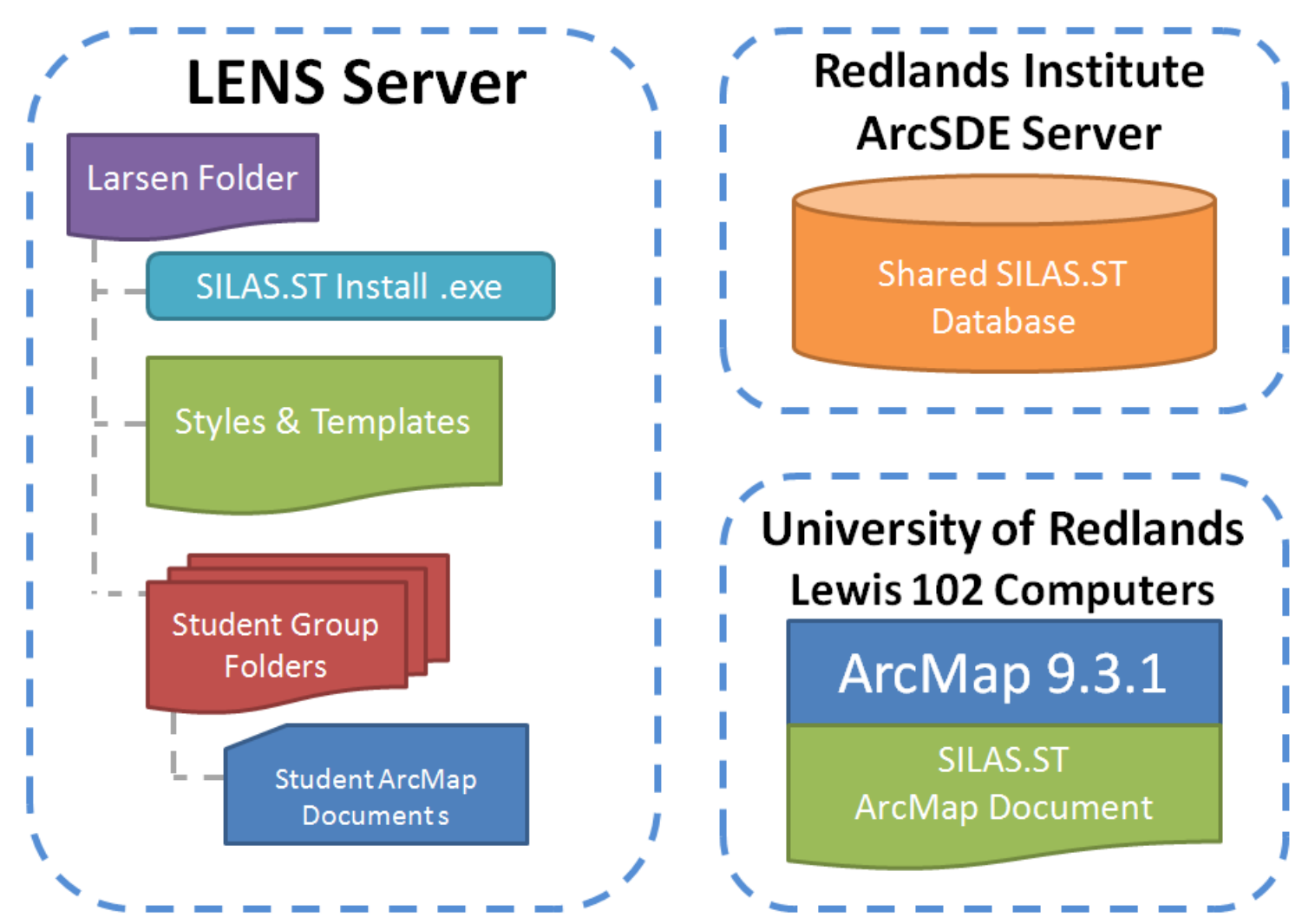

Figure 43 Final SILAS.ST system architecture

During the course of the data research and documentation, I asked for publisher permission to derive map information from their published maps. I specifically stated that I was a master's student at the University of Redlands and that all data derived from the specified maps will be used and solely available to University of Redlands students. The published maps would be used as authoritative base maps in ArcGIS for my master's thesis project. I also specifically stated that all data derived from these maps would be fully referenced with full copyright attribution in the metadata accompanying the datasets I would create. I received only one response, declining my request. I then resubmitted my letter, clarifying and reducing my request. I had not heard back by the time I had finalized my database. (See Appendix C for an example of my permissions request)

\subsubsection{Task Seven: Revision, Documentation}

Once the metadata editor project was completed and functioning on my laptop, I collected the other components of SILAS.ST (stylesheet, custom map document, styles, templates) so Nathan Strout could compile them into an install executable file. This file will be available on the LENS server, and will install all the SILAS.ST components on the Lewis Hall lab computers. 
I also had meetings with David Smith, who was working with the newly created LENS server. We constructed a folder system that would contain all of the SILAS.ST components and student folders. When my client is ready to use SILAS.ST, she will need to meet with a University of Redlands Help Desk staff member to set up group folders for her students.

Once the ArcSDE Enterprise database was updated, I configured the linkages between the student map document and database.

\subsubsection{Task Eight: Revision, Fine Tuning, Documentation}

Nathan Strout had completed the install file and I tested it on one of the Lewis Hall computers. However, due to insufficient privileges of the installer, I was unable to install the application. Coordination with ITS to make SILAS.ST part of the lab image is necessary. That said, I have tested the install on a virtual machine on my laptop without any glitches. I finalized my MIP and turned it in to my advisor before the ESRI User Conference in San Diego.

Before I left the program, I held a meeting with David Smith to demonstrate the install on the server. A workflow diagram was assembled to illustrate the necessary proceedings for a successful classroom implementation. SILAS.ST will need to be added to the campus computer image, or made available via a virtual machine. Some adjustments to the install on the server may need to be made to accommodate the different system architectures. I provided my client the contact information for each person at the University of Redlands that will act as a SILAS.ST support member. When my client is ready to implement any of the various components of SILAS.ST the necessary information is available so SILAS.ST can be implemented in time for her courses. 


\section{Chapter 6 - Results and Analysis}

\subsection{Metadata Design Analysis}

\subsubsection{Evaluation by the Manager of Instructional Technology and a Consultant in GIS and Mapping}

To evaluate the SILAS.ST metadata efficacy, I scheduled a sit down evaluation with Catherine Walker, University of Redlands’ Manager of Instructional Technology Services, and David Smith, University of Redlands' GIS and Mapping Support Consultant. To measure the value of the metadata, I had them complete the same series of questions posed to the undergraduate students in Chapter 4.4. However, to get a quantitative gauge of the efficiency of the metadata content I had them answer the questions on a scale of one to ten for each tab in terms of their agreement with the question (Figure 44), and gave them room for suggestions and comments to explain their ranking. An example of the evaluation format is included in Appendix B.

$\begin{array}{cccccccccc}1 & 2 & 3 & 4 & 5 & 6 & 7 & 8 & 9 & 10 \\ \text { Strongly Disagree } & & & & \begin{array}{c}\text { Disagree } \\ \text { Somewhat Agree }\end{array} & & & & \text { Strongly Agree }\end{array}$

Figure 44 Evaluative quantifier scale

The purpose of the evaluation was to provide feedback on the contents and questions within the metadata and if it will get the user thinking about the challenges of documenting historical sources. I wanted to know if my organization and descriptive fields made sense to someone who had not seen this custom metadata before. The suggestions and comments from these two individuals with experience in GIS technology and instruction helped establish the value of this project as a teaching tool.

I introduced the two volunteer evaluators to my project, describing the aim of the metadata, the audience, the nature of the candidate map information sources, and the purpose of the metadata format. I led them through the evaluation form, and pointed out that each tab in the metadata should be evaluated with its own evaluation form of five questions and associated scale of agreeableness. Each evaluator had their own copy of color screen captures of the metadata fields. Once I was done introducing the tasks, I stayed in the conference room for individual questions, as the final metadata they were evaluating represented the cumulative effort of my research and observations. Over the course of an hour and a half, I entertained questions as the evaluators made their way through the graphic images of the metadata and the evaluative forms.

Both evaluators were very thorough in going through the metadata forms, and all of their questions targeted areas in the metadata that were known "trouble spots" and open to multiple interpretations. In Table 13 and Table 14, I calculated the mean score of the individual content tabs, and questions, summarized by version (Student Made or General Maps) with a cumulative mean score. 
Table 13 Evaluation Summary Results, by Tab

\begin{tabular}{r|c|c|c} 
Tab & Student & General & Both \\
Quick Facts: & 8 & 8 & 8 \\
\hline Origin \& Authority: & 7.6 & 8.6 & 8.1 \\
\hline Relevance \& Purpose: & 8.7 & 8.6 & 8.65 \\
\hline Accuracy \& Reliability: & 7.35 & 7.55 & 7.45 \\
\hline Notes: & 9 & 8.7 & 8.85 \\
\hline
\end{tabular}

From the evaluation questionnaire, the Accuracy \& Reliability tab received the lowest score, because of misleading language of "reliability" and "accuracy". Because of the language, the evaluators were confused about the type of information required to fill in the fields. Differentiating between reliability and accuracy was not immediately clear, and they worried that students would not know how to discuss reliability or data accuracy. I explained that this section would need to be filled out by someone who knew GIS, and they suggested that there be additional information or prompts to help clarify these two sections. It became clear that my client will need to provide her students with a lesson on "accuracy" in historical research for this section to make sense, and for them to take away a qualitative understanding of the historical data in GIS. This section attempts to address a complex problem that emerges when users try to bring historical sources into GIS, and I was not surprised that the evaluators critiqued this section quite heavily.

Also from Table 13, the student version of Origin \& Authority received a significantly lower score than the General Maps version. What differed between the student-made map and general map was the recognition of the originator. I stated on the opening slide that student map was compiled by a student, while a general map did not have any of its information altered by a student. Creating this section I imagined a student would use multiple sources to compile their map, to make it more comprehensive than any one of the original sources, and that the distinction between the two would be easily recognized. My evaluators imagined a student adding minimal alterations or additions, and because of this, they were not sure if ownership was appropriate in this student section. They were also unsure if any of the identifiers in this section (Name, Title, Date) would reflect the historical sources used by the student compiling the map. Ownership of information, especially historical geospatial information, is challenging to define. Origin \& Authority for the general maps section was clearer to the evaluators, because the origination of the information was more straightforwardly identified.

Other suggestions from my evaluators regarded standardizing the entered information, either with specific examples, or drop-down menus that would contain select choices. David Smith, in particular, saw value in the metadata being searchable, which is a desired trait of metadata. While I agree with his perspective, for the purposes of this project, the open-ended format of the fields is more in line with the practices of humanities students. In turn, classifying and standardizing information entry is more appropriate for data intensive projects. For historical research, when data can be scarce and imprecise, the open-ended format allows students to include all relevant information.

Many of the questions raised during the evaluation could easily have been mitigated had I enabled access to a table with all definitions and descriptions of the fields, similar to the table composed for the ECAI metadata standard in Appendix A. This table of 
SILAS.ST Map Information specifications is appropriately called up when students click the Help button on the bottom of the metadata form, to the right of the Cancel button (Figure 33). This would have provided additional help when the evaluators were confused on the date of the original map in the student section of the Origin \& Authority. Was the date in reference to the date of the data sources, or the date compiled by the student? During our session I was able to answer these questions directly, though I realize I could have shared this table of definitions earlier.

I would like to comment on a trend I noticed between the student-made map section and the general maps section. When calculating the mean values of the individual questions (Table 14), the student section consistently scored lower than the general map section, and this reflects that the questions were originally written for all map types, a format I was testing during the student evaluation. It was interesting to me that the context of "Student Made" altered the evaluator's interpretation of the questions. As such, I would suggest a revised questionnaire format for future evaluations. I also understand how the SILAS.ST Map Information is better suited for historical maps, for example those from the David Rumsey Map Collection, rather than modern or recently published maps depicting historic information. A modern map naturally exudes more authority, because users assume it represents a superior quality of information, even if the modern map depicts historical information.

Table 14 Evaluation Summary Results, by Question

\begin{tabular}{c|c|c|c}
\hline $\begin{array}{c}\text { Question } \\
\begin{array}{c}\text { Would you be able to fill out } \\
\text { all of these fields? }\end{array}\end{array}$ & Student & General & Both \\
\hline $\begin{array}{c}\text { Do these fields help you } \\
\text { understand the map? }\end{array}$ & 8.25 & 8.35 & 8.225 \\
\hline $\begin{array}{c}\text { Would you keep the order of } \\
\text { the content the same? Does } \\
\text { this form make sense as is? }\end{array}$ & 8.35 & 8.6 & 8.475 \\
\hline $\begin{array}{c}\text { Does this form make sense } \\
\text { when you're documenting a } \\
\text { "historic" map? }\end{array}$ & 8.05 & 8.2 & 8.125 \\
\hline $\begin{array}{c}\text { Does this form make sense } \\
\text { when you're documenting a } \\
\text { modern map of historic } \\
\text { information? }\end{array}$ & 7.9 & 8 & 7.95 \\
\hline
\end{tabular}

I was pleased that the questionnaire used to evaluate the metadata provoked so many questions. During the evaluation, my evaluators recognized early on that creating a metadata standard for historical research constituted a very big challenge. 


\subsection{SILAS.ST Analysis}

\subsubsection{Client's Reflection and Recommendations}

After this paper's defense, I had to opportunity to sit with my client and hear her reflections regarding the project and final application. She is excited to use the customized toolbars and ArcMap document, which is a big improvement to the ArcMap document and data her students were using this last spring. The time trade-off for learning these tools and applying them is high. Thus the immediate use of SILAS.ST will be for introductory lessons, specifically using the functions on the Explore Data and Hand Draw toolbar. These introductory lessons will contribute to students' conceptualizing of space, as they learn how to organize information in layers. From there, Professor Larsen is eager have students add data to the main database. She hopes that over time additional data will make SILAS.ST a self propagating study tool that will allow students to overlay their own layers of information.

Professor Larsen appreciated how the metadata identifies and qualifies map sources. She applauded how the metadata is applicable to textual sources, making history more tangible. The SILAS.ST method of citation is a healthy practice of combining visual interaction and critical evaluation. She sees the SILAS.ST metadata being an invaluable component once more data is available in the main database. Until then, the metadata content and organization will be useful for when she teaches with historical sources. A true evaluation of the project's metadata standard will emerge once my client has used the application in her courses.

\subsubsection{Roadblocks}

Reflecting back on the implementation of SILAS.ST, there were a few roadblocks encountered when trying to install and share the SILAS.ST application on the University of Redlands network and Lewis Hall lab computers. For SILAS.ST to be functional and accessible on University computers, the necessary privileges must be granted by the systems manager and Information Technology Services (ITS).

The LENS server requires permission to access and edit the content of the folders on the server. The server administrator can grant read and write abilities to specific people using their Redlands network login. Setting up individual University student access to the server will require assistance from the University Help Desk.

Additional unforeseen difficulties arose when trying to install SILAS.ST on the Lewis Hall lab computers. Because of insufficient privileges to access the directory, the installer created by Nathan Strout could not successfully install. Coordination with the University’s ITS Academic Technical Services Manager to include the SILAS.ST application on the University lab image will need to start soon in order to get SILAS.ST up and running.

I did not foresee administrative and access issues when designing and implementing SILAS.ST for my client. I recommend to future students with similar projects that will be implemented on the University of Redlands network to start coordinating with ITS early on. This is necessary because ITS updates their image every summer. Additional coordination with Nathan Strout may be necessary to update the install so it is compatible with the University Network. 


\section{Chapter 7 - Conclusions and Future Work}

\subsection{Conclusions}

Is GIS an appropriate tool for humanities research? A common pitfall in humanities based GIS projects is that the chosen tools and nature of GIS software often shape the researcher's own agenda. Humanities scholars who begin to use geospatial technologies recognize that there needs to be a clear and justifiable reason to use GIS because it requires such a high level of expertise (Jessop, 2008). Professor Larsen uses geography and derivatively mapping tools to push her students to read ancient texts with a critical eye. Professor Larsen recognizes that having MS GIS students customize GIS can help her meet this agenda. The final SILAS.ST application presents an appropriate tool for humanities research, and meets the requirements of my client's desire to teach history by incorporating visual sources.

As noted earlier, a real evaluation of the project will only come about once my client has used all the components of SILAS.ST in her courses. In the near future, because of the high time trade-off, the customized toolbars and interface will have the most immediate impact. SILAS.ST will initially be used for introductory lessons, like those covered in her course Historical Search for Jesus, because of my clients familiarity with the exercises and their learning benefits. As Professor Larsen adds more data sources to the SILAS.ST database, more advance lessons will incorporate the metadata and atlas functions. She sees the SILAS.ST metadata as a valuable pedagogical tool for bringing to light the ambiguous nature of accuracy and uncertainty in historical research.

\subsection{Future Work}

\subsubsection{Historical GIS Course}

A suggested future course, to be taught by a University of Redlands faculty member and possibly co-taught by an MS GIS faculty member, is a course on Historical GIS. This course would be designed for undergraduate humanities students wanting to learn how to interpret historical sources in GIS, utilizing the technology available at the university. This course would emphasize the processing of data from a primary or secondary source and then bringing it into SILAS.ST or ArcMap. This course would bring to light the processing that data must undergo to be "GIS ready" and allow students to explore firsthand how historical accuracy in GIS is limited, relative to the primary source of the map information. Students would learn how to communicate this in the SILAS.ST metadata. This would be an appropriate introductory GIS course, and a very practical and hands-on way of learning how to digitize sources and understand the limitations of accuracy. This would appeal to students interested in history, visual culture, modern day culture/media, information technologies and possibly geography and/or psychology.

An introductory lesson would have students hand draw a geographic location that they personally know well, such as a mental map of their home town, state or country. They would then explain how they came to know that geographic area. Whether it was from driving/walking/hiking through that space that helped them "learn" the area and its 
features, or if they had just studied it from a pre-existing map. They might take note of why they selected a particular area, and how they chose to represent different features. Once complete, with labels and geographic features (streets, mountains, buildings, to the best of their knowledge), students would scan their map. Each would be encouraged to scan multiple times, playing with the DPI and other scan quality factors. The goal would be to determine "the best" scan resolution (drawing quality preserved, minimal file size?) after viewing the multiple files.

Once the optimal scan resolution was achieved, students would learn to georeference their map to make it "GIS ready." Hopefully their chosen geographical extent would overlap with other existing spatial data sets that would be used as a reference. Students would learn that their hand drawing will never perfectly match up with the commercial data that arrives with GIS software. However, through georeferencing students would note accuracy as it is measured through RMSE. Students might be invited to reflect on how the georeferencing warped or distorted their hand drawing (including the outline, labels and geographic features). This would be an appropriate time to discuss RMSE and what the values mean.

Students could then learn to digitize their map, deciding which vector types best fit their map (a line or polygon for a river, a point or polygon for a city center). Students might also try to symbolize their vector features.

To finalize this first lesson, students would assemble a map in ArcMap that included the scanned image of the original, a screen shot of the georeferenced image and a final layout of the digitized map. The students would write about the quality and accuracy of the three maps, and how the information changed through the process. What makes a good map? How is the content information affected through the process? How is scale relevant to the map, both before and after processing? How could this apply to a historical map?

For subsequent assignments, students might download and georeference images from the David Rumsey Map Collection, taking advantage of the creative commons license that allows images to be used in this fashion.

Ideally students would eventually supply their own historic maps, drawn from books or atlases from the school library. Students could be assigned a cartographer, a specific time period, or topic that spans multiple time periods. They could then go through the entire process of scanning, georeferencing and digitizing, and reflect on the "accuracy" of their maps. Does a certain topic for a specific audience warrant more quality or accuracy in the map? Are maps from a certain time period differently "accurate"? The SILAS.ST map information would help students think about these kinds of questions.

Suggested Reading:

Maps in those days: Cartographic methods before 1850 by J.H. Andrews (2009)

How to Lie with Maps (2nd Edition) by Mark Monmonier (1996)

\subsubsection{Representing Uncertainly with Cartography and Fuzzy Logic}

Future MS GIS students who are interested in this topic might focus on creating fuzzy boundaries. They might also consider developing a way of automatically graduating a line or fill color to represent a categorized level of uncertainty. There is a wealth of writing on fuzzy logic, and developing ways to "categorize" uncertainty. This angle alone could be a very sophisticated project. The end product would be a set of symbols (point, 
line and polygon) and/or fonts, accompanied by demonstrations of the various ways the symbols could be modified, combined and overlaid.

This project could also focus on visually representing the concept of RMSE and how it affects accuracy. A graphic or interactive calculator/translator to help interpret RMSE values would be a helpful tool in an introductory GIS course. This kind of tool would also be desired by the MS GIS program.

\subsubsection{ArcSDE Database Management \& System Architecture for a Multiuser Work Environment}

For an MS GIS student interested in multiuser work environments, they might look to design and develop a better way of data sharing and versioning to keep the data centrally located and up-to-date. Research on metadata versioning and storage would be a relevant add-on to future phases of SILAS.ST. This project could also be spun to those interested in integrating GIS software into classrooms. Developing a way to report database edits and contributions by user is another avenue for integration. For SILAS.ST to be successful, understanding this aspect of multiuser work environments is a critical aspect. 



\section{Works Cited}

Alibrandi, M. (2003). GIS in the Classroom: Using Geographic Information Systems in Social Studies and Environmental Science. Portsmouth, NH: Heinemann.

Association American Library. (1982). Anglo-American Committee on Cataloguing of Cartographic Materials, Cartographic materials: A manual of interpretation for AACR2. Chicago: American Library Association http://www.fgdc.gov/metadata/csdgm/08.html.

Benzek, S. (2008). Spatially Interactive Literature Analysis System (SILAS): An Interactive Tool to Study the Narrative Landscape of Ancient Texts. Redlands: University of Redlands.

Claiden-Yardley, K. (2008, November 3-27). DEBATE: What can GIS offer World History? Retrieved November 18, 2008, from History Compass Theory \& Methods Blog: http://historycompass.wordpress.com/2008/11/03/debate-what-can-gis-offer-worldhistory/

Douglas, M. P. (1998). The History, Psychology, and Pedagogy of Geographic Literacy. Westport, CT: Praeger Publishers.

Downs, R. M. (2004). From Globes to GIS: The Paradoxical Role of Tools in School Geography. In S. D. Brunn, S. L. Cutter, \& H. J. (Eds.), Geography and Technology (pp. 177-200). Netherlands: Kluwer Academic Publishers.

ESRI. (2009, March 21). ArcGIS Desktop - ArcObjects General forum. Retrieved February 25, 2009, from ESRI Support Center, ArcGIS Desktop Discussion Conference: http://forums.esri.com/Thread.asp?c=93\&f=993\&t=269320

Evaluating Information -- Applying the CRAAP Test . (2007 , December 24). Retrieved January 2009, from Meriam Library ReSEARCH Station: http://www.csuchico.edu/lins/handouts/evalsites.html

Frye, C. (2009, May 15). ESRI Chief Cartographer. (A. King, \& D. Sinton, Interviewers)

Frye, C. (2008). The ArcGIS Citation Data Model and Method. Social Science History Association (SSHA). Miami.

Gregory, I. N., \& Ell, P. S. (2007). Historical GIS : Technologies, Methodologies and Scholarship. New York: Cambridge University Press.

How to create a custom metadata editor. (2004, February 23). Retrieved March 10, 2009, from ESRI Developer Network: C:MMyDocs\MIP\MetaData\SimpleEditorOverview.htm

How to create a custom stylesheet. (2009). Retrieved April 6, 2009, from ESRI Developer Network:

http://edn.esri.com/index.cfm?fa=codeExch.sampleDetail\&pg=/arcobjects/9.1/Samples/ Metadata/Stylesheets/Basic_Stylesheet/Other/Description.htm 
Jessop, M. (2008). The Inhibition of Geographical Information in Digital Humanities Scholarship. Literary and Linguistic Computing , 39-50.

Johnson, I. (1998). ECAI Metadata Manual. Retrieved April 2009, from http://www.ecai.org/documentation/ecai_metadata_standard.html

Knowles. (2000). A Case for Teaching Geographic Visualization without GIS. Cartographic Perspectives , 24-37.

Knowles. (2008). GIS and History. In A. K. Knowles (Ed.), Placing History (pp. 1-25). Redlands: ESRI Press.

Knowles. (2002). Past Time, Past Place : GIS for History. Redlands, CA: ESRI Press.

Larsen, L. (2009, January 12th). Course Description: Religion 305- Historical Jesus. University of Redlands.

Plewe, B. (2002). The Nature of Uncertainty in Historical Geographical Information. Transactions in GIS , 431-456.

Pritchard, J. B. (2008). HarperCollins Atlas of Bible History. Hong Kong: HarperOne.

Reed, J. L. (2007). The HarperCollins Visual Guide to the New Testament: What Archaeology Reveals About the First Christians. China: HarperOne.

Schultz et al. (2008). The Use of Virtual Globes as a Spatial Teaching Tool with Suggestions for Metadata Standards. Journal of Geography, 27-34.

Sinton, D., \& Lund, J. (2007). Understanding Place: GIS and Mapping across the Curriculum. Redlands, CA: ESRI Press.

Wiegand, P. (2006). Learning and Teaching with Maps. New York, NY: Routledge. 


\section{Appendix A. ECAI Metadata Standard}

\begin{tabular}{|c|c|}
\hline ECAI Field & Description \\
\hline \multirow{2}{*}{ Title } & The name given to the resource by the CREATOR or PUBLISHER \\
\hline & Use for subtitles and variant titles, including parallel titles in different languages. \\
\hline \multirow{2}{*}{ Creator } & $\begin{array}{l}\text { Creator or Author. The person or organization primarily responsible for creating the intellectual content } \\
\text { of the resource. }\end{array}$ \\
\hline & Where the creator is unknown, enter "Unknown". \\
\hline \multirow[b]{2}{*}{ Subject } & The topic of the resource - keywords or phrases. \\
\hline & $\begin{array}{l}\text { Notes: Provide keywords or phrases (generally no more than six) that describe the subject or content of } \\
\text { the resource. }\end{array}$ \\
\hline \multirow{2}{*}{ Description } & $\begin{array}{l}\text { Textual description of the content of the resource, including abstracts in the case of document-like } \\
\text { objects or content descriptions in the case of visual resources. }\end{array}$ \\
\hline & Approximately 100 words, absolute maximum 500 words. \\
\hline \multirow{2}{*}{ Publisher } & $\begin{array}{l}\text { The entity responsible for making the resource available in its present form, identifies the entity that } \\
\text { provides access to the resource. }\end{array}$ \\
\hline & The address of the publisher. Includes any type of address. \\
\hline Contributor & $\begin{array}{l}\text { Person(s) or organization(s), in addition to those specified in the CREATOR element, who have made } \\
\text { significant though secondary intellectual contributions to the resource eg. editors, transcribers, } \\
\text { illustrators, and convenors. }\end{array}$ \\
\hline \multirow{3}{*}{ Date } & Date of creation or availability of the resource. \\
\hline & $\begin{array}{l}\text { Provide all significant dates associated with the creation of the resource, or its being made available in } \\
\text { its present form. Use slash ( / ) to specify a range of dates (e.g. } 1992 / 1996) \text {. }\end{array}$ \\
\hline & The date can be a single date or a range of dates. ISO 8601 uses the format YYYY-MM-DD. \\
\hline \multirow{2}{*}{ Type } & $\begin{array}{l}\text { The type of resource, used to categorise the resource being described. Repeat for all types included in } \\
\text { the resource. }\end{array}$ \\
\hline & Notes: The resource must be classified according to one of the major types listed. \\
\hline \multirow[b]{2}{*}{ Format } & The data representation of the resource. e.g. text, image, application \\
\hline & $\begin{array}{l}\text { Scheme: The IMT scheme is a standardised list of Internet Media Types. An authoritative list can be } \\
\text { downloaded: ftp://ftp.isi.edu/in-notes/iana/assignments/media-types/media-types }\end{array}$ \\
\hline \multirow{2}{*}{ Identifier } & String or number used to uniquely identify the resource \\
\hline & Optional, URL *, URN, ISBN, ISSN, SICI, FPI, Free Text \\
\hline Source & The work, either print or electronic, from which this resource is derived. \\
\hline \multirow[b]{2}{*}{ Language } & Language of the intellectual content of the resource \\
\hline & $\begin{array}{l}\text { Notes: We have defined a subset of around } 20 \text { languages most likely to be used by ECAI members in } \\
\text { the creation of databases. }\end{array}$ \\
\hline \multirow{2}{*}{ Relation } & $\begin{array}{l}\text { Provides a means to express relationships among resources that have formal relationships, but exist as } \\
\text { discrete resources themselves, such as images in a document, chapters in a book, or items in a } \\
\text { collection. ALWAYS USE TOGETHER. }\end{array}$ \\
\hline & $\begin{array}{l}\text { Relationships include: Creative (translation, annotation), Mechanical (copy, format change, mirror } \\
\text { copy), Versions (edition, draft), Inclusions (collection, part), Citations (bibliographic citations, } \\
\text { acknowledges), Physical (software or hardware dependency) }\end{array}$ \\
\hline
\end{tabular}




\section{Appendix A. ECAI Metadata Standard (Continued)}

\begin{tabular}{|c|c|}
\hline ECAI Field & Description \\
\hline \multirow{7}{*}{ Coverage } & $\begin{array}{l}\text { ECAI requires the extent of the resource or dataset to be defined by a bounding box consisting of } \\
\text { minimum and maximum longitude }(\mathrm{x}) \text { and latitude }(\mathrm{y}) \text { values, and a minimum and maximum time/date } \\
\text { (t). }\end{array}$ \\
\hline & Historical or archaeological period(s) represented in the resource. \\
\hline & $\begin{array}{l}\text { Resolution of a map or digital position recording (e.g. GPS) is the ground-distance between points or } \\
\text { features which can be distinguished, recorded in metres. }\end{array}$ \\
\hline & $\begin{array}{l}\text { The geography by which the data is aggregated, for example U.S. Census Bureau data is aggregated by } \\
\text { census tract. }\end{array}$ \\
\hline & Limits of temporal coverage of the dataset \\
\hline & $\begin{array}{l}\text { The geography(ies) by which individual data records are tagged indicating the granularity of the data. } \\
\text { For example, places of worship may be tagged by the state, province, county, and/or census tract in } \\
\text { which they are located. }\end{array}$ \\
\hline & $\begin{array}{l}\text { In order to simplify searching, ECAI limits the coverage metadata to a single bounding box by making } \\
\text { these elements non-repeatable. }\end{array}$ \\
\hline Rights & $\begin{array}{l}\text { Rights management. The terms and conditions or copyright statements for the resource or collection of } \\
\text { resource. Provides textual information or a link to a copyright notice, a rights-management statement, } \\
\text { or a server that provides such information in a dynamic way. }\end{array}$ \\
\hline Team* & The ECAI team responsible for collecting the dataset or overseeing its incorporation into ECAI. \\
\hline \multirow{2}{*}{ Theme* } & $\begin{array}{l}\text { The ECAI theme is used as an overall classification of datasets, particularly when browsing for } \\
\text { resources of interest. A dataset may fall into more than one theme. }\end{array}$ \\
\hline & $\begin{array}{l}\text { Scheme: Controlled list of ECAI themes (Archaeology, Art, Religion, ... see metadata clearinghouse } \\
\text { for authoritative list). }\end{array}$ \\
\hline \multirow[t]{2}{*}{ Notes* } & $\begin{array}{l}\text { This Element has been added by ECAI as Dublin Core provides no satisfactory elements for a general } \\
\text { description of background information about the resource. }\end{array}$ \\
\hline & Additional information about the resource being described. \\
\hline \multirow{4}{*}{$\begin{array}{l}\text { Use } \\
\text { Restrictions* }\end{array}$} & Defines the level of access permitted to the data through the ECAI data browser \\
\hline & 1. No restrictions. All data in the dataset can be displayed and/or downloaded; \\
\hline & $\begin{array}{l}\text { 2. Licensed. A sample of the data can be displayed and/or downloaded. Full download requires } \\
\text { payment of a license fee and supply of an unlocking code by the data owners; }\end{array}$ \\
\hline & $\begin{array}{l}\text { 3. Restricted. Only the dataset structure and record count can be shown. Access to the data will require } \\
\text { supply of an unlocking code by the data owners. }\end{array}$ \\
\hline \multirow{5}{*}{ Content* } & Describes the nature of the material available in the dataset. \\
\hline & 1. Data rich. Typically direct access to a database or searchable database-driven web site. \\
\hline & 2. Synthesis. Typically a significant web site which synthesizes information about a topic. \\
\hline & 3. Links. A site which is primarily characterised as a jumping-off point to other sites of interest. \\
\hline & 4. Other. Any site not falling into the above categories. \\
\hline \multirow{3}{*}{ Expert* } & $\begin{array}{l}\text { Authoritative comments for public viewing written by the ECAI team editor or other ECAI expert on } \\
\text { the quality, validity, usefulness etc. of the resource. }\end{array}$ \\
\hline & Notes: Data can only be entered/altered by the ECAI team editors or their delegates. \\
\hline & $\begin{array}{l}\text { Authoritative notes from the ECAI team editor or other ECAI expert on the quality, validity, usefulness } \\
\text { etc. of the resource. For internal use only. }\end{array}$ \\
\hline
\end{tabular}

* ECAI-Specific Metadata Elements (Johnson, 1998) 


\section{Appendix B. SILAS.ST Metadata Evaluation}

\section{Student-- Quick Facts}

Would you be able to fill out all of these fields?

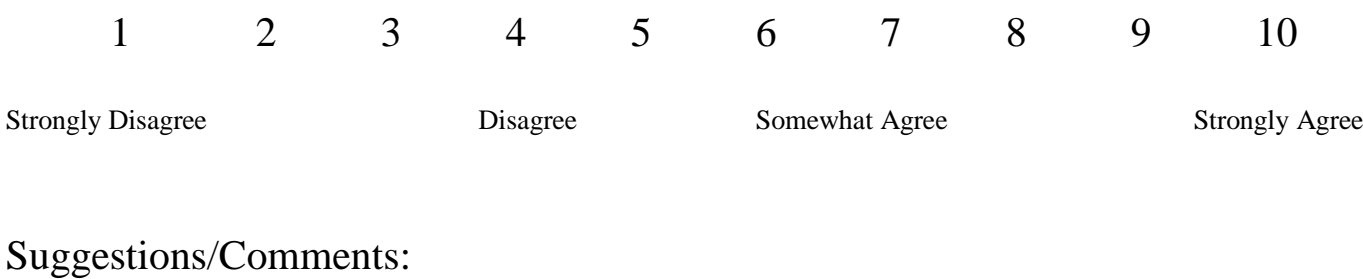

Do these fields help you understand the map?

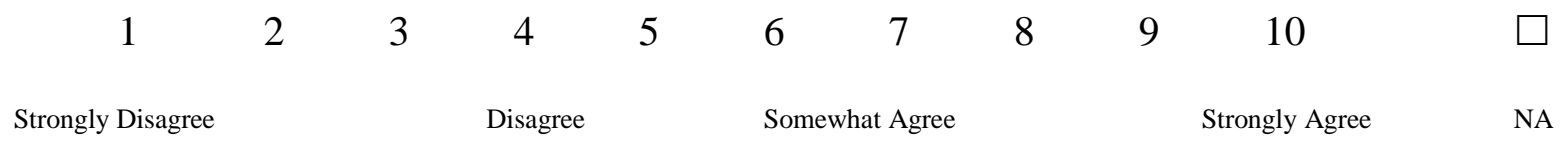

Suggestions/Comments:

Would you keep the order of the content the same? Does this form make sense as is?

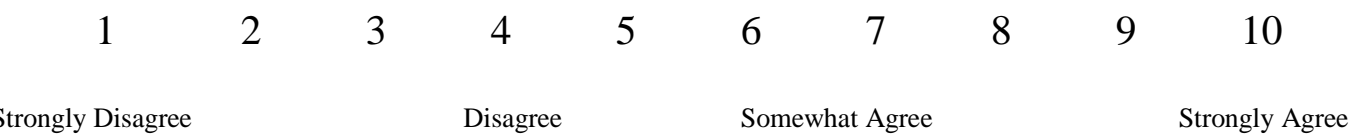

Suggestions/Comments:

Does this form make sense when you're documenting a 'historic' map?

$\begin{array}{lrrrrrrrrr}1 & 2 & 3 & 4 & 5 & 6 & 7 & 8 & 9 & 10 \\ \text { Strongly Disagree } & & & \text { Disagree } & & & \text { Somewhat Agree } & & & \text { Strongly Agree } \\ \text { Suggestions/Comments: } & & & & & & & & \end{array}$

Does this form make sense when you're documenting a modern map of historic information?

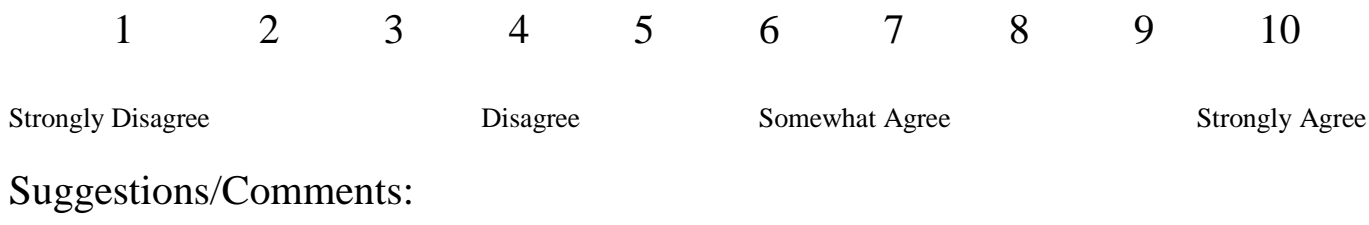




\section{Appendix C.Example Permissions Request}

March 18th, 2009

Permissions Department

HarperCollins Publishers

10 East 53rd Street

New York, NY 10022

Permissions Department:

I am a master's student at the University of Redlands and I am asking for permission to derive data from scanned copies of your maps as published in:

Pritchard, James B. HarperCollins Atlas of Bible History. HarperOne, 2008:

The Growth of the Roman Empire, 265-31 BC, Pages 142-143

Judea After Pompey: Herod's Kingdom, Page 145.

Herod's Kingdom, 4 BC, Page 149

Paul's Travels according to Acts, Pages 166-167

The Diaspora during the Roman Period, Pages 160-161.

I am a master's student and all data derived from the specified maps will be used and solely available within the University of Redlands. These maps will be used as authoritative base maps in ArcGIS for my master's thesis project. Data derived from these maps will be fully referenced with full copyright attribution in the metadata that will accompany the datasets I create. Static images of your maps may be included within my thesis paper, which may be available outside the University of Redlands; if that is the case I will fully reference your material within the body of my thesis paper. If you need any additional information, please contact me.

Please sign the agreement below with an invoice and return to me. Thank you for your attention to this request.

Sincerely,

Alyssa King

MS GIS Program, University of Redlands

1200 E. Colton Ave. P.O. Box 3080

Redlands, CA 92373-0999

Alyssa_King@spatial.redlands.edu

Phone: (510) 502-4491

Fax: (909) 335-5388

Permission is granted for the use of the material as describe above:

Name \& Title:

Affiliation:

Date: 


\section{Appendix D. Implementation Workflow}

This collection of diagrams and figures are meant for assisting Professor Larsen in implementing SILAS.ST into her classroom. Meetings and collaborations with specific university services will be necessary in making SILAS.ST available on the Lewis Hall lab computers, as illustrated in Figure 45.

\section{Initiate a conversation with Osman Trad about adding the SILAS.ST application to the Lewis Hall lab image}

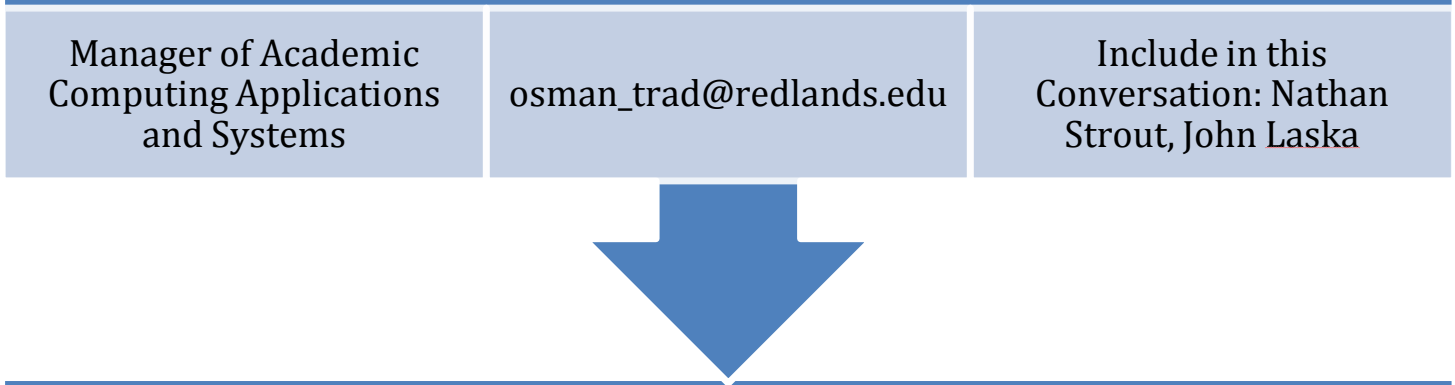

Based on the conversation, Nathan Strout may have to reconfigure the SILAS.ST Install for the Lewis Hall Lab Computers

All necessary documents and files are included on the SILAS.ST CD

John Laska is the owner of the SILAS.ST ArcSDE database

If adding SILAS.ST to the image is not possible, John Laska can run the application via a virtual system

Nathan Strout may have to reconfigure the SILAS.ST Install
This option will change how SILAS.ST is accessed. John Laska will need to create a VM for each student

Figure 45 Implementing SILAS.ST on the university computers flowchart 
I worked with a number of individuals as I developed the system architecture (Figure 46). After I leave, these individuals will be available to assist Professor Larsen in implementation. It will be important that Professor Larsen include these support individuals in on meetings.
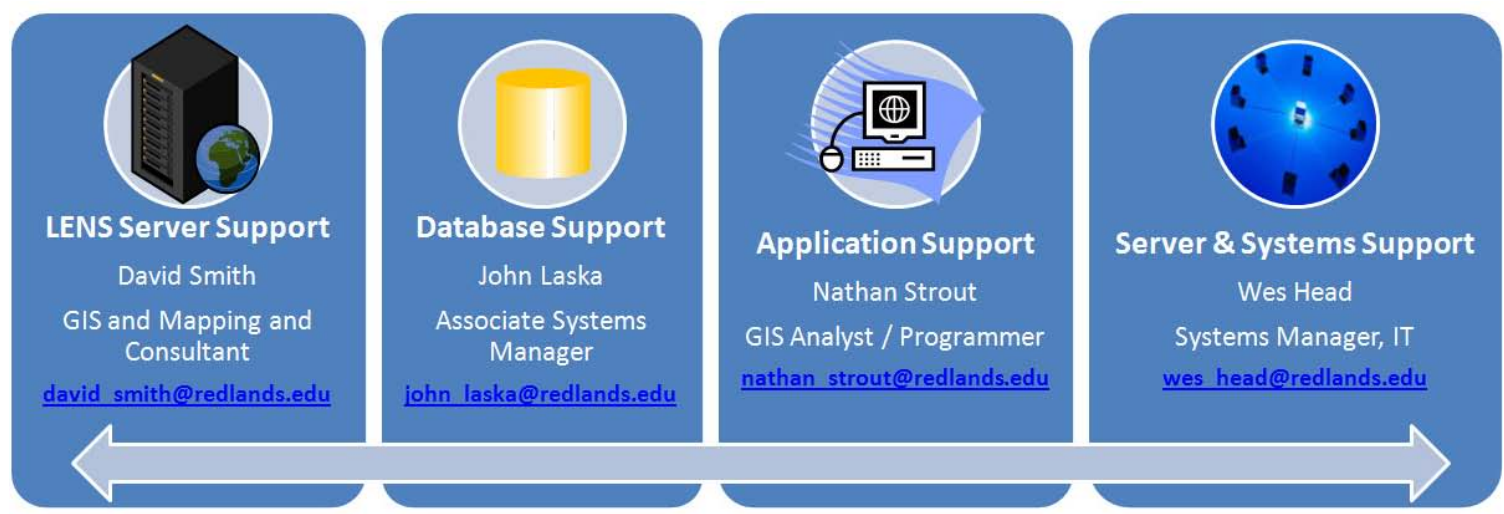

Figure 46 SILAS.ST Support Team

Once SILAS.ST is functioning on the Lewis Hall lab computers, as soon as Professor receives her class roster, she will need to set up individual student accounts, illustrated below in Figure 47.

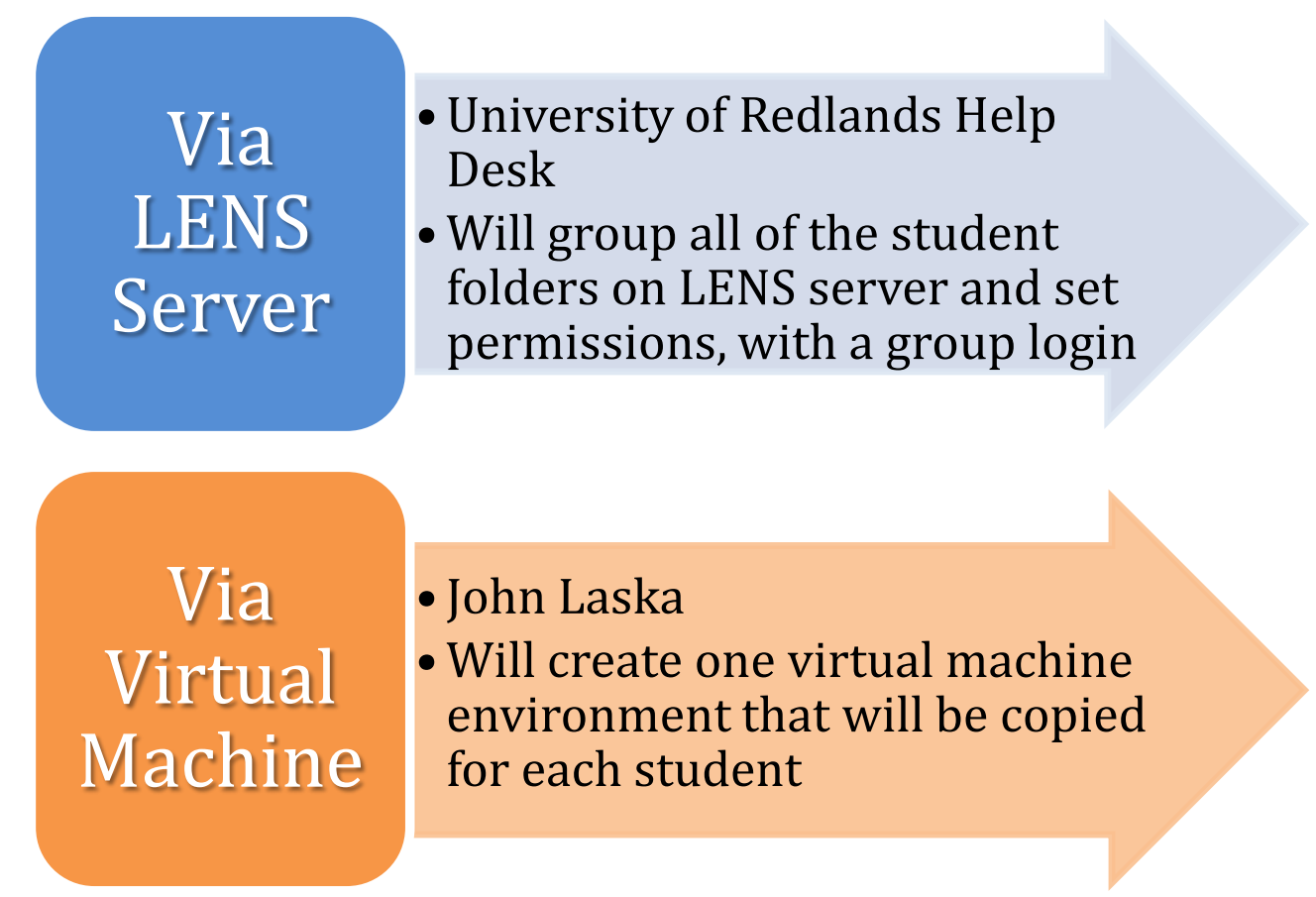

Figure 47 Setting up student accounts

Once individual accounts are created, SILAS.ST will be ready for use. Should any glitches occur, Professor Larsen should consult one of the SILAS.ST support team. 


\section{Appendix E. SILAS.ST Lesson Plans}

To smoothly integrate SILAS.ST into my client's classroom, I have developed a list of lesson topics that give both an introduction to ESRI's ArcMap and to using the customized toolbars and functions. The first set of lessons, illustrated in Figure 48, could be taught easily in 30 minute periods. If Professor Larsen is not confident teaching these introductory tutorials, any member of the MS GIS faculty would be qualified to instruct.
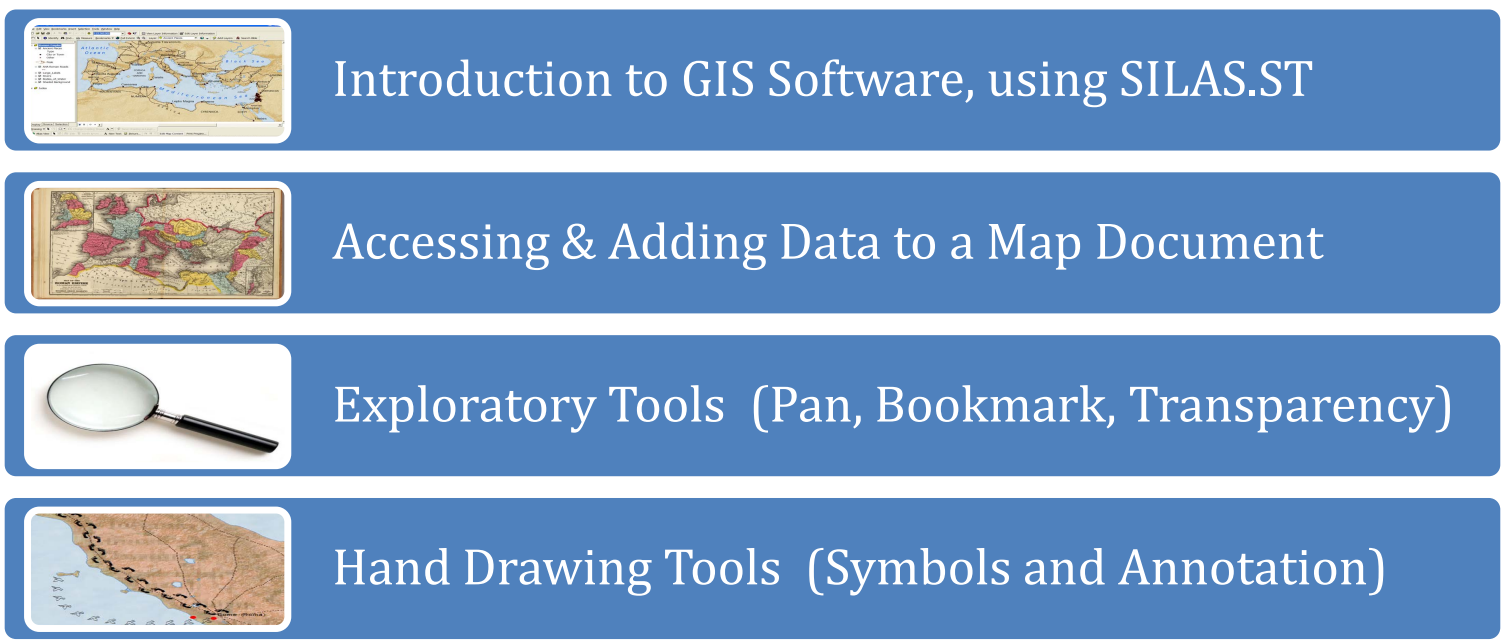

Figure 48 Introductory lessons

After the introductory lessons, the logical first exercise or class assignment would be the exercise describe in Section 4.1.1, in which students draw in lines and points according to their assigned reading. The next set of lesson topics are more advanced, requiring at least one hour of instruction and training (Figure 49).

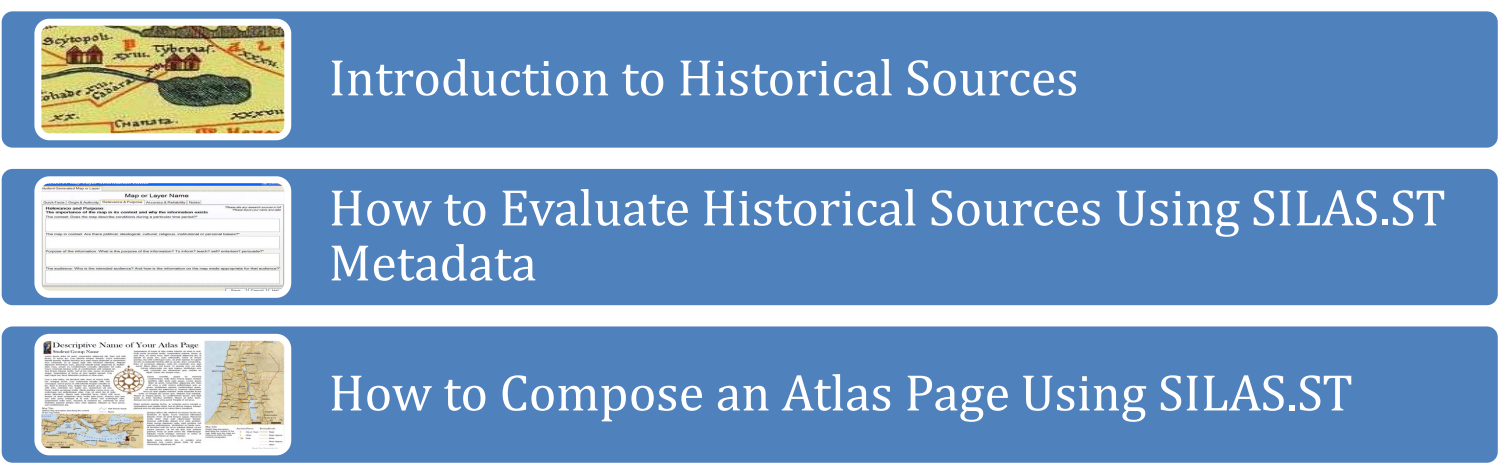

Figure 49 Advanced lessons

The first two lessons follow in line with topics taught during her Historical Search for Jesus course. The first and second lesson would not require using ArcMap. For the last lesson however, Professor Larsen may require a MS GIS faculty member for map layout instruction. As for a project following these lessons, students would be capable of assessing historical sources and composing an atlas page of their findings and conclusions. 